\title{
Distribution, growth, and transport of larval fishes and implications for population dynamics
}

By

\author{
Christina M. Hernández \\ B.S., Columbia University, 2014 \\ Submitted to the Department of Earth, Atmospheric, and Planetary Sciences in \\ partial fulfillment of the requirements for the degree of \\ Doctor of Philosophy \\ at the \\ MASSACHUSETTS INSTITUTE OF TECHNOLOGY \\ and the \\ WOODS HOLE OCEANOGRAPHIC INSTITUTION
}

February 2021

(C)2021 Christina M. Hernandez. All rights reserved.

The author hereby grants to MIT and WHOI permission to reproduce and to distribute publicly paper and electronic copies of this thesis document in whole or in part in any medium now known or hereafter created.

Author

Department of Earth, Atmospheric, and Planetary Sciences Massachusetts Institute of Technology and Woods Hole Oceanographic Institution

October 29, 2020

Certified by

Joel K. Llopiz

Thesis Supervisor

Woods Hole Oceanographic Institution

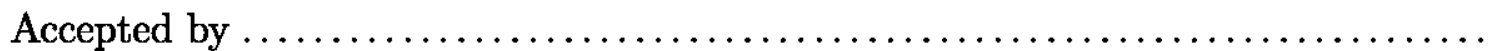

Ann Tarrant

Chair, Joint Committee for Biological Oceanography Massachusetts Institute of Technology/ Woods Hole Oceanographic Institution 


\title{
Distribution, growth, and transport of larval fishes and implications for population dynamics
}

\author{
by
}

\author{
Christina M. Hernández \\ Submitted to the Department of Earth, Atmospheric, and Planetary Sciences \\ on October 29, 2020, in partial fulfillment of the \\ requirements for the degree of \\ Doctor of Philosophy
}

\begin{abstract}
ABSTRACT

The early life stages of marine fishes play a critical role in population dynamics, largely due to their high abundance, high mortality, and ease of transport in ocean currents. This dissertation demonstrates the value of combining larval data, collected in the field and the laboratory, with model simulations. In Chapter 2, analyses of field observations of ontogenetic vertical distributions of coral reef fish revealed a diversity of behaviors both between and within families. In Caribbean-wide particle-tracking simulations of representative behaviors, surface-dwelling larvae were generally transported longer distances with greater population connectivity amongst habitat patches, while the evenly-distributed vertical behavior and downward ontogenetic vertical migration were similar to one another and led to greater retention near natal sites. However, hydrodynamics and habitat availability created some local patterns that contradicted the overall expectation. Chapter 3 presents evidence of tuna spawning inside a large no-take marine protected area, the Phoenix Islands Protected Area (PIPA). Despite variation in temperature and chlorophyll, the larval tuna distributions were similar amongst years, with skipjack (Katsuwonus pelamis) and Thunnus spp. tunas observed in all three years. Backtracking simulations indicated that spawning occurred inside PIPA in all 3 study years, demonstrating that PIPA is protecting viable tuna spawning habitat. In Chapter 4, several lines of larval evidence support the classification of the Slope Sea as a major spawning ground for Atlantic bluefin tuna with conditions suitable for larval growth. The abundance
\end{abstract}


of bluefin tuna larvae observed in the Slope Sea aligns with typical observations on the other two spawning grounds. Age and growth analyses of bluefin tuna larvae collected in the Slope Sea and the Gulf of Mexico in 2016 did not show a growth rate difference between regions, but did suggest that Slope Sea larvae are larger at the onset of exogenous feeding. Collected larvae were backtracked to locations north of Cape Hatteras and forward tracked to show that they would have been retained within the Slope Sea until the onset of swimming. As a whole, this thesis presents valuable contributions to the study of larval fishes and the attendant implications for marine resource management.

Thesis Supervisor: Joel Llopiz

Title: Associate Scientist 


\section{Acknowledgments}

The work presented in this dissertation was supported by funding from the National Science Foundation Graduate Research Fellowship Program (to C.M.H.), the Woods Hole Oceanographic Institution Ocean Life Institute (Grant 22569.01 to J. Llopiz and C.M.H.), the Adelaide and Charles Link Foundation, the Phoenix Islands Protected Area Trust, the J. Seward Johnson Endowment in support of the Woods Hole Oceanographic Institution's Marine Policy Center, and the WHOI Academic Programs Office.

There are so many people that have made this thesis possible, both materially and by shaping me into the person I am and the scientist I'm still becoming.

Thank you to my advisor, Joel Llopiz, for taking a chance on me as a summer student (in 2013!) and for your steadfast support of me ever since. Thank you to Michael Neubert, my "second advisor," for nurturing my mathematical side and helping me dream scientific dreams. Thank you to David Richardson for opening doors for me to work on bluefin tuna larvae and for being one of my most trusted co-authors. Thank you to Stephanie Dutkiewicz for providing encouragement and *ahem* reasonable limits to what one person should try to accomplish in their thesis.

Thank you to the WHOI Academic Programs Office, the Joint Committee for Biological Oceanography, the WHOI Biology Department, and MIT-EAPS for providing me with so many opportunities for learning and growing.

Many co-authors and labmates made this work possible- and far more enjoyable. Sarah Glancy, Justin Suca, Martha Hauff, Helena McMonagle, Paul Caiger, Julia Cox, and Andy Jones all made being part of the Llopiz (FOLFE) lab so much better. Thank you to Kristin Gribble, Hal Caswell, Silke van Daalen, Julie Kellner, Irina Rypina, Randi Rotjan, Kathy Mills, Andy Pershing, Jan Witting, Ke Chen, Ciara Willis, Simon Thorrold, Katey Marancik, Claire Paris, Ana Vaz, Robert Cowen, Su Sponaugle, Katie Shulzitski, and Ben Jones for working on various projects with me, much of which forms this thesis. Thank you to the crew and science parties of numerous cruises for making this work possible including: S261, S268, S274, HB1603, GU1608, HB1704, and GU1702.

I also owe a debt of gratitude for my growth as a scientist (and a person) to my friends, the SWMS community, and my co-conspirators in the fight for greater justice, equity, diversity, and inclusion in science: Lizzie Wallace, Rachel Housego, Ryan O'Shea, Kassandra Costa, Alex Pan, Mira Armstrong, EeShan Bhatt, Gabi Serrato Marks, Mara Freilich, Suzi Clark, Jen Karolewski, Joleen Heiderich, Alexa Sterling, Anna Robuck, Sophie Chu, Kwanza Johnson, Jessica Dabrowski, Billy Shinevar, Casey Zakroff, Julia Middleton, Paris Smalls, Adam Subhas, Henri Drake, Ashley 
Bulseco, and probably 50 more people I'm failing to mention. $\mathrm{Oh}$, and shout out to Arnault Le Bris for winning our bet.

Thank you to EAPS Cookie Hour and Jeffrey Mei for introducing me to Harry Matchette-Downes. I'm so happy that you're by my side, Harry. I can't wait for our next adventure.

Finally, I'd like to list a few people who were instrumental in shaping me into someone who would even end up in the Joint Program. My parents, Cathy Chambers and Albert Hernández, my brother, Steven Hernández, and my grandmothers, Judy Chambers and Doris Pérez, have always believed I was capable of anything I set my mind to. I was also blessed to have some amazing mentors and cheerleaders in high school and college: June Van Thoen, David Sabella, Robert Sabella, Samuel Baskinger, Joe Kyle, and Jerry McManus. Thank you for seeing me. 


\section{Contents}

1 General Introduction 10

2 Larval traits drive patterns of marine dispersal and connectivity 17

2.1 Abstract . . . . . . . . . . . . . . . . . 17

2.2 Introduction $\ldots \ldots \ldots \ldots \ldots \ldots \ldots \ldots \ldots \ldots$

2.3 Methods . . . . . . . . . . . . . . . . . . . 20

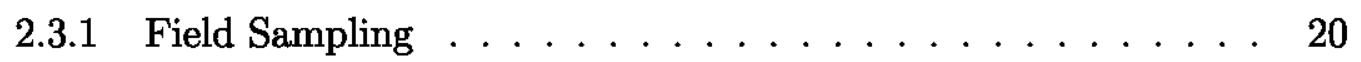

2.3.2 Data Analysis . . . . . . . . . . . . . . . . . . . . 22

2.3.3 Model simulations . . . . . . . . . . . . . . . . 23

2.3.4 Analysis of simulation output $\ldots \ldots \ldots \ldots$

2.4 Results . . . . . . . . . . . . . . . . . . 27

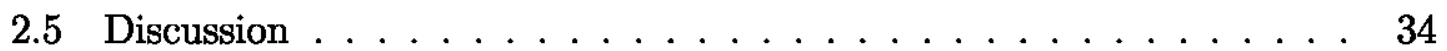

2.6 Supplemental Figures and Tables $\ldots \ldots \ldots \ldots \ldots$

3 Evidence and patterns of tuna spawning inside a large no-take Marine Protected Area $\quad 47$

3.1 Abstract . . . . . . . . . . . . . . . . . 47

3.2 Introduction $\ldots \ldots \ldots \ldots \ldots \ldots \ldots \ldots \ldots \ldots$

3.3 Results . . . . . . . . . . . . . . . . . . . . 52 
3.3.1 Oceanographic conditions $\ldots \ldots \ldots \ldots \ldots$

3.3.2 Larval tuna abundance and distribution . . . . . . . 55

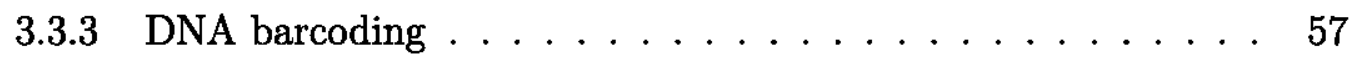

3.3.4 Spawning sites and relative output $\ldots \ldots \ldots \ldots \ldots$

3.4 Discussion . . . . . . . . . . . . . . . . . 60

3.5 Methods . . . . . . . . . . . . . . . . . 66

3.5 .1 Field sampling $\ldots \ldots \ldots \ldots \ldots 6$

3.5.2 Lab processing $\ldots \ldots \ldots \ldots \ldots \ldots \ldots$

3.5.3 Relative spawning output estimation . . . . . . . . . 70

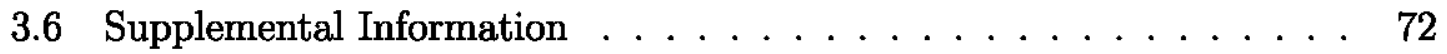

3.6.1 Manual inspection of DNA barcoding sequences for species identification of Thunnus larvae . . . . . . . . . 72

3.6.2 Genetic barcoding insights for morphological identification . . 73

3.6 .3 Length at age analyses . . . . . . . . . . . . . . 73

3.6.4 HyCOM validation . . . . . . . . . . . . . . . . 74

3.6 .5 CTD data $\ldots \ldots \ldots \ldots \ldots \ldots \ldots \ldots \ldots$

4 Support for the Slope Sea as a major spawning ground for Atlantic bluefin tuna: evidence from larval abundance, growth rates, and backtracking simulations $\quad 83$

4.1 Abstract . . . . . . . . . . . . . . . . . 83

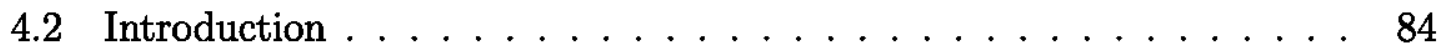

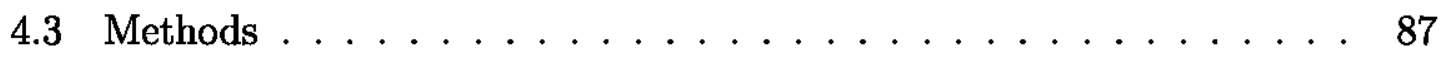

4.3.1 Larval sampling methods . . . . . . . . . . . . . . 87

4.3.2 Laboratory processing of plankton samples . . . . . . . . 89

4.3 .3 Larval distribution maps . . . . . . . . . . . . . . 90 
4.3.4 Age and growth analyses $\ldots \ldots \ldots \ldots$

4.3.5 Larval drift simulations . . . . . . . . . . . . . . . . . 94

4.4 Results . . . . . . . . . . . . . . . . . . 95

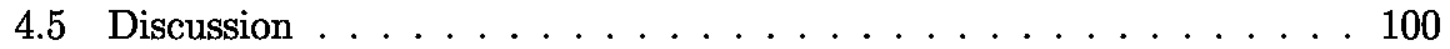

4.6 Supplemental Information $\ldots \ldots \ldots \ldots \ldots$

5 Conclusion 113

6 References $\quad 119$ 


\section{Chapter 1}

\section{General Introduction}

As human populations grow and anthropogenic influence stretches to every inch of the globe, there are few resources that are not directly impacted by humans. Marine resources, specifically fish and shellfish protein, represent one of the only large-scale 'wild harvest' industries. Some species are affected by human activities without being directly targeted, either through bycatch in commercial fisheries or through ecosystem effects such as eutrophication, dredging, and habitat degradation. As valuable fisheries species experience anthropogenic influences, resource managers work to understand and predict the productivity of these stocks, either to set quotas for sustainable fisheries or to protect species and ecosystem health. Studies of spawning behavior and early life history stages offer valuable contributions towards the goal of improved management.

The importance of the early life stages of fishes has been recognized since the early 1900s. The seminal work by Johan Hjort (1914) used cohort analyses and novel aging techniques to demonstrate that strong year-classes could dominate a given fishery for several years. Hjort attributed much of the variation in year-class strength to 
effects during a "critical period," which he identified as the first-feeding period of recently hatched larvae. Following on from Hjort's work, important contributions to fisheries oceanography and early life history theory include the match-mismatch hypothesis which generalizes Hjort's "critical period" hypothesis to focus on the relative phenology of larvae and their planktonic food sources throughout the larval period (Cushing, 1990), the member-vagrant hypothesis wherein transport and retention processes play a crucial role in both stock delineation and stock dynamics (Iles and Sinclair, 1982), and the stage-duration or "bigger is better" hypotheses wherein faster growth and/or development decrease cumulative mortality due to predation (Cushing, 1990; Miller et al., 1988). Edward Houde also made important contributions to our understanding of the relationships among temperature, growth rate, and mortality of larval fishes, and latitudinal patterns in these factors (Houde, 1989; Houde, 1997).

Much of the work mentioned thus far focused on mid- to high-latitude fisheries species, such as Atlantic herring, Atlantic cod, and other species in the family Gadidae (Hjort, 1914; Houde, 1989; Iles and Sinclair, 1982). A hallmark of these temperate environments is the strong seasonality of plankton production, which influences the phenology of both spawning and larval development. A theory like the match-mismatch hypothesis is less relevant in the tropics, where seasonal variation in plankton biomass is much weaker (i.e., larval food availability is more constant). The other important characteristic of Atlantic herring that influenced these foundational theories is that they are a pelagic species- their ideal habitat tracks water masses and oceanographic features rather than bottom type or structure.

On the other hand, many species of fish settle onto bottom habitat after their pelagic larval period, to live as demersal adults with varying levels of site fidelity. Bottom habitat with the correct features or substrate is often available in a patchy 
distribution. As the distance between high-quality habitat (or the risk of predation along that distance) increases, adult fish are more likely to show high site fidelity. However, pelagic larvae can be transported amongst these patches, linking the various habitat patches into a metapopulation (Hanski, 1998). A critical question for the study and management of coral reef fish populations was the degree to which individual populations were open or closed (Cowen et al., 2000; Cowen et al., 2006). If a population is completely closed, then its population dynamics are set by the production of offspring by adults within that same patch of habitat. In a completely open or fully connected population, the population dynamics in any one habitat patch depend on the supply of larvae from all of the other patches.

The reality, for most populations, is somewhere in the middle of the open-closed spectrum, and depends on a plethora of both biotic and abiotic factors (Cowen and Sponaugle, 2009). The local and regional hydrodynamics, as well as the distribution of habitat patches clearly play a role in the connectivity of a metapopulation. The pelagic larval duration- the amount of time that larvae spend developing before seeking settlement habitat- sets an upper limit on larval dispersal distance (Sponaugle et al., 2002). Individual-based biological-physical models have allowed us to move beyond the early concept of larvae as passive particles to understand the importance of larval traits, such as vertical distribution behaviors (Paris et al., 2013; Vaz et al., 2016) and swimming abilities (Rypina et al., 2014). Despite the increased availability of sophisticated models that can incorporate larval behavior, the vast majority of recent modeling studies of larval dispersal continue to treat larvae as passive tracers (Swearer et al., 2019). Furthermore, those studies that do incorporate larval behavior tend to focus on a single species, or comparisons between very different species (Faillettaz et al., 2018; Kough and Paris, 2015; Petrik et al., 2016). Therefore, the general consequences of small changes in larval behavior between otherwise quite 
similar species is not well understood.

Connectivity and its impact on the population dynamics at any given reef site are important considerations in the management of both harvested and protected reef populations. Studies of connectivity, through genetic, chemical tagging, and computer simulation approaches, have influenced marine protected area management (MPA) by highlighting the importance of MPA size and the potential value of MPA networks (Botsford et al., 2001; Ross et al., 2017; Watson et al., 2011). A generalized, trait-based approach could help to fill our knowledge gap with respect to the role of larval behaviors, while also providing managers with a method to estimate connectivity when they are unable to undertake a new study targeting their location or species of interest.

Regardless of the causal mechanisms, the fact remains that tiny proportional changes in the survival or growth of offspring, or in the number of settlers arriving at a given patch of habitat, can have outsized impacts on cohort strength and, by extension, population dynamics. This fact arises from the prodigious fecundity of fishes (thousands to millions of eggs per individual) and the high mortality rates during early life stages (>99\%). However, eggs and larvae disperse quickly in the ocean and therefore are often present at low density or in a patchy distribution that makes systematic sampling difficult and costly. Furthermore, larvae may sample a range of conditions during their pelagic period of days to months, complicating our ability to identify the relevant covariates to estimates of growth and mortality. Therefore, despite our long-term understanding that early life history conditions modulate population dynamics of fishes, these stages are still generally poorly-represented in stock assessment models and management frameworks.

In spite of these difficulties, studies of the early life history conditions of harvested or protected species continue to have important benefits for fisheries science and 
management. In Atlantic bluefin tuna, the discovery of larvae in the Slope Sea has re-opened important questions about age-at-maturity, stock mixing, and stock productivity (Richardson et al., 2016 and this thesis, Chapter 4). Larval distributions can be combined with age analysis and particle tracking simulations to provide insight into probable spawning locations (by running the simulations backwards) and larval transport to settlement locations (by running the simulations forwards). Particle tracking simulations are employed in all three projects presented in this thesis. In Chapter 2, I used forward-tracking simulations to test hypotheses about how larval vertical behaviors impact larval dispersal and population connectivity for coral reef fishes. In Chapters 3 and 4, I used backward-tracking simulations to estimate the likely spawning sites for highly-migratory species in locations where we have analyzed larval distribution, age, and growth, but where we have very limited data on adult spawning behavior. In Chapter 4, I also use forward-tracking simulations to explore the transport and retention conditions in a highly dynamic ecosystem.

Because of the high number of fish eggs released and the extremely high mortality rates that the larvae face during their first weeks of life, the removal of larvae from the environment has a relatively small impact on the population. Compared to the millions of larvae that might be present across an ecosystem, the few hundred of any given species that we might remove for larval studies will not have an appreciable effect on the mortality rate- and many of the larvae we sample would have died anyway. Therefore, sampling of eggs and larvae can be a lower-impact way to study fish populations, particularly in locations where fishing is prohibited. In Chapter 3, I demonstrate how larval sampling inside a large no-take Marine Protected Area (the Phoenix Islands Protected Area, PIPA) can enable us to study the spawning of highly-migratory species of tunas that are both ecologically and economically valuable. Furthermore, larval studies were more feasible in this remote protected 
area than adult tagging or maturity studies because a plankton net can be deployed from a smaller vessel with less-specialized expertise and equipment. The highly repeatable nature of plankton studies has also enabled us to build a multi-year time series of tuna larvae in PIPA.

Fish otoliths are fantastic tools that unlock a wealth of information. These calcium carbonate structures, essentially fish ear bones, record daily variations in feeding and growth as differences in the density of the calcium carbonate matrix. These density differences are visible as concentric rings or growth increments. We can estimate larval age in days from the number of rings present in the otoliths, and the width of each ring is a proxy for daily growth rate. Furthermore, since larval size is correlated with otolith radius, we can also use otolith measurements to back-calculate the size of each fish on previous days of its life. These otolith metrics record the overall combined effect of several intrinsic and extrinsic mechanisms that can cause variations in growth, including temperature, food availability, and genetic or species-level differences. With larval otoliths, we can compare the larval conditions for the same species spawning at different locations or times of year, and gain greater insight into the vulnerability or productivity of different stock segments. In Chapter 4, I took this approach to explore whether Atlantic bluefin tuna larvae spawned in the Slope Sea differ significantly in their growth from those spawned in the Gulf of Mexico. Because larval growth rate is thought to be related to survival, differences in larval growth rates between two stock segments imply differences in the contribution of those two groups to overall stock productivity. I also employed otolith analyses for Chapter 3, in which I built a relationship of larval length and age. Then, I ran backtracking simulations to generate a map of estimated relative spawning output that corresponded to our observed larval distributions.

The studies presented in this dissertation focus on a variety of settings, from the 
tropical Pacific to the temperate Atlantic and include both highly-migratory and demersal site-attached species. They combine field, laboratory, and modeling methods to draw new connections between early life history of fishes and the population dynamics of managed species and ecosystems. They highlight gaps in our knowledge of valuable and intensively-studied species. Through this dissertation, I seek to fill a few of those gaps and to demonstrate the value of continuing to invest in the sampling and study of larval marine fishes. 


\section{Chapter 2}

\section{Larval traits drive patterns of marine dispersal and connectivity}

\section{$2.1 \quad$ Abstract}

Larvae of coral reef fishes have taxon-specific traits that can influence larval transport, but we lack a clear understanding of how such traits, specifically vertical distribution behaviors, influence dispersal and population connectivity. We analyzed field observations of larval vertical distribution behaviors for 23 taxa of coral reef fish. We selected three representative behaviors - surface-dwelling, evenly-distributed, and ontogenetic vertical migration (OVM) —and two pelagic larval durations (PLDs) to parameterize a biological-physical model of larval dispersal throughout the Caribbean Sea. When all releases across the Caribbean were combined to generate dispersal kernels, the shorter PLD reduced dispersal, but for a given PLD, surface-dwelling behavior generally led to longer-distance dispersal, lower regional retention, and higher population connectivity than the evenly-distributed and OVM behaviors. However, 
there was region-specific variability in these trends. The same combination of traits led to different retention and connectivity outcomes depending on the region of larval release, demonstrating the complex interplay among larval traits, oceanic currents, and habitat availability.

\subsection{Introduction}

Due to the prevalence of a pelagic larval phase across marine taxa, and the ease with which propagules are dispersed in the marine environment, a fundamental aim of marine ecology is to understand the processes governing the transport of pelagic larvae and their subsequent arrival at suitable settlement habitat (Cowen and Sponaugle, 2009; Pineda et al., 2007). The connectivity of suitable habitat patches has implications for population persistence and community dynamics, including the resilience and replenishment of disturbed communities (Aiken and Navarrete, 2011; Hastings and Botsford, 2006; Thrush et al., 2013). Shallow-water coral reefs are a canonical example of patchy habitat, and the study of larval population connectivity is critically important to conservation of the reefs and management of their associated fish populations (Botsford et al., 2001; Burgess et al., 2014).

Dispersal modeling is a valuable tool for investigating connectivity of reef fish populations (Werner et al., 2007). In the past 15 years, major advances in computing power have enabled the development of high-resolution models of ocean currents and their use in increasingly complex biological-physical models. These models can now incorporate more biologically-realistic larval behaviors, notably vertical distribution, vertical migration, and horizontal swimming ability (Brochier et al., 2008; Edwards et al., 2008; Faillettaz et al., 2018; Paris et al., 2013; Petrik et al., 2016; Rypina et al., 2014; Staaterman et al., 2012; Sundelöf and Jonsson, 2012; Vaz et al., 2016). 
Regardless of the importance of larval movement and the existence of models that are able to simulate such behaviors, most recent Lagrangian models of larval dispersal have considered larvae as passive tracers (Swearer et al., 2019), highlighting the need to understand the broad consequences of larval behavior.

Across the many taxa of coral reef fish, a wide variety of larval traits, including morphology, diet, developmental rate, swimming abilities, sensory abilities, and depth preferences have been documented. Adult reproductive traits, such as fecundity, as well as spawning season, periodicity, and location can also vary between and within species. Any of these traits can directly or indirectly affect larval dispersal and connectivity. For example, innate or environmentally driven differences in developmental rates affect the pelagic larval duration (PLD), or the length of time in the water column, which sets an upper limit for the scope of larval dispersal (Sponaugle et al., 2002). The few studies on the depth distributions of larval coral reef fish during their pelagic phase highlight taxon-specific behaviors (Cha et al., 1994; Huebert et al., 2010; Irisson et al., 2010; Leis, 1991), and, due to vertical differences in ocean current velocity, it seems likely that such differences should influence dispersal (Huebert et al., 2011; Irisson et al., 2010). Of particular interest are patterns in vertical distributions related to larval age or ontogeny. Ontogenetic vertical migration (OVM) is characterized by a downward trend in depth distribution with larval age (Irisson et al., 2010; Paris and Cowen, 2004) and, amongst modeling studies that include depth behavior, OVM behavior is commonly used (Butler et al., 2011; Kough et al., 2013; Staaterman et al., 2012; Truelove et al., 2017; Vaz et al., 2016; Yannicelli et al., 2012). Additionally, OVM has been proposed as an adaptive mechanism for constraining larval dispersal with Ekman transport, particularly in locations where sub-surface flow can deliver larvae back to shore (Paris and Cowen, 2004). However, it is not clear how widespread this behavior is across taxa or how regional variability 
in flow regimes and bathymetry modulate the effect of this behavior on retention, so further study of its prevalence and its consequences for dispersal is warranted.

A generalized and trait-based approach to modeling pelagic larval connectivity would provide important insights into the relative influence of various larval traits, and would enable more reliable predictions of connectivity scaling based on larval traits. We report here the vertical behaviors observed from extensive field sampling for the larvae of 23 taxa of coral reef fish. Based on these field observations, we selected three representative larval distribution behaviors, as well as two pelagic larval durations (PLDs), to examine how these behaviors and PLDs influence dispersal and connectivity across the Caribbean region. To do this, we used the Connectivity Modeling System (Paris et al., 2013), which is a biological-physical Lagrangian particle tracking model that simulates observed distributions of larval traits and settlement to reef habitat, enabling the estimation of dispersal probability and potential connectivity. Our study provides insight into how life history traits might enable population persistence for fish living in patchy coral reef habitat.

\subsection{Methods}

\subsubsection{Field Sampling}

Between January 2003 and December 2004, a transect of 17 stations across the Straits of Florida was sampled monthly for fish larvae [details in (Llopiz and Cowen, 2008)]. Larvae were collected with a $4-\mathrm{m}^{2}$ multiple opening-closing net and environmental sensing system (MOCNESS) (Guigand et al., 2005; Wiebe et al., 1976) and a 1 x $2 \mathrm{~m}$ neuston net, both with 1-mm mesh. The MOCNESS nets each sampled approximately $25 \mathrm{~m}$ of water depth, with four target depth bins: 0-25 m, 25-50 

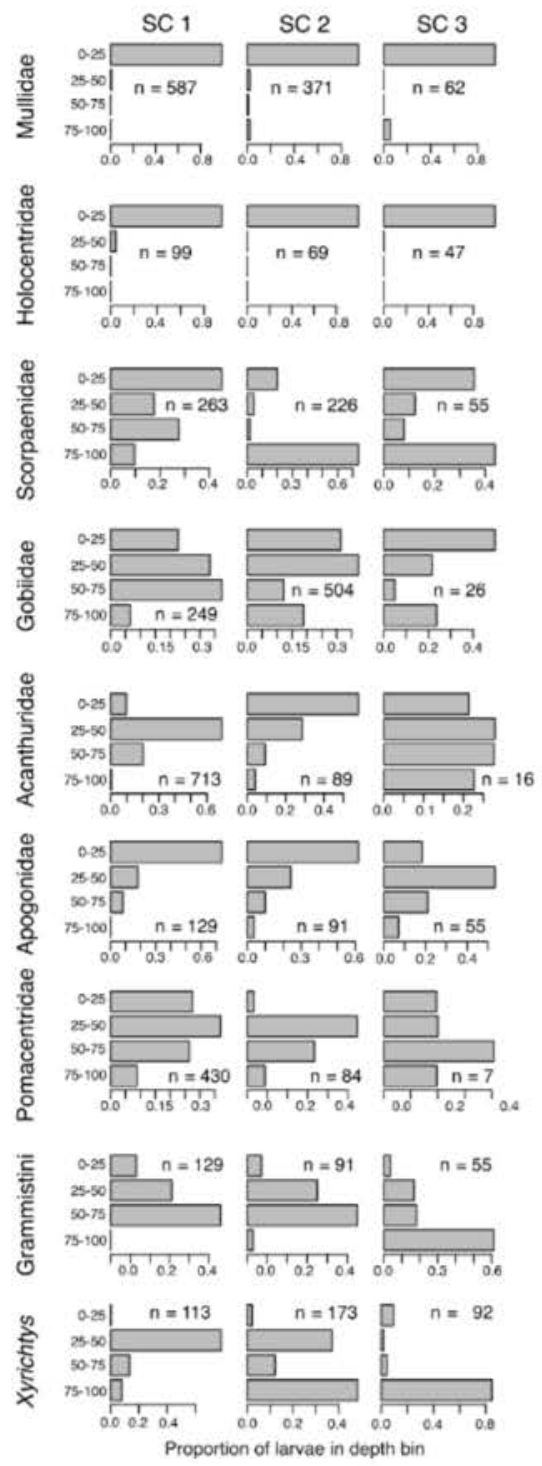

Figure 2-1: Selected ontogenetic vertical distributions. Each row of panels represents a different taxon. The first 7 rows are Family-level taxa, and the final 2 rows are at a lower taxonomic level: Grammistini is a tribe in the Family Serranidae, and Xyrichtys is a genus of the Family Labridae. The columns of sub-panels refer to size classes (SC) 1 through 3 that represent respectively 25,25 , and $50 \%$ of the observed size range. Each sub-panel shows the proportional abundance in 4 depth bins in the upper $100 \mathrm{~m}$, and the total sample size (n) for each taxon and size class. 
$\mathrm{m}, 50-75 \mathrm{~m}$, and $75-100 \mathrm{~m}$. The neuston net sampled the upper $0.5 \mathrm{~m}$ of the water column. Nets were outfitted with flowmeters to estimate the volume of water sampled during each tow. In the lab, larvae were identified to the family, subfamily, tribe, or genus level. Of the 55,603 coral reef fish larvae that were identified, a subset of 2530 were measured to provide the size-class-specific vertical distribution results presented here. Measured larvae came from every other monthly cruise (starting with Feb, with Jan and March also included for 2003) and every other station across the Straits of Florida (for a total of 8 stations). Within each station-depth bin combination, all larvae for each taxon were measured for standard length up to a maximum of 30 randomly selected individuals.

\subsubsection{Data Analysis}

In order to identify common vertical behaviors, we calculated proportions at depth, with size (as a proxy for age), for 23 coral reef fish taxa in the Straits of Florida collections: 14 families, 2 subfamilies, 1 tribe, and 6 genera. For each study taxon, measured larvae were split into three size classes, representing 25,25 , and $50 \%$ of the observed size range. There were some particularly large larvae that were outliers in the size distribution, which were $2.86-13.09 \mathrm{~mm}$ longer than the next longest larva of that taxon. To have a reasonable sample size in each size class, we adjusted the length range using the second-longest larva in Scorpaenidae, Acanthuridae, Chaetodontidae, Scaridae, Gobiidae, and Pomacanthidae, and the third-longest larva in Pomacentridae. For taxa at lower taxonomic levels, we adjusted the size range using the secondlongest larva in Anthiinae and Sparisoma, and the third-longest larva in Serraninae. These particularly large larvae were still included in size class 3 for the purpose of calculating proportions at depth. 
Larvae were also separated into depth bins. The MOCNESS net samples were classed according to their target depth range (0-25, 25-50, 50-75, and 75-100 m). Surface (neuston) net samples were combined with the 0-25 m MOCNESS depth bin. Larval abundance (ind. $\mathrm{m}^{-2}$ ) for each net was calculated as: $a_{i}=n_{i} / v_{i} * h_{i}$, where $n_{i}$ is the number of individuals collected in the net, $v_{i}$ is the total volume filtered by that net, and $h_{i}$ is the range of depth sampled (Irisson et al., 2010). The range of depth sampled was set to $0.5 \mathrm{~m}$ for the neuston nets, but for the MOCNESS nets, was determined from the actual minimum and maximum depths recorded.

After classifying the larvae according to size and depth, all stations were pooled to determine the mean abundance of each size class and depth bin combination. For each taxon, we produced proportions at depth for each size class. The proportion in a given depth bin is the sum of all sample abundances in that depth bin, divided by the sum of all sample abundances across the four depth bins.

\subsubsection{Model simulations}

We used the Connectivity Modeling System (CMS) (Paris et al., 2013), an opensource individual-based biological-physical model, together with a 3D field of ocean currents from the Hybrid Coordinate Ocean Model (HyCOM) Global (1/12 ${ }^{\circ}$ resolution) and Gulf of Mexico ( $1 / 25^{\circ}$ resolution) data. While HyCOM does have vertical

velocities available, we use only the horizontal velocities, at the 7 available depths in the upper $100 \mathrm{~m}$.

A main focus of this study is the use of the depth assignment module of CMS. This module moves particles by a single depth bin at each time step, so that the simulated depth distribution is as similar as possible to a user-provided matrix of the proportions at depth at various ages throughout the PLD. Note that if all larvae begin 
at the same depth, it may take several time steps for the population of particles to match the intended vertical distribution. This study utilizes three vertical behaviors: (1) surface-dwelling larvae, held at $1 \mathrm{~m}$ depth; (2) larvae that are evenly distributed across 9 depth bins in the upper $100 \mathrm{~m}$; and (3) a generalized 9-depth OVM behavior based on five taxa (two families: Pomacanthidae and Pomacentridae; one subfamily and one tribe: Anthiinae and Grammistini, both in the family Serranidae; one genus: Xyrichtys in the family Labridae) (Figure 2-9). For the evenly-distributed and OVM larvae, the 9 depths we used were $4,12.5,21,31.25,43.75,56.25,68.75,81.25$, and $93.75 \mathrm{~m}$.

We calculated a generalized OVM distribution by averaging the observed proportions at depth from the five taxa that demonstrated OVM and then smoothing that distribution to 9 depths (Figure 2-9). First, we took the average value across taxa of the proportion in each of the 4 observed depth bins, and re-normalized the average proportions to sum to 1 . We then used the "density" function in $\mathrm{R}$ to estimate a kernel density curve from the 4-depth average proportions, and used the "integrate.xy" function in the R package "sfsmisc" to estimate the area under the kernel density curve for 9 depth bins, centered on the depths listed above.

To simulate settlement and calculate connectivity, we used the seascape module in CMS. When this module is in use, particles that pass into one of the userdefined polygons during a specified competency period are considered settled and stop moving. We used the same 261 polygons used in a previous Caribbean-wide study (Cowen et al., 2006) based on the Coral Reef Millennium Mapping dataset (Andréfouët, 2008), with a $9 \mathrm{~km}$ buffer and a maximum width of $50 \mathrm{~km}$ in the alongshore direction (Figure 2-12). This buffer is used to incorporate a wide range of near-shore processes that are not present in models of this scale, including physical and behavioral phenomena. 
Because we used shallow-water coral reefs as our target settlement habitat while focusing on particle behaviors down to $100 \mathrm{~m}$, some polygons would be more accessible to simulated competent larvae in the surface simulations than to simulated competent larvae in the evenly-distributed or OVM simulations. To account for this, we specified that all particles in the evenly-distributed and OVM simulations would use a shallow water distribution at locations where HyCOM data were unavailable at $100 \mathrm{~m}$. The shallow water distribution moves particles to an even distribution across 3 depths in the upper $25 \mathrm{~m}(4,12.5$, and $21 \mathrm{~m})$.

We also used the turbulence module in the CMS, which adds a random kick to particle velocities and is integral to the probabilistic framework of the model. These simulations used horizontal diffusivity components of 10 and $20 \mathrm{~m}^{2} \mathrm{~s}^{-1}$ for the Global and Gulf of Mexico HyCOM grids, respectively (Table 2.2). We did not use a vertical diffusivity coefficient because we used vertical behaviors in all simulations. The timesteps used for integration of the CMS model are given in Table 2.2.

Spawning was simulated by releasing 1000 particles from each polygon at midnight of each day between January 1, 2004 through December 31, 2008. In general, release points are at the centroid of the polygon, except when this would place the particle on "land" according to the HyCOM landmask. For these release sites that cannot coincide with the polygon centroid, they were manually moved into the "ocean," either within or close to the polygon.

We selected two durations that correspond with peaks in the distribution of reef fish PLDs reported in a synthesis paper (Mora et al., 2012). Simulated larvae were competent to settle starting on day 20 in the "short" PLD simulations, representative of taxa such as the bicolor damselfish (Stegastes partitus) (Sponaugle and Cowen, 1996), as well as several other fishes in the families Labridae and Pomacentridae (Mora et al., 2012; Victor, 1986). In contrast, for the "long" PLD simulations, 
simulated larvae were competent to settle starting on day 40 , representative of taxa such as the bluehead wrasse (Thalassoma bifasciatium) (Sponaugle and Cowen, 1997; Victor, 1986), as well as several other species in the families Labridae and Serranidae (Mora et al., 2012). In both cases, larvae remain competent to settle for a period of 10 days.

We do not include mortality in our model simulations, because it is insufficiently constrained and it is unlikely to change our main conclusions. Daily larval mortality rates should vary spatially (horizontally and vertically), with larval ontogeny, and across taxa, but these nuances are extremely difficult to estimate and are essentially unknown for reef fish larvae. Thus, models tend to use a constant daily mortality rate, which, if done so here, should not affect the conclusions we draw when comparing how traits influence connectivity and dispersal.

\subsubsection{Analysis of simulation output}

The model output was processed using MATLAB 2019a. Post-processing analyses were done only for larvae that successfully settled. We calculated larval dispersal kernels using the total dispersal distance for all successful larvae from a given simulation (i.e., a combination of behavior and PLD length). These distances were binned at $50 \mathrm{~km}$ intervals (i.e., the approximate size of each polygon) from 0 to $3000 \mathrm{~km}$, and the frequency of occurrence in each bin was normalized such that the sum of all bins is 1 . We also note that the dispersal distance is the total distance a particle traveled, not the straight-line distance between release and settlement locations.

We defined retention as the proportion of successful larvae from a given release site that settle in the habitat polygon corresponding to that release site. Following the geographical regions in Cowen et al. (2006), we summarized retention on a 
regional basis as the mean value of retention from all polygons within a region.

Connectivity matrices were created to display the probability of larval transport from a series of source nodes (the rows, $i$ ) to the receiving nodes (the columns, $j$ ). Each $(i, j)$ entry is the proportion of settlers from source node $i$ that settle in receiving node $j$; the sum of each row of the connectivity matrix is 1 .

To address how behavior influenced connectivity, independent of the effect of behavior on settlement probability, we defined a matrix, $\mathrm{C}$, that measures the relative change in larval transport due to behavioral differences. Matrices A and B contain the counts of larvae transported from source node $i$ to receiving node $j$ under two behavioral scenarios. The entries of the matrix $\mathbf{C}$ are $c_{i j}=\frac{a_{i j}-b_{i j}}{1 / 2\left(a_{i j}+b_{i j}\right)}$. This method scales the difference by the average of the two matrices, such that the comparison matrix $\mathbf{C}$ is symmetrical for pairwise comparisons. However, this method cannot distinguish connections that change from 0 to 1 transported particle from those that change from 0 to 1000 transported particles. Connections that appear to be behaviordependent, but which are formed by a single transported particle may be due more to stochasticity in the model, as opposed to demonstrating a true new connection under one of the behaviors. To focus on connections, both behavior-dependent connections and those that are maintained between behaviors, that are less affected by stochastic transport events, we mask source-receiver pairs where the number of transported particles is $\mathbf{1 0 0 0}$ or fewer in both $\mathbf{A}$ and $\mathbf{B}$.

\subsection{Results}

Amongst the 14 families, 3 subfamilies, and 6 genera investigated for ontogenetic patterns in larval vertical distribution, our analysis revealed a wide variety of behaviors (Figures 2-1, 2-6, and 2-7). A persistent association with surface waters was 
seen in 3 families (Mullidae, Holocentridae, Figure 2-1; Gerreidae, Figure 2-6; also see Figure 2-8). A downward ontogenetic vertical migration was evident in 2 families (Pomacentridae and Pomacanthidae, Figures 2-1 and 2-6), 1 subfamily (Anthiinae, Figure 2-7), 1 tribe (Grammistini, Figure 2-1), and 1 genus (Xyrichtys sp., Figure 2-1). In the other taxa, larvae showed almost no depth preference (e.g., Gobiidae and Scorpaenidae, Figure 2-1), a relatively consistent depth preference (e.g., Apogonidae, Figure 2-1; Chaetodontidae, Figure 2-6), or widened their preferred depth range with ontogeny (e.g., Acanthuridae, Figure 2-1; Callionymidae, Figure 2-6).

To investigate the implications of these observed behaviors for larval dispersal and population connectivity, we selected three generalized larval behaviors for the dispersal simulations: (1) surface-dwelling, (2) evenly distributed across depths, and (3) ontogenetic vertical migration (hereafter, OVM). The OVM behavior is a composite based on taxa that exhibited this behavior (Figure 2-9). We selected two PLDs, "short" (20-30 d) and "long" (40-50 d), that are highly representative of coral reef taxa (Mora et al., 2012).

Dispersal kernels, representing the probability of larval settlement at a range of distances from release site, showed higher probability of long-distance dispersal for surface-dwelling than for the other two behaviors (Figure 2-2). The median dispersal distance of surface-dwelling larvae was greater than that for the evenlydistributed and OVM larvae, by $39-47 \%$ for the short PLD simulations, and by 29-39\% for long PLD simulations. Surface-dwelling larvae also had a slightly higher probability of settling: probability of success in the short PLD simulations was $43 \%$ for surface-dwelling larvae, while evenly-distributed and OVM larvae experienced $38-39 \%$ successful settlement. In the long PLD simulations, settlement success for surface-dwelling larvae was reduced to $38 \%$ and $29-30 \%$ for evenly-distributed and OVM larvae. 


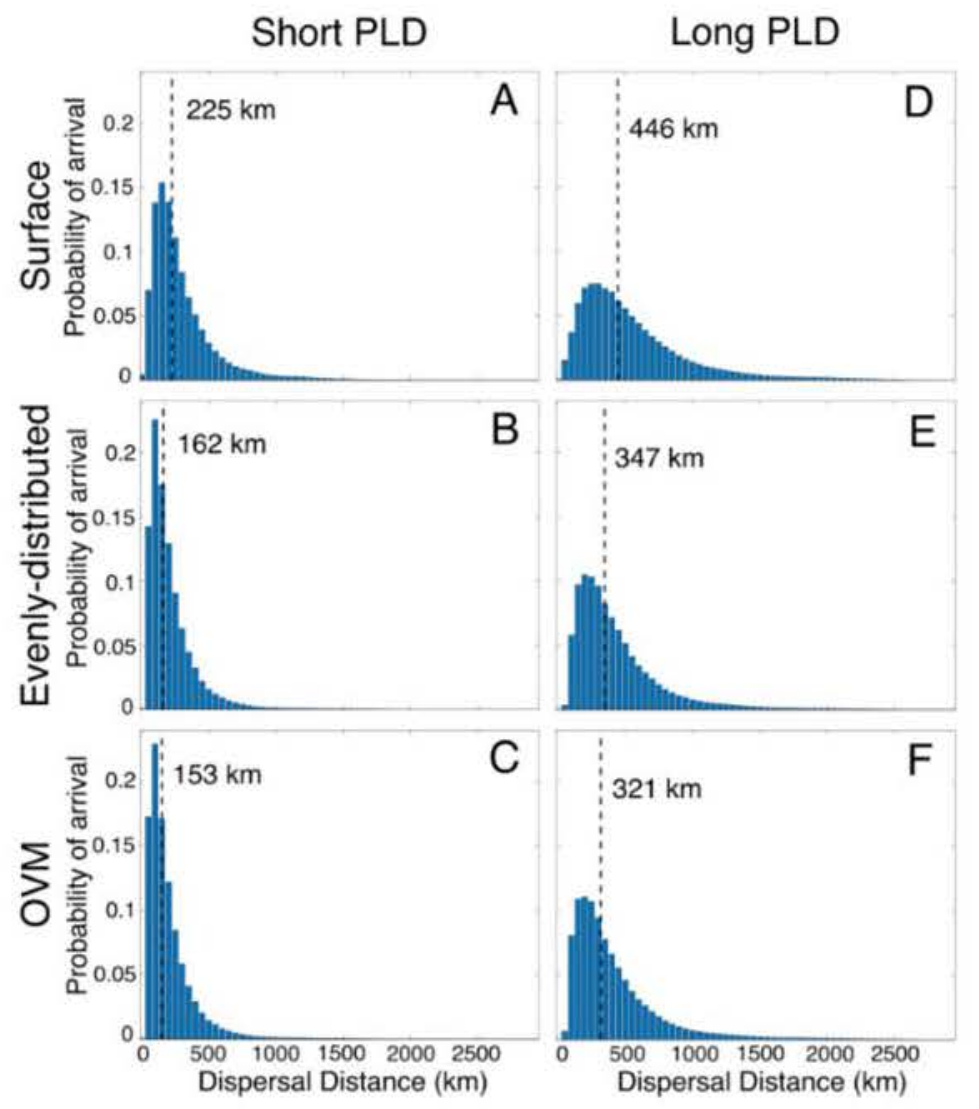

Figure 2-2: Overall dispersal patterns. Dispersal kernels of successfully settled larvae for combinations of larval behavior and pelagic larval duration (PLD). The kernels are plotted as probability densities in 50-km wide bins and frequencies are normalized such that the sum of all bars is equal to 1 . The median dispersal distance is numerically displayed and shown as a vertical dashed line. Note that all 6 sub-panels have the same horizontal and vertical axes. (Rows) Three larval behavior simulations were conducted: surface-dwelling, evenly-distributed, and ontogenetic vertical migration (OVM). (Columns) Short and long PLD simulations correspond to 20-30 days and 40-50 days, respectively.

Our focal traits, vertical distribution behavior and PLD, have markedly stronger effects on dispersal than the effects due to season or year. Dispersal kernels did not have strong seasonal variability in any of the 6 experiments (Figure 2-10). Median 
dispersal distance between seasons varied by $0-14 \%$, with the greatest difference seen between the summer and fall quarters for surface-dwelling larvae with long PLDs (Table 2.1). Likewise, dispersal kernels look very similar amongst the 5 years of simulations, with the greatest variability seen in the surface-dwelling larvae (Figure 2-11), as their transport is influenced by wind-driven circulation.

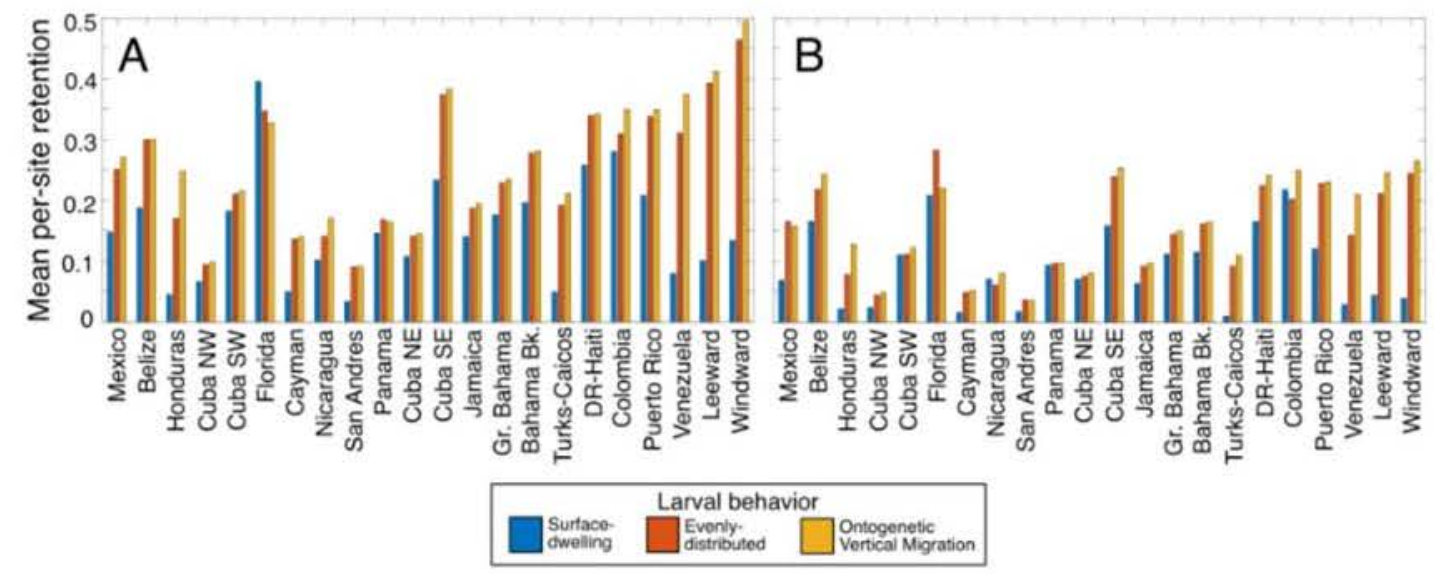

Figure 2-3: Mean regional retention, by behavior and pelagic larval duration (PLD). The height of each bar is the mean value of retention for all habitat polygons in each region, where retention is the proportion of successful larvae that settled in the same habitat polygon as their release site. Regions are arranged roughly west to east. Short PLD simulations (A) were 20-30 days long, and long PLD simulations (B) were 40-50 days long. For a map of regions, see Figure 2-12.

We examined retention by calculating the proportion of successful larvae that settled in the same habitat polygon as they were released from, and then summarized for each geographic region (Figure 2-12) using the mean regional retention. Overall, ontogenetically migrating and evenly-distributed larvae experienced greater retention than surface-dwelling larvae (Figure 2-3). Time spent in the plankton (PLD) decreased retention in most of the regions. However, the effect of surfacedwelling behavior on retention appears strongest in the eastern Caribbean regions of 
Turks and Caicos, Puerto Rico, Venezuela, and the Windward and Leeward Islands, where habitat is spaced far apart and surface currents are influenced by directional circulation patterns. This is in contrast to regions to the north and west where surface-dwelling larvae experienced similar rates of retention as deeper-dwelling larvae, such as Nicaragua, Panama, Colombia, the Florida Keys, the Bahamas, and much of Cuba (Figure 2-3).

Connectivity matrices, which display probability of transport between source and receiving pairs of coral reef sites, show that connectivity increases with a longer dispersal time, and changes with behavior (Figure 2-4). Connectivity was most constrained in the OVM behavior, the evenly-distributed behavior led to an intermediate pattern of connectivity, and the surface-dwelling behavior resulted in the most connectivity among reef sites.

The effect of behavior on connectivity can be visualized more clearly from the relative difference in the transport of larvae amongst reef sites between the surface and OVM behavior (Figure 2-5). This confirms that there is an overall pattern of greater dispersal in surface-dwelling than in OVM simulations (off-diagonal sites) and greater local retention in OVM simulations (diagonal sites). Behavior-dependent connections, wherein a given source-receiving node pair had larval transport under one behavior and not the other, were more likely to occur with surface-dwelling behavior than OVM behavior. There were 538 connections that appear for surfacedwelling larvae but not for OVM larvae with short PLD and 703 with long PLD, and there were 21 behavior-dependent connections for OVM larvae but not for surfacedwelling larvae with short PLD and 26 with long PLD.

Contrary to this overall pattern, there were some areas where OVM larvae exhibited greater transport than surface-dwelling larvae, particularly under the long PLD simulations. For example, OVM larvae released from Venezuelan reefs were more 


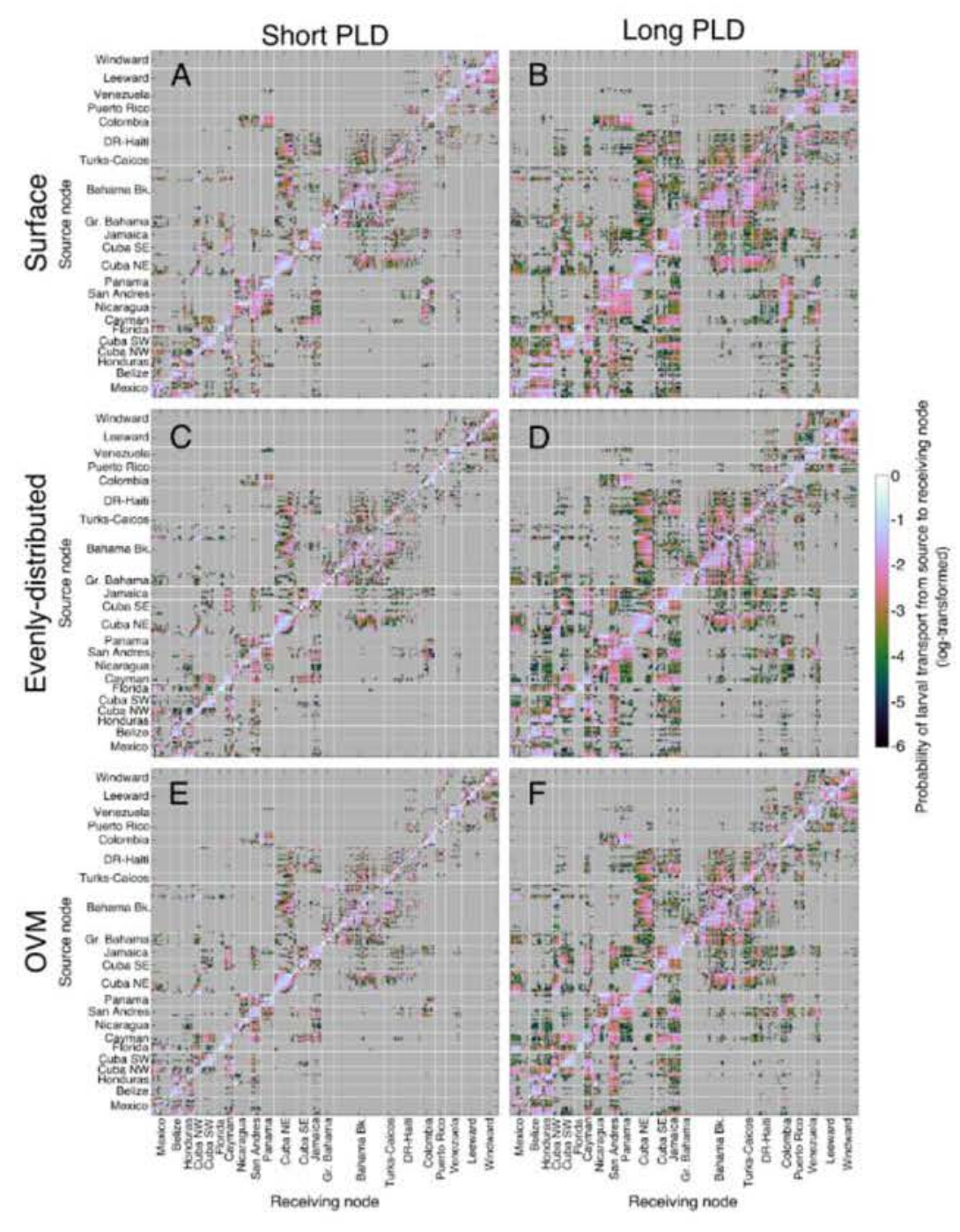

Figure 2-4: Connectivity matrices. Connectivity is defined as the probability of larval transport from the source nodes (rows) to receiving nodes (columns) of the matrix, where the sum of each row of the matrix is 1 . Source and receiving nodes are organized into geographic regions, from west to east. For a map of regions, see Figure 2-12. Note that the colorbar is log-scaled. (Rows) Three larval behavior simulations were conducted: surface-dwelling, evenly-distributed, and ontogenetic vertical migration (OVM). (Columns) Short and long PLD simulations correspond to $20-30$ days and $40-50$ days, respectively. 


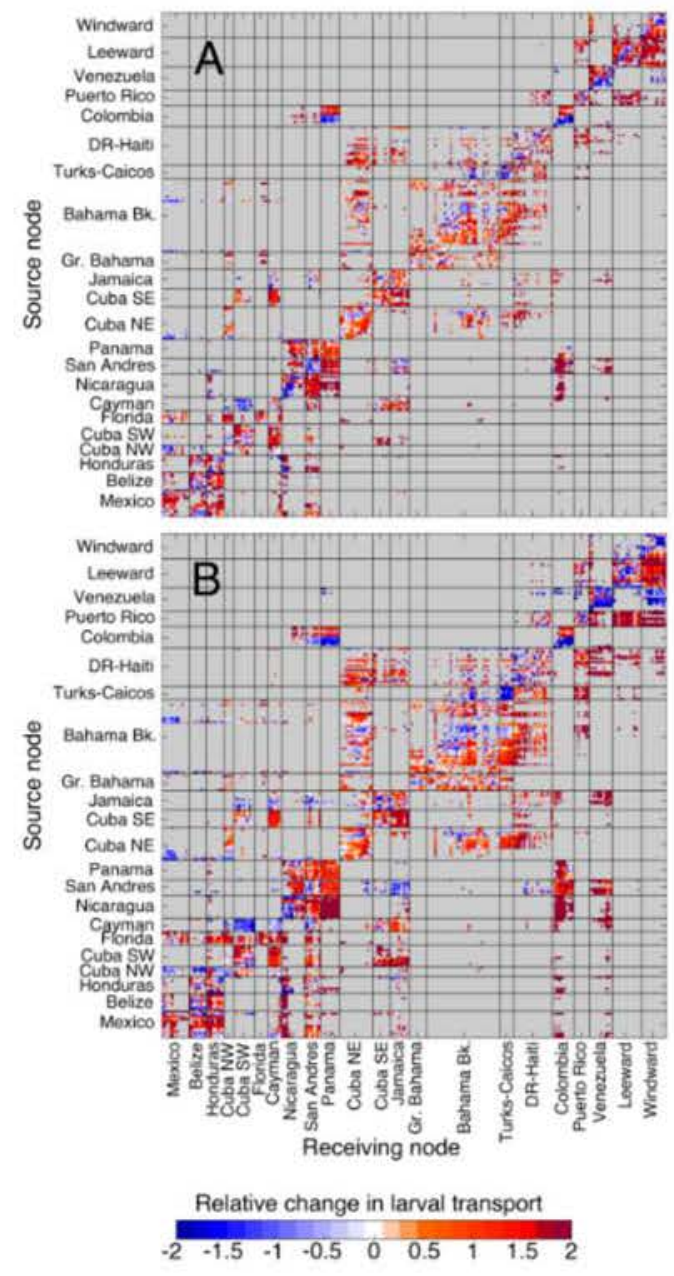

Figure 2-5: Relative change in larval transport between the surface-dwelling and OVM simulations. Entries in the relative change matrix are given by $c_{i j}=\frac{a_{i j}-b_{i j}}{1 / 2\left(a_{i j}+b_{i j}\right)}$ where the $a_{i j}$ is the larval transport for surface-dwelling larvae and $b_{i j}$ is the larval transport for OVM larvae. Rows within each matrix correspond to release sites (source nodes) and columns to settlement sites (receiving nodes). Red colors indicate more larvae transported in the surface-dwelling simulations, and blue colors indicate more larvae transported in the OVM simulations. Source and receiving nodes are grouped within regions, and regions are arranged roughly west to east. For a map of regions, see Figure 2-12. Two pelagic larval durations (PLD) were investigated: (A) short (20-30 d) PLD and (B) long (40-50 d) PLD. 
likely to reach the neighboring regions of the Gulf of Colombia, Puerto Rico, and the Windward Islands compared with surface-dwelling larvae (Figure 2-5). Likewise, Mexican reefs were more likely to receive larvae from the northern coast of Cuba and from the Bahamas Bank under OVM simulations than surface-dwelling simulations.

Relative change in larval transport between evenly-distributed and surface simulations (Figure 2-13) and between evenly-distributed and OVM larvae (Figure 2-14) confirm that the dispersal and transport of evenly-distributed larvae is similar to that of OVM larvae (note that Figure 2-5 and Figure 2-13 show the same regional patterns mentioned above). Evenly-distributed behavior led to slightly greater transport than OVM (Figure 2-14), but the changes were much smaller in magnitude than the relative differences observed between the surface-dwelling behavior and either of the deeper-dwelling behaviors (Figures 2-5 and 2-13).

\subsection{Discussion}

In this study, we comprehensively examined vertical distribution patterns across the larval period for various taxa of coral reef fish, finding distinct and notable differences both within and between coral reef fish families. We identified three prevalent patterns in the field observations: surface-dwelling, evenly-distributed, and ontogenetic vertical migration (OVM). We simulated these vertical behaviors in a biophysical model to investigate the implications for dispersal and population connectivity that arise from these innate, taxon-specific behavioral differences. By simulating five years of daily larval releases from 261 coral reef sites across the Caribbean region, we were able to evaluate the robustness of dispersal patterns across time and space.

We found that surface-dwelling fish larvae - representative of, for example, the often-abundant goatfishes and mojarras - disperse substantially longer distances than 
larvae that were evenly-distributed in the upper $100 \mathrm{~m}$ or those that were ontogenetically migrating. The difference in the dispersal kernels between the evenlydistributed and the OVM larvae was surprisingly small. This suggests that the constraint on dispersal distance is imposed by having some larvae spend time at depth, but an age-specific pattern of increasing depth is not required to restrict dispersal distance. The difference in dispersal distance due to changes in our focal traits, vertical behavior and PLD, are much greater than the differences in dispersal kernels between seasons or years. This suggests that selective forces acting on the evolution of spawning seasonality are likely due to factors other than dispersal potential (e.g., food availability, avoidance of larval predators, energy constraints on adults).

In contrast to these overall results, retention and connectivity on a regional and local (per-polygon, ca. $50 \mathrm{~km}$ in alongshore direction) basis showed spatial variation in which traits maximize dispersal or connectivity. Surface-dwelling larvae were as likely as deeper-dwelling larvae to be retained in Panama, Nicaragua, and Florida, while OVM and evenly-distributed larvae were more likely than surface-dwelling larvae to be exchanged between Cuba and the Mesoamerican reefs (Figures 2-3, 2-5, and 2-13). Surface-dwelling larvae are entrained by wind-driven circulation, predominantly to the northwest in the Caribbean (Tang et al., 2006). In contrast, vertically migrating larvae are more likely to be transported into the eddy field, riding the mesoscale anticyclonic gyre linking Mexico to Southwest Cuba (Kough et al., 2013; Paris et al., 2005). Other studies have found that a cyclonic gyre formed in the Gulf of Honduras drives retention and connectivity in the Mesoamerican reefs (Butler et al., 2011; Martínez et al., 2019; Tang et al., 2006). Subsurface geostrophic flows are important in the eastern Caribbean, where OVM larvae were more likely than surface-dwelling larvae to be retained in Venezuela, and transported from Venezuela to the Windward Islands (Figure 2-5). Off the coast of Venezuela, westward currents 
have been observed at the surface, overlaying a subsurface eastward jet (Andrade et al., 2003; Hernandez-Guerra and Joyce, 2000). Because of the complex interaction among larval behavior, PLD, spatial variation in ocean currents, habitat availability, and seascape geomorphology, the same larval vertical behavior can lead to different dispersal and connectivity outcomes, and concomitant population effects, across regions. Therefore, pan-Caribbean species might have regional differences in behavior or PLD [e.g., especially in species that exhibit an extended competency period like the bluehead wrasse (Sponaugle and Cowen, 1997; Victor, 1986)], or distinct population genetic structure across regions (Kool et al., 2010; Selkoe et al., 2014; Truelove et al., 2017).

The diversity of larval vertical behaviors that we observed, and their strong effect on dispersal and population connectivity in our simulations, indicates that these behaviors can play a role in coral reef fish population persistence and evolution (Sponaugle et al., 2002; Strathmann et al., 2002). Furthermore, our results shed light on how larval traits could have evolved to maximize the chance of reaching suitable settlement habitat, particularly if we consider that suitable habitat may be distributed in accordance with other traits of each species. For example, if intraspecific competition for resources, including space, is low for adult and juvenile fish of a given species, then retention near suitable habitat-i.e. where the adults spawned - may be a successful strategy (Burgess et al., 2014; Hovestadt et al., 2001; Waser, 1985). On the other hand, if intraspecific competition is high and spawning adults are occupying habitat already at or near carrying capacity, then suitable habitat would be elsewhere and longer-distance dispersal would increase the probability of larvae finding suitable settlement habitat. Traits such as deeper-dwelling larvae, which restrict dispersal, can therefore facilitate local adaptation (Strathmann et al., 2002). 
On the other hand, the interplay of multiple larval traits determines larval survival and population persistence. In our results, surface-dwelling larvae dispersed to greater distances from their natal reef and had a higher overall probability of arriving at settlement habitat compared to deeper-dwelling larvae with the same PLD. However, life in the surface waters is likely to come with greater risks of starvation, predation, and UV light damage. Vertical distributions of chlorophyll and zooplankton generally show a peak in the subsurface, with lower values at the very surface (Espinosa-Fuentes et al., 2009; Hopkins, 1982; Llopiz, 2008). In addition to lower food availability, larvae living in the uppermost part of the water column must contend with high light, which increases their risk of predation and requires high levels of pigmentation to protect against UV damage. Therefore, greater dispersal and connectivity seems to be the only discernable advantage to a coral reef fish of spending its entire larval duration in the surface waters.

In addition to the traits that we examine in this study, there are myriad processes that determine the successful settlement of larval coral reef fish. Larval growth rates, and therefore often the pelagic larval duration, depend on temperature and food availability (Houde, 1989). Larval mortality rates decrease with size (Houde, 1997) and will vary spatially - horizontally due to patchy predator distributions and vertically due to predator behaviors and light availability. While mortality rates can have important impacts on modeled population connectivity and recruitment (Cowen et al., 2006; Paris et al., 2007), true recruitment and demographic connectivity will also depend on tradeoffs among larval traits (e.g., behavior, growth rate, PLD, mortality) as well as adult traits (e.g., longevity, fecundity, spawning periodicity) (Cowen et al., 2006). Horizontal swimming ability increases with size and fin development (Peck et al., 2012), and larvae may use directional swimming in response to cues as they prepare to settle (Leis, 2006). Nearshore physical processes, including tides, internal 
waves, and coastal boundary currents can also affect larval transport and settlement (Pineda et al., 2007). As models increase in complexity, more of these processes can be incorporated. However, the strength of modeling studies lies in their ability to isolate parameters for the purposes of hypothesis testing, and we have analyzed the interaction of two larval traits-pelagic larval duration and vertical distribution behavior - to test the hypothesis that species with surface-dwelling larvae disperse further and exhibit greater population connectivity.

The experiences of planktonic larvae, from their large-scale transport in ocean currents to their small-scale movement in response to both biotic and abiotic cues, remain difficult to study. Although biological-physical modeling is one of our strongest tools for forming and testing hypotheses about larval dispersal and connectivity, there is a lack of detailed knowledge of the behaviors of many species. By probing the trait space that is defined by larval vertical behavior and PLD, we demonstrate an approach that could be used to predict the dispersal and connectivity across many taxa. Our study is limited to three vertical behaviors and two pelagic larval durations, but shows the value of a trait-based analysis of dispersal and connectivity. For example, we can now predict that two species with similar larval durations, one that undergoes ontogenetic vertical migration and another that shows weak depth preferences, would be predicted to have similar patterns of dispersal, although retention and connectivity may vary on a regional basis. These findings can help guide a management system that must take into account numerous species, goals, and constraints. 


\subsection{Supplemental Figures and Tables}

\begin{tabular}{|l|l|l|l|l|l|l|}
\hline & \multicolumn{3}{|l|}{ Short Duration } & \multicolumn{3}{l|}{ Long Duration } \\
\cline { 2 - 7 } & Surface & Even & OVM & Surface & Even & OVM \\
\hline Winter & 223 & 173 & 165 & 443 & 364 & 342 \\
\hline Spring & 225 & 155 & 151 & 449 & 334 & 317 \\
\hline Summer & 234 & 157 & 152 & 479 & 335 & 321 \\
\hline Fall & 217 & 165 & 158 & 421 & 355 & 341 \\
\hline
\end{tabular}

Table 2.1: Median dispersal distance by season. The median dispersal distance $(\mathrm{km})$ of all larvae that reach settlement habitat under each behavior and duration combination, separated by the larval release season. Seasons are defined by release dates with winter covering Jan-March, spring April-June, summer July-Sept, and fall Oct-Dec. Distances are rounded to the nearest integer.

\begin{tabular}{|l|l|}
\hline & Timestep (seconds) \\
\hline Update location of particles & 1200 \\
\hline Add sub-gridscale turbulence & 2400 \\
\hline Update particle depths to match desired vertical distribution & 2400 \\
\hline & Diffusivity (m2 s-1) \\
\hline HyCOM Global grid & 10 \\
\hline Gulf of Mexico grid & 20 \\
\hline
\end{tabular}

Table 2.2: Timesteps and diffusivity parameters used for integration of Connectivity Modeling System simulations. 

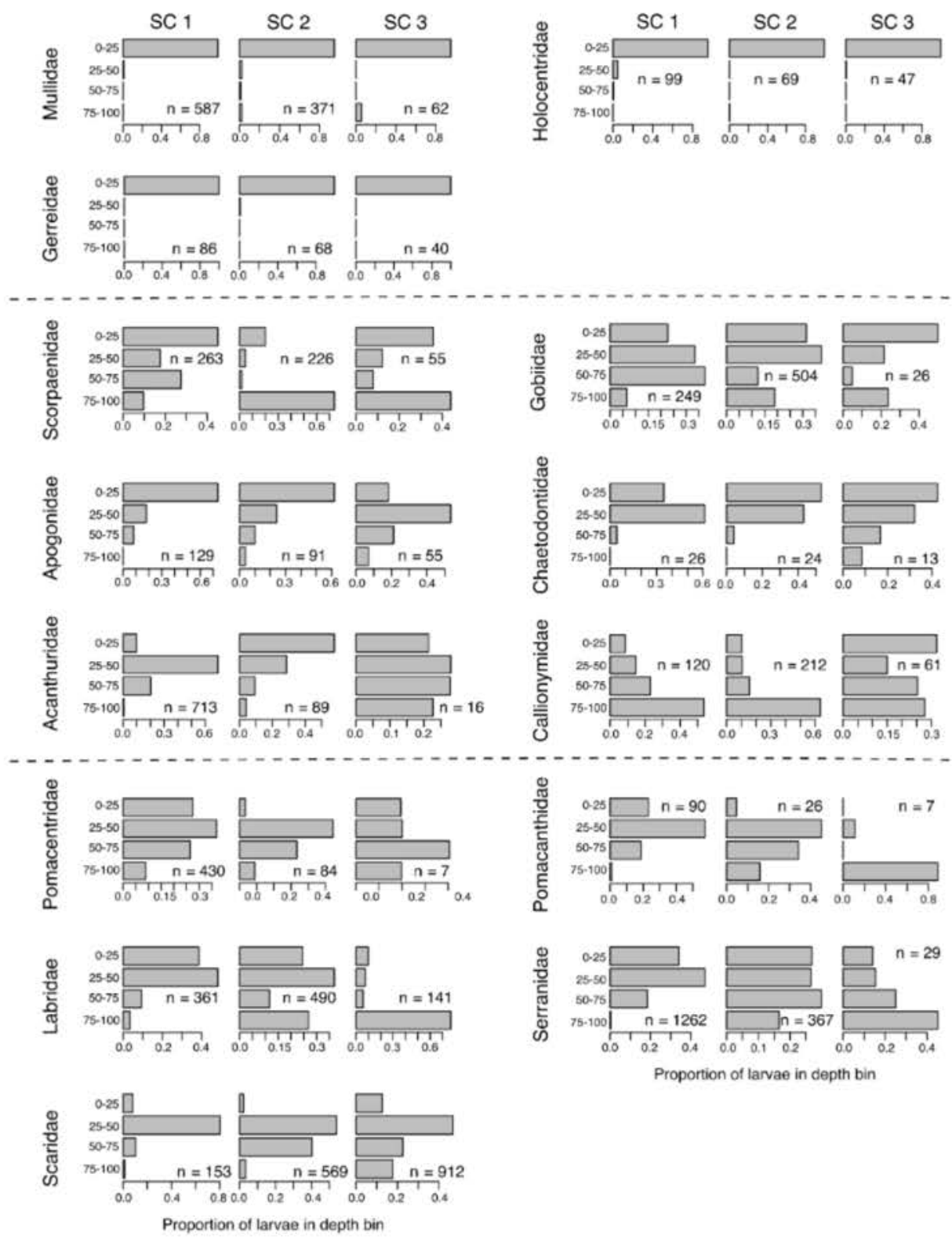

Proportion of larvae in depth bin

Figure 2-6: The full set of family-level larval fish vertical distributions. Each set of 3 panels represents a taxon, with the name given on the left. The columns of subpanels refer to size classes 1 through 3 that represent respectively 25,25 , and $50 \%$ of the observed size range, excluding a small number of outliers. Each sub-panel shows the proportional abundance in 4 depth bins in the upper $100 \mathrm{~m}$, and each sub-panel lists the sample size in that taxon and size class. 

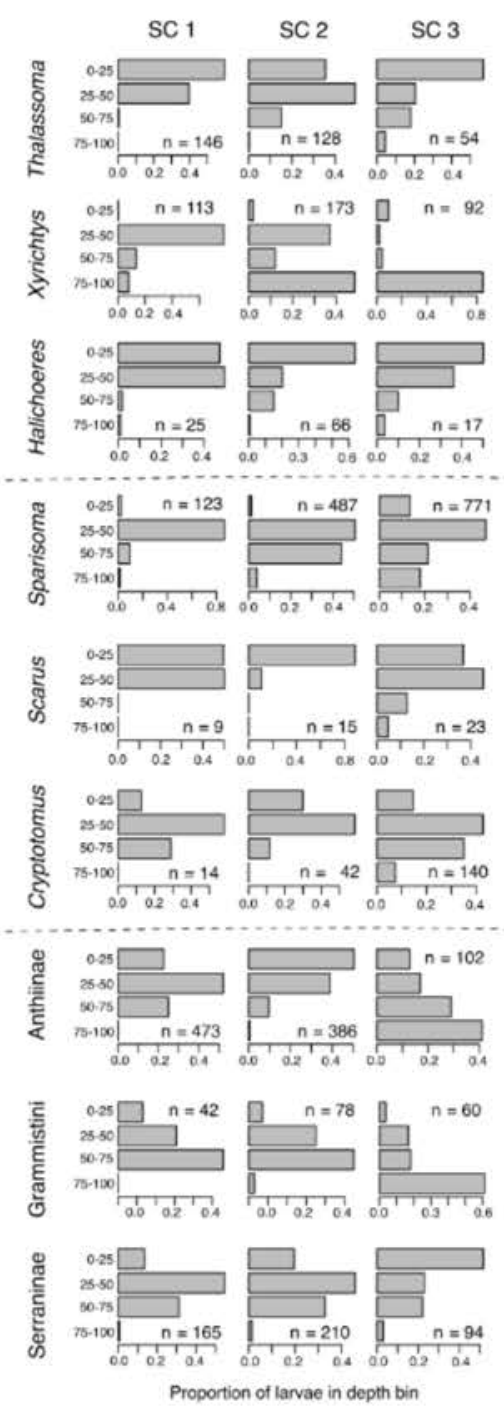

Figure 2-7: The full set of subfamily-, tribe-, and genus-level larval fish vertical distributions. Each set of 3 panels represents a taxon, with the name given on the left. The upper three rows are genera in the family Labridae; the middle three rows are genera in the family Scaridae; the bottom three rows are two subfamilies and one tribe in the family Serranidae. The columns of sub-panels refer to size classes 1 through 3 that represent respectively 25,25 , and $50 \%$ of the observed size range, excluding a small number of outliers. Each sub-panel shows the proportional abundance in 4 depth bins in the upper $100 \mathrm{~m}$, and each sub-panel lists the sample size in that taxon and size class. 


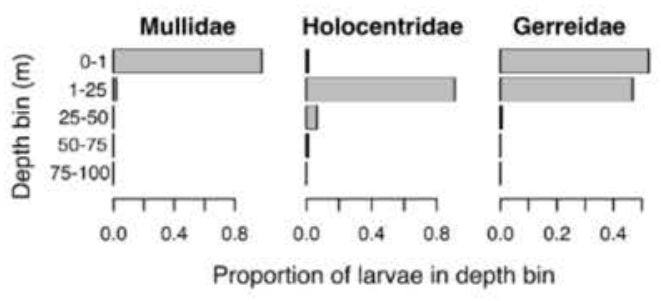

Figure 2-8: Surface associated taxa and their depth in the water column. In order to show the importance of the neuston net sampling (0-1 m depth bin), we use proportional concentration $\left(\mathrm{N} \mathrm{per}^{3}\right)$ instead of abundance $\left(\mathrm{N} \mathrm{per} \mathrm{m}^{2}\right)$.

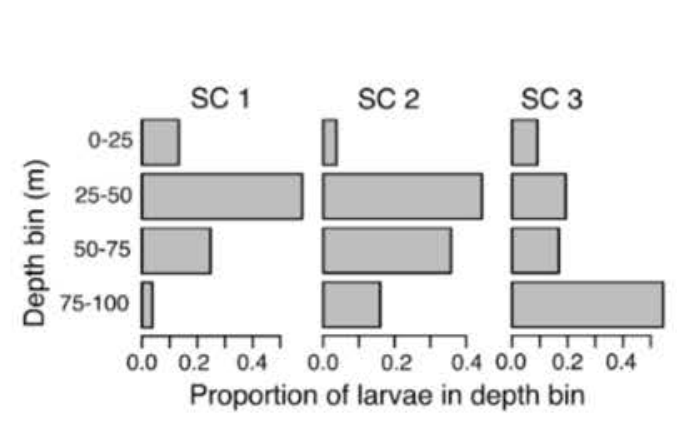

(a) Combined observations of OVM

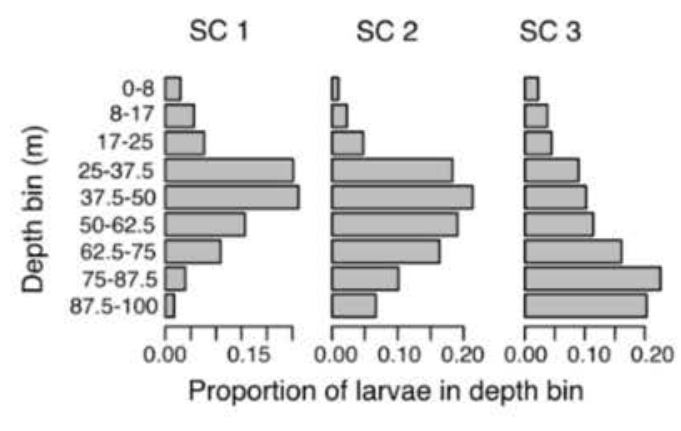

(b) Simulated OVM

Figure 2-9: Combined observations of ontogenetic vertical migration (OVM) and Simulated OVM. The left panel (a) shows the field observations of proportions at depth, averaged across the 5 taxa showing OVM behavior: Pomacentridae, Pomacanthidae, Grammistini, Anthiinae, and Xyrichtys. The right panel (b) shows the OVM behavior used in model simulations, which was generated by smoothing the 4-depth distribution to a 9-depth distribution by fitting a density kernel to the 4-depth distributions and then integrating that kernel within the depth bins shown in the right panel. 


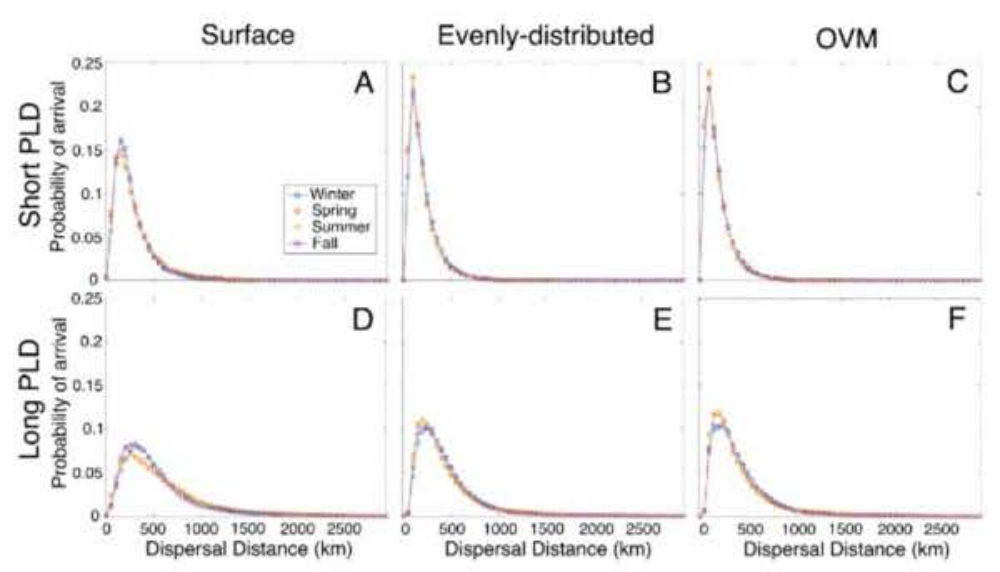

Figure 2-10: Seasonal dispersal kernels. Shown for short PLD (first row) and long PLD (second row) for surface-dwelling (first column), evenly-distributed (middle column) and OVM (third column) simulations. Seasons are defined by release dates with winter covering Jan-March, spring April-June, summer July-Sept, and fall OctDec. All kernels are displayed on the same axes, and the sum of probabilities in each kernel (each colored curve) is equal to 1 .

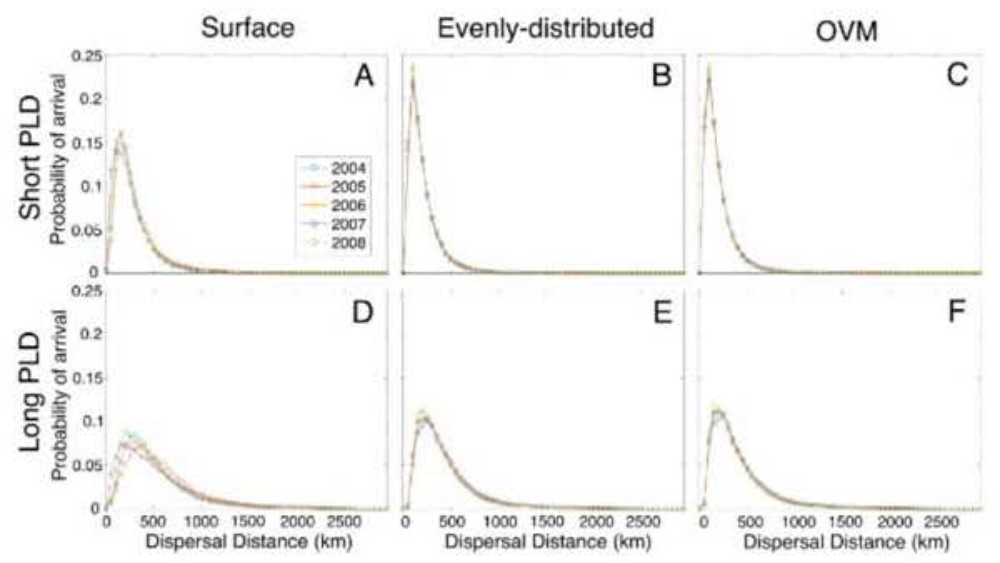

Figure 2-11: Annual dispersal kernels. Dispersal kernels of successfully settled larvae for combinations of larval behaviors and pelagic larval durations (PLD). (Columns) Three larval behavior simulations were conducted: surface-dwelling, evenly-distributed, and ontogenetic vertical migration (OVM). (Rows) Short and long PLD simulations correspond to 20-30 days and 40-50 days, respectively. Larvae are assigned to a year based on their release date between January 12004 and December 31 2008. All kernels are displayed on the same axes, and the sum of probabilities in each kernel (each colored curve) is equal to 1. 


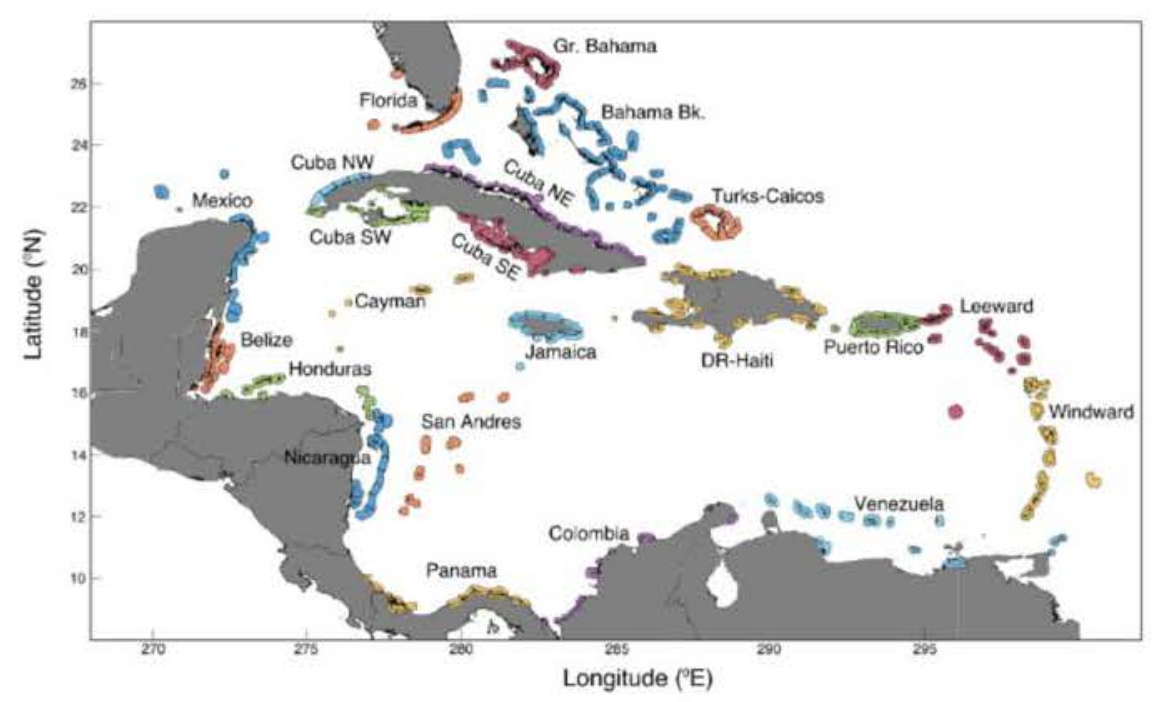

Figure 2-12: Map of coral reef habitat used in larval dispersal simulations. The Caribbean coral reefs, represented by 261 polygons, are colored by region, following Cowen et al. (2006). Region names shown here match the region names used on Figs. 3, 4, S7, S8 and S9. The regions are (roughly west to east): Mexican Caribbean and Campeche Bank (Mexico); Belize; Gulf of Honduras (Honduras); Northwest Cuba (Cuba NW); Southwest Cuba (Cuba SW); Florida Keys and west coast reefs (Florida); Cayman Islands, Rosario and Misteriosa (Cayman); Nicaraguan Rise Islands (Nicaragua); Colombian Archipelagos (San Andres); Panama and Costa Rica (Panama); Northeast Cuba (Cuba NE); Southeast Cuba (Cuba SE); Jamaica and Pedro Bank (Jamaica); Grand Bahama (Gr. Bahama); Bahamas Bank and SE Bahamas Island (Bahama Bk.); Turks and Caicos Islands (Turks-Caicos); Dominican Republic and Haiti (DR-Haiti); Gulf of Colombia (Colombia); Puerto Rico and Mona Islands (Puerto Rico); Venezuelan Corridor, Tobago to Aruba (Venezuela); Leeward Islands (Leeward); Windward Islands (Windward). 


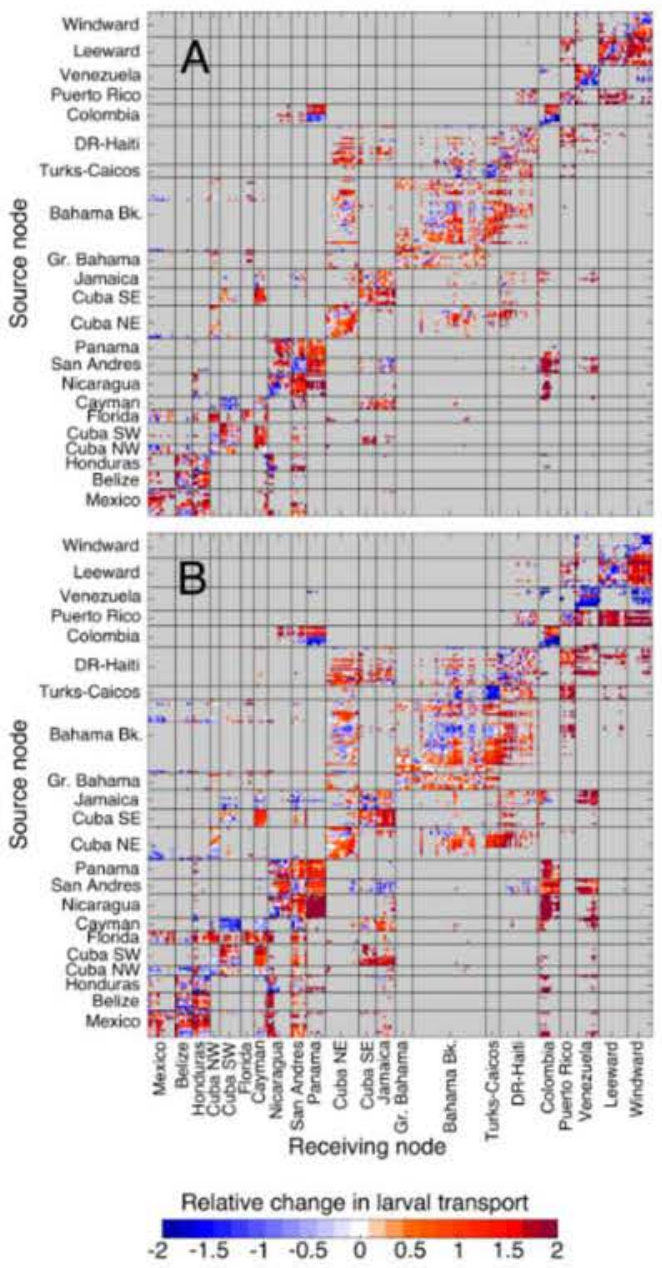

Figure 2-13: Relative change in larval transport between the surface-dwelling and evenly-distributed simulations. Entries in the relative change matrix are given by $c_{i j}=\frac{a_{i j}-b_{i j}}{1 / 2\left(a_{i j}+b_{i j}\right)}$ where the $a_{i j}$ is the larval transport for surface-dwelling larvae and $b_{i j}$ is the larval transport for evenly-distributed larvae. Rows within each matrix correspond to release sites (source nodes) and columns to settlement sites (receiving nodes). Red colors indicate more larvae transported in the surface-dwelling simulations, and blue colors indicate more larvae transported in the evenly-distributed simulations. Source and receiving nodes are grouped within regions, and regions are arranged roughly west to east. For a map of regions, see Figure 2-12. Two pelagic larval durations (PLD) were investigated: (A) short (20-30 d) PLD and (B) long (40-50 d) PLD. 


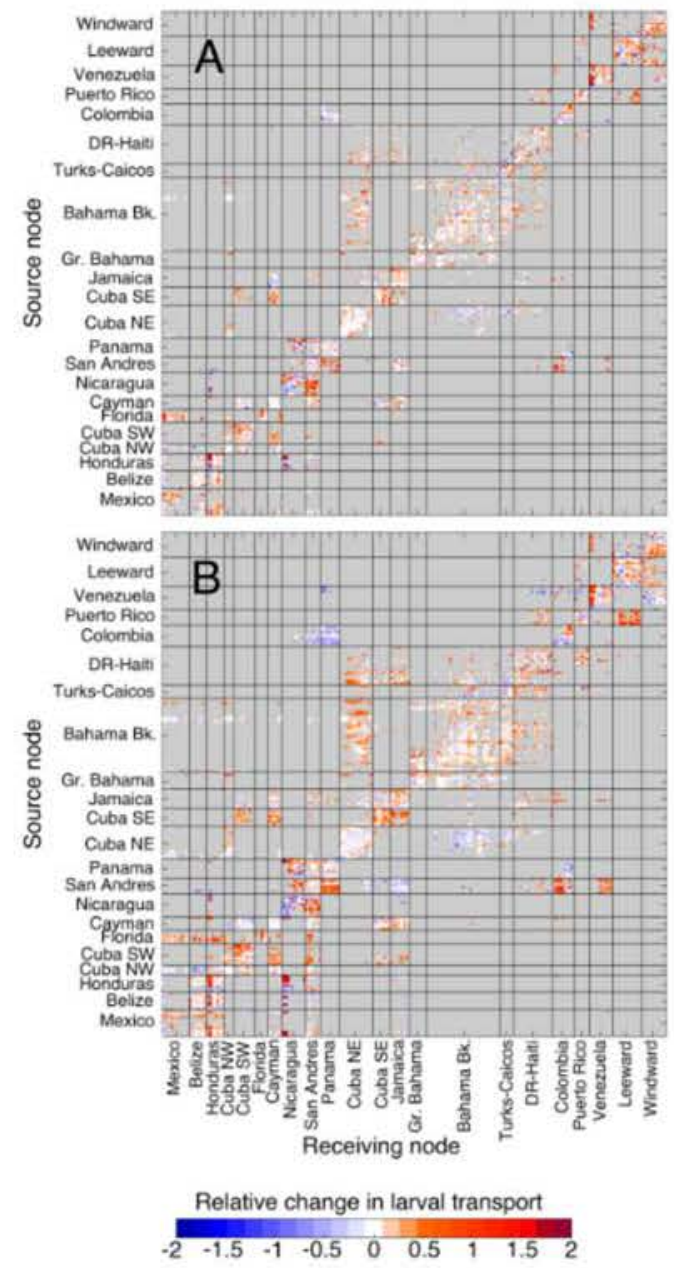

Figure 2-14: Relative change in larval transport between the evenly-distributed and ontogenetic vertical migration (OVM) simulations. Entries in the relative change matrix are given by $c_{i j}=\frac{a_{i j}-b_{i j}}{1 / 2\left(a_{i j}+b_{i j}\right)}$ where the $a_{i j}$ is the larval transport for evenlydistributed larvae and $b_{i j}$ is the larval transport for OVM larvae. Rows within each matrix correspond to release sites (source nodes) and columns to settlement sites (receiving nodes). Red colors indicate more larvae transported in the evenlydistributed simulations, and blue colors indicate more larvae transported in the OVM simulations. Source and receiving nodes are grouped within regions, and regions are arranged roughly west to east. For a map of regions, see Figure 2-12. Two pelagic larval durations (PLD) were investigated: (A) short (20-30 d) PLD and (B) long (40-50 d) PLD. 


\section{Chapter 3}

\section{Evidence and patterns of tuna}

\section{spawning inside a large no-take}

\section{Marine Protected Area}

\subsection{Abstract $^{1}$}

The Phoenix Islands Protected Area (PIPA), one of the world's largest marine protected areas, represents $11 \%$ of the exclusive economic zone of the Republic of Kiribati, which earns much of its GDP by selling tuna fishing licenses to foreign nations. We have determined that PIPA is a spawning area for skipjack (Katsuwonus pelamis), bigeye (Thunnus obesus), and yellowfin (Thunnus albacares) tunas. Our approach included sampling larvae on cruises in 2015-2017 and using a biological-physical model to estimate spawning locations for collected larvae. Temperature and chloro-

\footnotetext{
${ }^{1}$ Originally published as "Hernández, C. M., Witting, J., Willis, C., Thorrold, S. R., Llopiz, J. K., \& Rotjan, R. D. (2019). Evidence and patterns of tuna spawning inside a large no-take Marine Protected Area. Scientific Reports, 9(1), 10772. https://doi.org/10.1038/s41598-019-47161$0 . "$ This version differs only in formatting.
} 
phyll conditions varied markedly due to observed ENSO states: El Niño (2015) and neutral (2016-2017). However, larval tuna distributions were similar amongst years. Generally, skipjack larvae were patchy and more abundant near PIPA's northeast corner, while Thunnus larvae exhibited lower and more even abundances. Genetic barcoding confirmed the presence of bigeye (Thunnus obesus) and yellowfin (Thunnus albacares) tuna larvae. Model simulations indicated that most of the larvae collected inside PIPA in 2015 were spawned inside, while stronger currents in 2016 moved more larvae across PIPA's boundaries. Larval distributions and relative spawning output simulations indicate that both focal taxa are spawning inside PIPA in all 3 study years, demonstrating that PIPA is protecting viable tuna spawning habitat.

\subsection{Introduction}

Tropical tunas are extremely valuable worldwide as a source of protein and income. Skipjack tuna alone provide approximately $50-60 \%$ of annual global tuna catches (Western and Central Pacific Fisheries Commission, 2018). Pacific island nations earn a large proportion of their gross domestic product (GDP) from tuna, many by selling fishing licenses to the commercial fleets of foreign nations to operate in their exclusive economic zones (EEZ) (Bell et al., 2013). One of these island nations is the Republic of Kiribati, which comprises 34 islands with a total land area of $810 \mathrm{~km}^{2}$ and an EEZ of 3.5 million $\mathrm{km}^{2}$, across 3 archipelagos that span $4.7^{\circ} \mathrm{N}$ to $11.4^{\circ} \mathrm{S}$ and $150.2^{\circ} \mathrm{W}$ to $187^{\circ} \mathrm{W}$ : the Line Islands, the Phoenix Islands, and the Gilbert Islands. For this low-lying ocean nation, tuna fishing by foreign commercial fleets is incredibly important to their economy: from 2006 to 2015, fishing license revenue represented $39.5 \%$ of GDP on average, ranging from $19.2 \%$ to $93.5 \%$ (GDP (Current US\$) 2018; Ministry of Finance and Economic Development and Ministry 
of Fisheries and Marine Resource Development, 2016). Some of the variance in fishing license revenue can be attributed to the El Niño Southern Oscillation (ENSO) cycles. El Niño conditions tend to cause skipjack tuna, which dominate the catch in Kiribati waters, to move from the western Pacific warm pool into the central Pacific, and particularly into the Phoenix Islands region (Hanich et al., 2018; Lehodey et al., 1997). The year of highest contribution of fishing licenses to GDP, 2015, was an El Niño year, and Kiribati reported fishing license revenue of USD 148.8 million (Ministry of Finance and Economic Development and Ministry of Fisheries and Marine Resource Development, 2016).

Despite heavy reliance on tuna license revenues, approximately half of the Kiribati EEZ in the vicinity of the Phoenix Islands archipelago-and $11.3 \%$ of their total EEZ - is currently a no-take marine protected area (MPA) with UNESCO World Heritage Designation. The Phoenix Islands Protected Area (PIPA) is one of the largest marine protected areas in the world at $408,250 \mathrm{~km}^{2}$. Created in 2008 as a mixed-use MPA, and closed entirely to all commercial fishing activities in January 2015, PIPA comprises 8 atolls, 2 shallow submerged coral reefs, at least 14 seamounts, and a large area of deep ocean (Rotjan et al., 2014; Witkin et al., 2016). This MPA was established to protect the many endangered and endemic species that live within its boundaries, as well as to protect the migratory birds, mammals, and sea turtles that pass through the area. Populations of previously exploited species, such as giant clam and coconut crab, have been recovering since the establishment of the MPA (Rotjan et al., 2014).

In addition to biodiversity goals, the PIPA Management Plan lays out the hope that, if well-enforced, PIPA may protect tuna breeding stocks and potential spawning grounds. Although enforcing a no-take policy in an area the size of PIPA can be difficult, Automatic Identification System (AIS) data from ships indicates that 
virtually all fishing activity did indeed stop after January 1, 2015 (Mccauley et al., 2016; Witkin et al., 2016). Furthermore, detected fishing days in (non-PIPA) Kiribati waters from AIS data actually increased from 2014 to 2015, indicating that fishing vessels moved out of PIPA but continued to fully subscribe fishing permit days for use in other parts of the Kiribati EEZ (Hanich et al., 2018; Witkin et al., 2016). With effective enforcement inside PIPA, but heavy fishing pressure outside (Mccauley et al., 2016), there may be value in protecting tuna spawning grounds, and potential for regional economic gain via "spillover effects" that may materialize once the closure has been in place long enough. Spillover effects occur when time- and/or area-closures result in increased biomass around MPA margins, which then moves outside the protected area where it can benefit fisheries, and these effects have been detected across a number of taxonomic groups and a range of MPA sizes (Di Lorenzo et al., 2016; Halpern et al., 2009; Thompson et al., 2017). For tunas in PIPA, it was assumed that fisheries protection of a large area where spawning occurs could have recruitment and biomass benefits in surrounding Kiribati waters, but tuna spawning activity within PIPA has not yet been confirmed.

Tropical tuna species that are likely to use the waters in PIPA for foraging and spawning include skipjack (Katsuwonus pelamis), yellowfin (Thunnus albacares), and bigeye (Thunnus obesus). Skipjack tuna are most abundant within $20^{\circ}$ of the equator, but are found as far north as $40^{\circ} \mathrm{N}$ (Arrizabalaga et al., 2015). Yellowfin tuna are concentrated in equatorial waters and prefer temperatures above $25^{\circ} \mathrm{C}$ (Arrizabalaga et al., 2015). Bigeye tuna, the largest and most valuable of the tropical tunas, have a range that extends from $40^{\circ} \mathrm{S}$ to $40^{\circ} \mathrm{N}$ (Arrizabalaga et al., 2015). Albacore tuna (Thunnus alalunga) may also pass through the region, but because of its subtropical to temperate habitat preferences, this species accounts for $<1 \%$ of the tuna catch in Kiribati (Ministry of Finance and Economic Development and Ministry of Fisheries 
and Marine Resource Development, 2016). Likewise, albacore larvae tend to be absent from equatorial waters and are more common at $20^{\circ} \mathrm{N} / \mathrm{S}$ (Nishikawa et al., 1985; Ueyanagi, 1969).

Skipjack, yellowfin, and bigeye tuna are all fast-growing and early-maturing species, maturing at 1-3 years old (Itano, 2000; Koido and Suzuki, 1989; Margulies et al., 2007; Reglero et al., 2014; Schaefer et al., 2005; Schaefer, 1998; Zhu et al., 2010). In all three species, individuals are likely to spawn every 1-3 days over a period of weeks to months and, at the population level, spawning occurs throughout the year in the tropical Pacific (Itano, 2000; Koido and Suzuki, 1989; Matsumoto, 1958; Schaefer et al., 2005; Schaefer, 1998; Strasburg, 1960; Zhu et al., 2010). For all three species, spawning and/or larval occurrence is generally observed at sea surface temperatures (SSTs) above $24^{\circ} \mathrm{C}$ (Margulies et al., 2007; Reglero et al., 2014; Schaefer et al., 2005; Schaefer, 1998).

Yellowfin and skipjack tuna larvae were found from $15^{\circ} \mathrm{S}$ to $23^{\circ} \mathrm{N}$ and across the full longitudinal range of sampling by NOAA expeditions in 1950-1952, from $110^{\circ} \mathrm{W}$ to $180^{\circ} \mathrm{W}$ (Matsumoto, 1958; Strasburg, 1960). The only other broad-scale sampling effort for larval tunas in the Pacific Ocean was carried out by the Japanese from 1956-1981. In these collections, the larvae of skipjack, yellowfin, and bigeye tunas were broadly distributed in the western and central Pacific from approximately $20^{\circ} \mathrm{S}$ to $30{ }^{\circ} \mathrm{N}$ (Nishikawa et al., 1985; Ueyanagi, 1969). There have been a number of other larval studies of tropical Pacific tunas, but they focused on distributions in the vicinity of islands and atolls and include limited sampling effort in deep pelagic zones (Boehlert and Mundy, 1994; Boehlert et al., 1992; Leis et al., 1991). Larvae of many tuna species are known to concentrate in the upper $50 \mathrm{~m}$ of the water column (Habtes et al., 2014; Llopiz et al., 2010; Matsumoto, 1958; Ueyanagi, 1969).

In this study, we combined empirical data on larval tuna abundance and growth, 
collected on annual cruises to PIPA in July/August in 2015-2017 (Figure 3-1), with individual-based model simulations to estimate spawning locations and relative spawning output. We estimated, for the first time, abundance of tuna larvae in PIPA waters and determined which species of tuna are spawning within and around PIPA, confirmed with genetic barcoding for species within the genus Thunnus. Our data set includes the $2015 \mathrm{El}$ Niño event that, along with global elevated temperatures, led to widespread coral bleaching across the tropical Pacific (Brainard et al., 2018). In the summers of 2016 and 2017, we determined conditions to be ENSO neutral. Because Thunnus spp. tunas show preferences for spawning in highly oligotrophic waters (Llopiz and Hobday, 2015), we expected to find higher larval abundances under the low chlorophyll El Niño conditions in 2015 than in the more productive conditions in 2016 and 2017.

\subsection{Results}

\subsubsection{Oceanographic conditions}

The surface mixed layer in PIPA extended to approximately $100 \mathrm{~m}$ with temperatures above $25^{\circ} \mathrm{C}$, below which there was a gradual thermocline to temperatures below $12^{\circ} \mathrm{C}$ at $300 \mathrm{~m}$ (Figure 3-8). In 2015 (El Niño year), the surface waters in PIPA were warmer than in 2016 and 2017 at the northern boundary by about $1-2^{\circ} \mathrm{C}$, while at the southern boundary, temperatures were quite similar in 2015 and 2016 (Figure 3-2AB). In 2017, surface temperatures were fairly uniform across the protected area, and slightly cooler than in 2016 (Figure 3-2C). From 2015 to 2016, there was a marked difference in sea surface chlorophyll concentrations in PIPA, both in terms of the typical value and a reversal in the latitudinal gradient. Surface chlorophyll plots for 


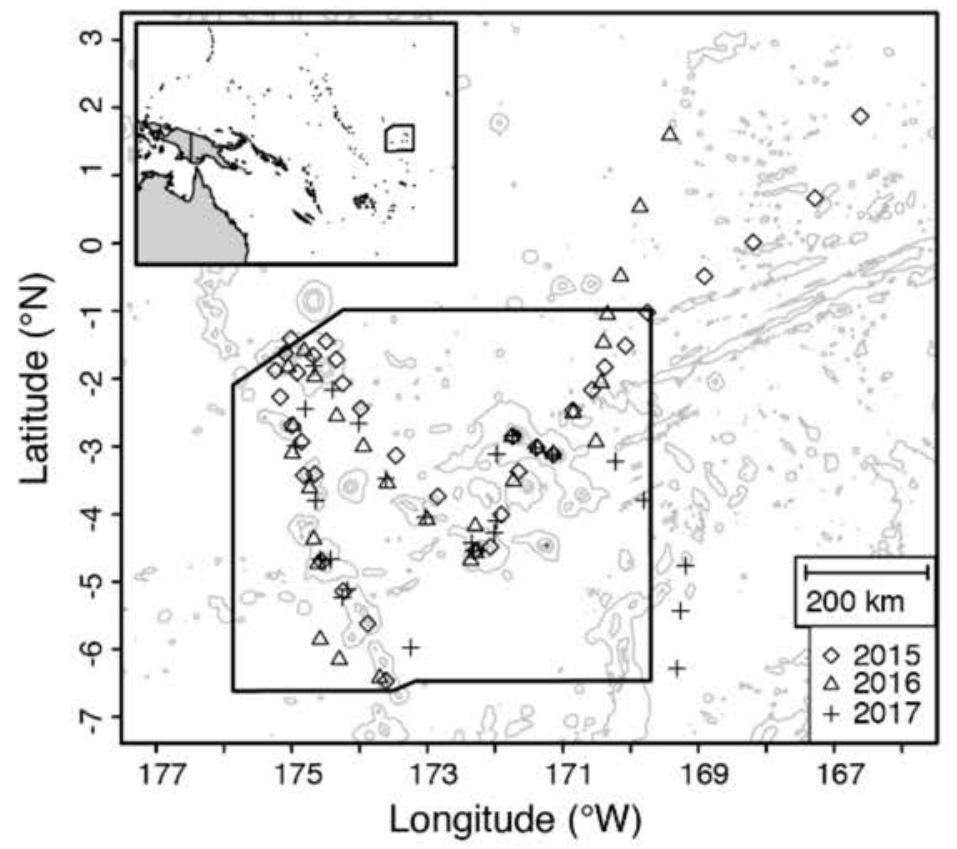

Figure 3-1: Map of sampling locations. For the cruises in 2015, 2016, and 2017, locations of all samples included in these analyses are shown. Bathymetric contours are shown at 1000, 3000, and $5000 \mathrm{~m}$ depth (accessed through GEBCO). The inset map shows the location in reference to Australia and the island of New Guinea. In both the main plot and the inset, the solid black line shows the boundaries of PIPA.

2015-2017 clearly demonstrate the broad extent of low relative productivity in 2015 (Figure 3-2D-F). In 2015, chlorophyll values were below $0.15 \mu \mathrm{g} / 1$ throughout all of PIPA, and the higher values (between 0.1 and $0.15 \mu \mathrm{g} / \mathrm{l}$ ) were found only around Kanton atoll and in the southern half of PIPA (Figure 3-2D). In 2016, chlorophyll values were above $0.1 \mu \mathrm{g} / \mathrm{l}$ throughout nearly all of PIPA, with the exception of the southwest corner; the highest values of over $0.2 \mu \mathrm{g} / \mathrm{l}$ were near the northern boundary and values decreased with distance from the equator (Figure 3-2E). The pattern of surface chlorophyll in 2017 resembled that in 2016 (Figure 3-2F).

Compared with July SST from 2003-2018, the July SST in PIPA in 2015 was the 

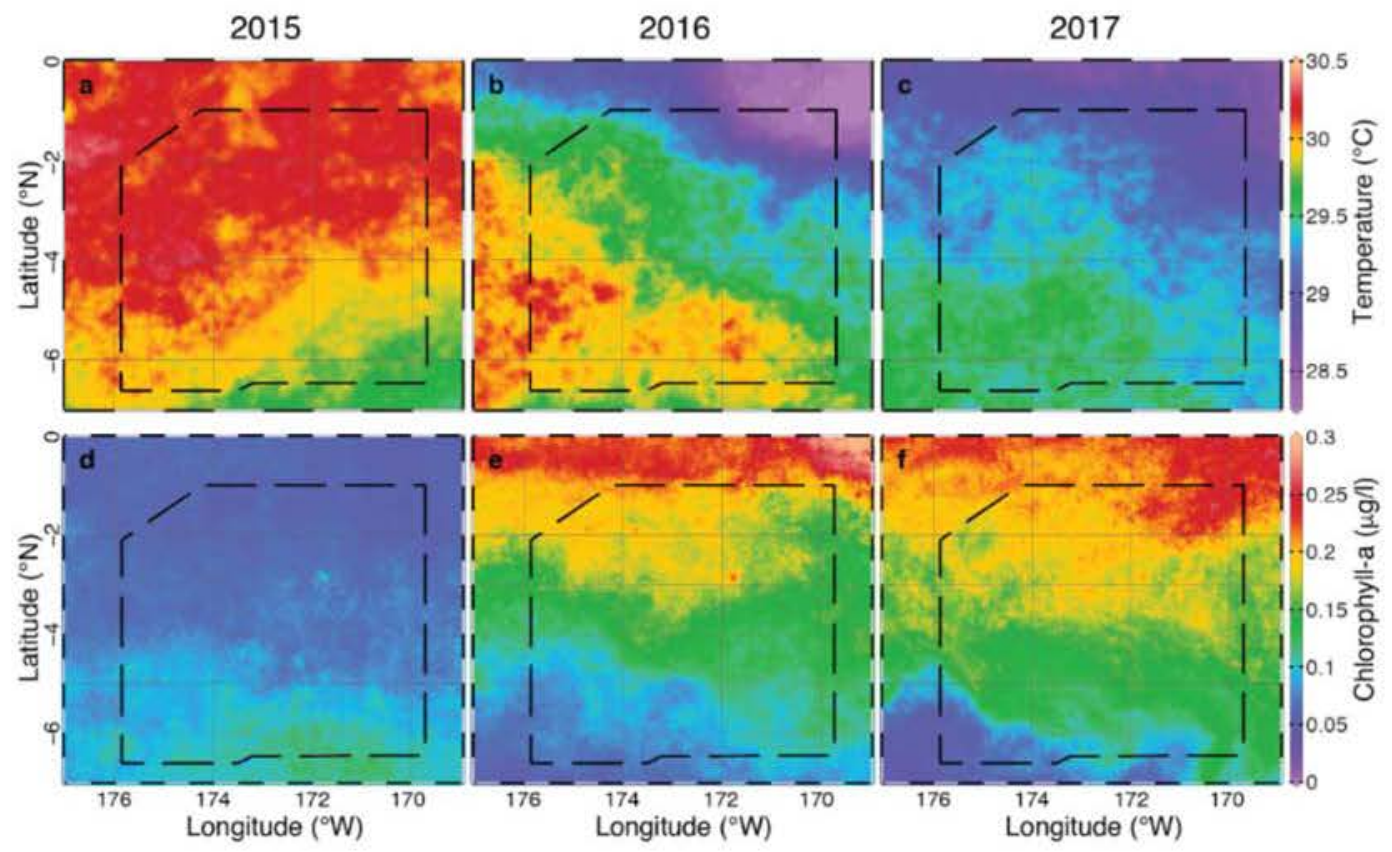

Figure 3-2: Environmental conditions across the three years of sampling. Panels show satellite-derived sea surface temperature (A-C) and chlorophyll (D-F) for 2015 $(A, D), 2016(B, E)$, and 2017 (C,F). The dashed lines show the boundaries of PIPA. Sea surface temperature data $\left({ }^{\circ} \mathrm{C}\right)$ comes from the MURSST dataset, and chlorophyll data $\left(\mu \mathrm{g} \mathrm{l}^{-1}\right)$ comes from the Visible and Infrared Imager/Radiometer Suite (VIIRS) satellite (both datasets through NASA).

hottest, with an anomaly of nearly $1^{\circ} \mathrm{C}$ from the 2003-2018 mean. The July SST in 2016 and 2017 were also slightly warmer than the 2003-2018 average climatology, with anomalies of 0.55 and $0.28^{\circ} \mathrm{C}$, respectively (Figure 3-3). The July SST from PIPA generally tracks the Niño3.4 index and the Multivariate ENSO index (MEI) ( $r=0.68$ and 0.66 , respectively), although those indices both indicated cool conditions in July of 2016 and 2017, while the PIPA temperatures showed weak positive anomalies. In years with strong signals in the MEI (2010 and 2015), the chlorophyll-a concentration in PIPA moved out of phase with SST. Compared with the rest of the 15-year time series, the July chlorophyll-a concentration in PIPA had its lowest value in 2015 and 
its highest value in 2017 (Figure 3-3).

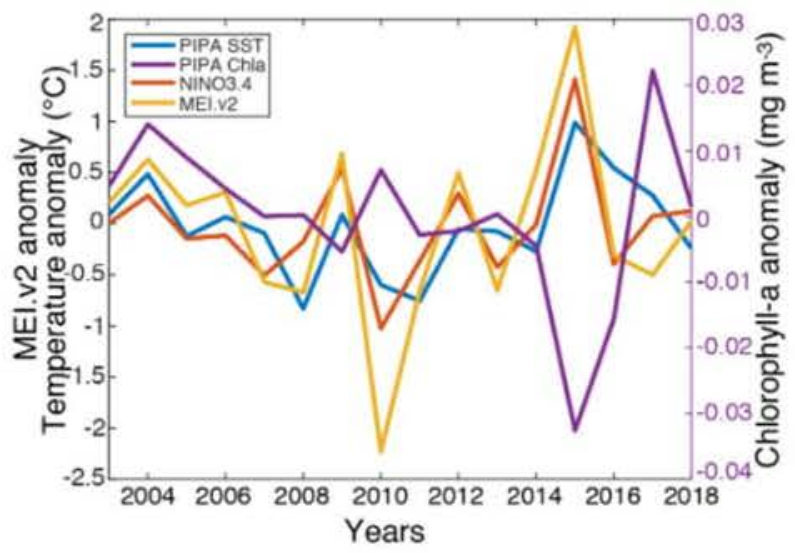

Figure 3-3: Environmental conditions in PIPA for 2003-2018. July SST anomaly in PIPA $\left({ }^{\circ} \mathrm{C}\right)$ are calculated from daily MUR SST data. July chlorophyll-a concentration anomaly in PIPA ( $\mathrm{mg} \mathrm{m}^{-3}$ ) are calculated from daily MODIS Level 3 data. Also plotted are the July Nino3.4 anomaly and the July Multivariate ENSO Index (MEI) anomaly.

\subsubsection{Larval tuna abundance and distribution}

Skipjack and Thunnus spp. larvae were caught in all 3 years, for a total of 64 non-zero stations (Table S1) and 42 stations with zero catch. In 2015, 163 skipjack larvae were caught in the study area; 59 of those inside PIPA, and a large catch of 101 skipjack larvae occurred outside of the northeastern corner of PIPA. The abundance of skipjack larvae at non-zero stations in 2015 ranged from 0.004 to 42.5 larvae per $10 \mathrm{~m}^{2}$ (Figure 3-4A). In 2016, 291 skipjack larvae were caught in the study area, all inside the PIPA boundaries, and a large catch of 184 skipjack larvae occurred in the northeast quadrant of PIPA. The abundance of skipjack larvae at non-zero stations in 2016 ranged from 0.22 to 40.75 larvae per $10 \mathrm{~m}^{2}$ (Figure 3-4B). In 2017, 82 skipjack larvae were caught; 72 of those were caught inside of PIPA. There was 
no single station with a markedly high catch, but there were no samples from 2017 in the farther northeast region where high catches were observed in 2015 and 2016 (Figure 3-4). The abundance of skipjack larvae at non-zero stations in 2017 ranged from 0.004 to 7.12 larvae per $10 \mathrm{~m}^{2}$ (Figure $3-4 \mathrm{C}$ ).

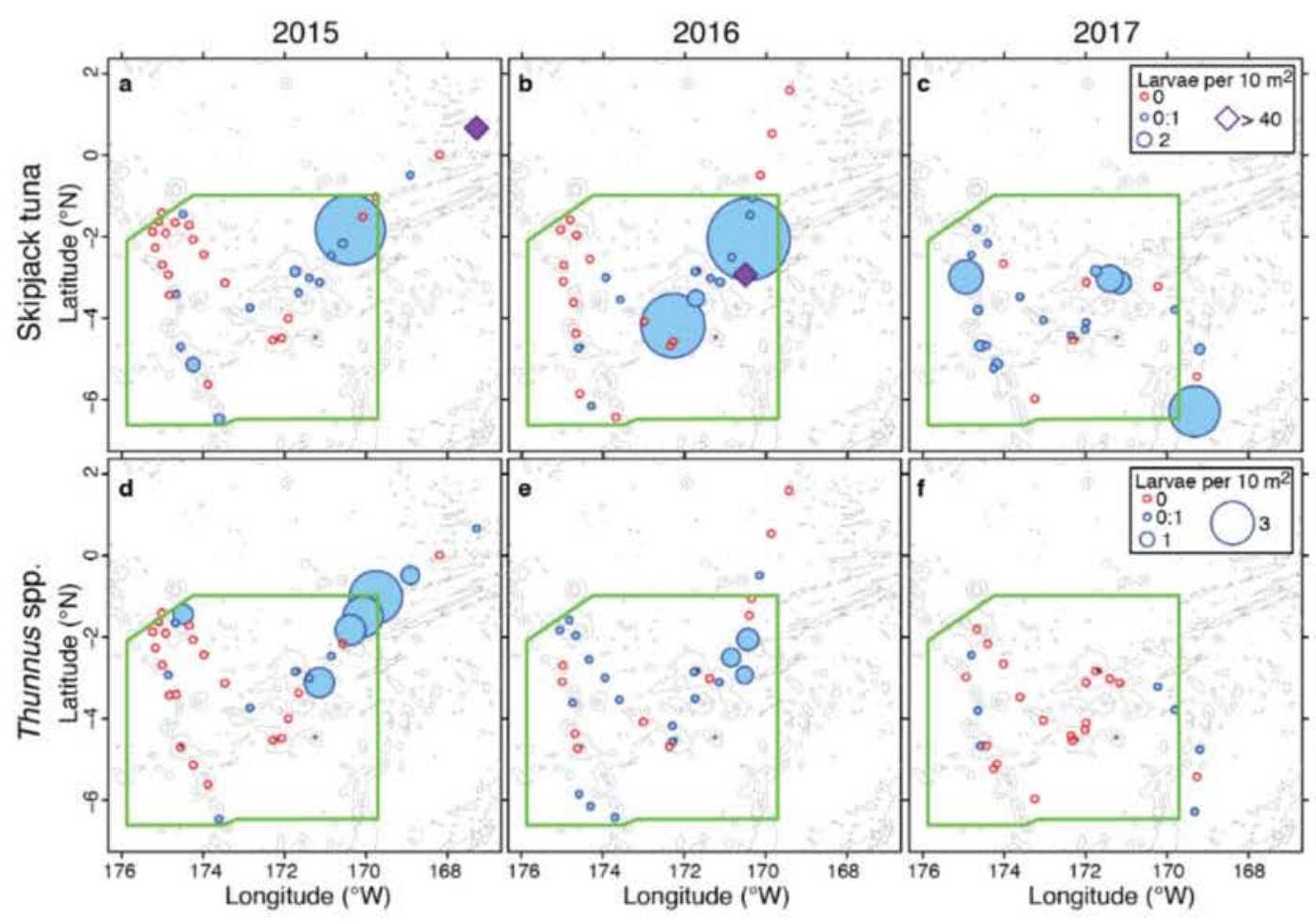

Figure 3-4: Larval tuna distribution maps. Subpanels depict abundance for Katsuwonus pelamis (panels A-C) and Thunnus spp. (panels D-F). Panels A and D show the larval distribution in 2015, panels $B$ and $E$ for 2016, and panels $C$ and $F$ for 2017 . Red circles indicate locations that plankton sampling occurred but no larvae of that taxon were collected. The size of blue circles is scaled to the abundance of larvae at that station, and purple diamonds in panels A and B correspond to an anomalously high station abundance ( 42.5 and 40 larvae per 10 sq. $\mathrm{m}$ in A and B, respectively). The boundaries of PIPA are shown in green. Bathymetric contours at 1000, 3000, and $5000 \mathrm{~km}$ depth are shown in light grey (accessed through GEBCO).

In 2015, 39 Thunnus spp. larvae were collected in the study area and 34 of these 
were collected inside of PIPA. The abundance of Thunnus spp. larvae at non-zero stations in 2015 ranged from 0.009 to 3.7 larvae per $10 \mathrm{~m}^{2}$ (Figure 3-4D). In 2016, 35 Thunnus spp. larvae were collected in the study area and 34 of these were caught inside PIPA; the abundances at non-zero stations ranged from 0.25 to 1.5 larvae per $10 \mathrm{~m}^{2}$ (Figure 3-4E). In 2017, 8 Thunnus spp. larvae were caught in the study area, and 6 of these were caught inside PIPA; the abundances at non-zero stations ranged from 0.005 to 0.89 larvae per $10 \mathrm{~m}^{2}$ (Figure $3-4 \mathrm{~F}$ ).

Overall, the abundance of skipjack tuna larvae was higher but more variable than the abundance of Thunnus spp. larvae (Figure 3-4). Abundances of skipjack larvae were higher in 2016 than 2015, while for Thunnus spp., larval abundances in 2015 and 2016 were similar. Abundances of both taxa were lower in 2017 than in the previous two years.

\subsubsection{DNA barcoding}

Due to morphological characters being unreliable for distinguishing yellowfin (Thunnus albacares) and bigeye (Thunnus obesus) tuna larvae (Nishikawa and Rimmer, 1987), DNA barcoding was used on a subsample of larvae for species identification. These analyses positively identified both bigeye and yellowfin larvae within PIPA. In 2015 , six were identified as bigeye tuna and 18 as yellowfin tuna. In 2016, nine were bigeye tuna and no other Thunnus species were identified. In 2017, one matched with bigeye tuna and two with yellowfin tuna. All seven of the barcoded Thunnus eggs

were from bigeye tuna (five from 2015 and two from 2016). Upon examination of a subset of the genetically identified larvae, we confirmed that morphological features were not useful for distinguishing bigeye from yellowfin larvae (details in SI). 


\subsubsection{Spawning sites and relative output}

Particle backtracking was performed using a coupled biological-physical dispersal model to estimate the spawning locations and relative output that contributed to our observed larval collections. We calculated relative spawning output by scaling the probability distribution of spawning locations for each larva by its age, using a temperature-based mortality rate, and then combining these scaled distributions by taxon and year.

In 2015, velocities of modeled currents were generally low with a weak anticyclonic retention feature present inside PIPA, centered around Kanton atoll (Figure 3-5A,3-5D). The larvae collected in 2015 inside PIPA generally originated from spawning that occurred inside of PIPA, while those collected outside the boundaries generally originated outside. The exceptions to this were the stations nearest to the protected area boundaries, including the southernmost station inside PIPA, the two stations near the northwest corner, and the station at the northeast corner. In 2016, modeled currents were stronger and there was more movement of eggs and larvae across the PIPA boundaries (Figure 3-5B, 3-5E). In the mean state of the currents over the sampling period, an anti-cyclonic circulation feature was present to the north of PIPA, with westward currents cutting through the protected area near the middle of its latitudinal range. As a result, inferred spawning activity was more spread out along the prevailing currents. In 2017, the modeled currents were intermediate in strength; there was an anti-cyclonic retentive feature in the northeast quadrant and westward currents at the middle latitude of the protected area (Figure 3-5C, 3-5F). The larvae collected in the western half of PIPA were likely from spawning inside the boundaries, while those collected in the eastern half likely originated near the eastern boundary. The larvae collected outside the eastern boundary of PIPA were 
likely from spawning outside of PIPA.

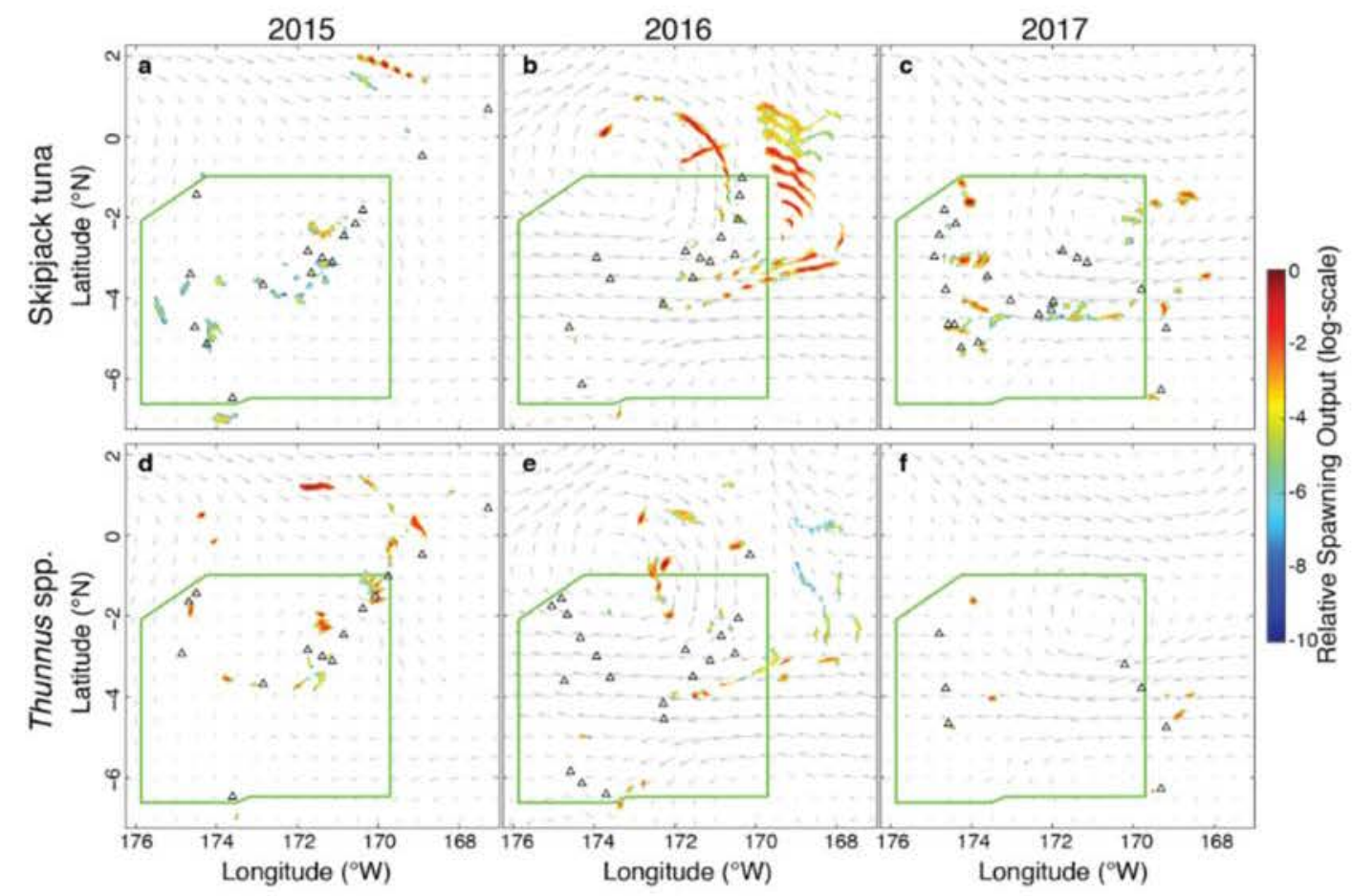

Figure 3-5: Relative spawning output map. Relative spawning output, from backtracking simulations, is shown for Katsuwonus pelamis (panels A-C) and Thunnus spp. (panels D-F). Panels A and D show the relative spawning output in 2015, panels $\mathrm{B}$ and $\mathrm{E}$ for 2016, and panels $\mathrm{C}$ and $\mathrm{F}$ for 2017. The log-scale colorbar corresponds to filled color contours of relative spawning output, which was calculated on $0.05^{\circ}$ by $0.05^{\circ}$ latitude/longitude grid and normalized such that the largest value in each panel is 1. Black triangles indicate the release locations for backtracking simulations, which are the same as the collection locations in Figure 3-4. The boundaries of PIPA are shown in green. Current vectors represent the mean HyCOM velocities in the upper $25 \mathrm{~m}$ of the water column for the sampling period of each year. 


\subsection{Discussion}

By combining three years of empirical data on larval tuna in PIPA with a biophysical modeling approach to backtrack larvae to infer spawning locations, we have conclusively demonstrated that spawning occurs inside PIPA for skipjack, bigeye, and yellowfin tunas. Moreover, the finding held during both El Niño and neutral conditions. The overall pattern of larval distribution and abundance was similar across years, and backtracking simulations suggest that spawning locations near PIPA are also similar across years. Larval studies such as this are valuable because they reveal both adult presence and spawning activity without removing adults or interrupting spawning behavior. Therefore, this study can help us understand the role that PIPA plays in tuna conservation, while adhering to the no-take policy of the protected area management plan.

The larval tuna abundances that we recorded in PIPA, at non-zero catch stations, range from 0.004 to 42.5 larvae per $10 \mathrm{~m}^{2}$, or approximately 0.008 to 85 larvae per $1000 \mathrm{~m}^{3}$ (assuming that larval habitat is the upper $50 \mathrm{~m}$ ). Past work on larval tuna distributions in the Pacific is limited, but the abundances presented here are within the range of previous studies. For example, the 1950-1952 surveys by NOAA in the pelagic tropical Pacific found 1-16 yellowfin tuna larvae per $1000 \mathrm{~m}^{3}$ and 0.5-25 skipjack tuna larvae per $1000 \mathrm{~m}^{3}$ (Matsumoto, 1958; Strasburg, 1960). The other example of broad-scale larval surveys in the tropical Pacific, undertaken by the Japanese from 1956-1981, observed larval yellowfin at densities of less than 1 per $1000 \mathrm{~m}^{3}$ and skipjack tuna larvae at densities of $0.1-5$ per $1000 \mathrm{~m}^{3}$ (Nishikawa et al., 1985; Ueyanagi, 1969). Sampling around Johnston atoll found Thunnus spp. larvae at 0.1-0.3 per $1000 \mathrm{~m}^{3}$, and skipjack larvae at 0.3-1.7 per $1000 \mathrm{~m}^{3}$ (Boehlert et al., 1992). Sampling around the Hawaiian archipelago yielded 1-10 larvae per $10 \mathrm{~m}^{2}$ for 
Thunnus spp. and 0.1-1 skipjack larvae per $10 \mathrm{~m}^{2}$ (Boehlert and Mundy, 1994). One study, in the waters around French Polynesia, found very high concentrations of tuna larvae; they observed a maximum station abundance of 446 Thunnus spp. larvae per $1000 \mathrm{~m}^{3}$, and a median of approximately 20 per $1000 \mathrm{~m}^{3}$, and skipjack tuna larvae had a median of about 8 per $1000 \mathrm{~m}^{3}$ (Leis et al., 1991). Our results fit well into the established literature on larval studies in the tropical Pacific, suggesting that spawning in PIPA likely contributes to recruitment in central Pacific tuna stocks.

Although July of 2015 had the warmest and lowest chlorophyll-a conditions that were seen in the month of July between 2003 and 2018 (Figure 3-3), the overall pattern of abundance of tuna larvae did not change substantially between 2015 and the other sampling years (Figure 3-4). The largest inter-annual difference was the much lower range of abundances in 2017. However, this coincides with lower effort in 2017, particularly in the northeast quadrant of PIPA. If we compare only the locations where sampling occurred in all three years, then abundances reported for 2017 are quite similar to the other two years.

Although we observed consistency in the overall patterns of larval abundance across years, there were differences in the details of those patterns. We expected to find higher larval abundances under low chlorophyll El Niño conditions because of the preference of Thunnus spp. tunas for spawning in highly oligotrophic waters (Llopiz and Hobday, 2015). The observed abundance of Thunnus spp. larvae was indeed higher-but patchier-in 2015 than in 2016. In 2016, there were more positive stations but abundance was generally lower at each station (Figure 3-4D-E). In 2015, barcoding results suggest the presence of both yellowfin and bigeye tunas, but in 2016 only bigeye tuna were identified (Table S1). Unfortunately, species identification with DNA barcoding was not possible for $74 \%$ of the Thunnus spp. larvae collected in 2016, so the possibility remains that yellowfin occurred in 2016 as well. 
(The quantity of pure ethanol brought in 2016 was insufficient for preserving the high amounts of plankton that occurred. As such, DNA was often degraded in these samples, or denatured ethanol - a poor DNA preservative - was used instead.) $\mathrm{Al}$ though surface temperatures were cooler in 2016, the entire area of PIPA had surface temperatures above $28^{\circ} \mathrm{C}$ (Figure 3-2B), well within the preference range of yellowfin tuna (Arrizabalaga et al., 2015). If there were truly no yellowfin larvae in our 2016 collections, it could indicate that bigeye tuna distribution and spawning activity is less responsive to changes in the surface waters than these aspects of yellowfin tuna biology. This, in turn, could be explained by observations that bigeye tuna often occupy colder waters and greater depths (Arrizabalaga et al., 2015; Schaefer and Fuller, 2010), and forage on deeper-dwelling organisms than do yellowfin tuna (Duffy et al., 2017).

Another important component of interannual variability is the influence of currents on the pattern of relative spawning output. The backtracked reproductive output maps show little movement of eggs and larvae across the boundaries of PIPA during El Niño conditions (i.e. 2015), and greater movement during neutral conditions. For example, the areas of highest relative spawning output for skipjack tuna were outside PIPA to the north in both 2015 and 2016 (Figure 3-5A-B), but the observed large catch locations were outside PIPA in 2015 and inside in 2016. This is due to weaker currents accompanied by a northerly position of the mesoscale circulation feature in 2015 compared to stronger currents and a more southerly mesoscale feature in 2016. In both 2016 and 2017, there is a westward current flowing near the middle latitude of PIPA. This is in line with observations of the westward-flowing southern branch of the South Equatorial Current, which is centered around $3^{\circ} \mathrm{S}$ and weakens during El Niño events (Johnson et al., 2002).

We used larval catch, ages, and estimated mortality rates to take a novel ap- 
proach to larval backtracking. In addition to showing that many of the tuna larvae originated from spawning activity in PIPA, we also shed light on spatial variability in spawning output. However, it is important to note that these results are based only on the observed collections and, as such, the backtracking results should be thought of as presence-only - spawning may have occurred in more of the domain, with larvae transported to locations where we did not sample. Furthermore, the results of individual-based modeling are quite sensitive to the choice of hydrodynamic model. We used HyCOM, a data-assimilative hindcasting model that generally replicates large-scale patterns in the ocean, and we find that it matches CTD data from PIPA reasonably well (Figure 3-7). However, further work on hydrodynamic models for the tropical Pacific would improve the reliability of larval dispersal, connectivity, and backtracking simulations that are often used in MPA design and assessments.

Studies of larval tuna abundance and its interannual variability can contribute substantially to our understanding of tuna spawning, stock productivity, and the role of large MPAs like PIPA in tuna conservation. While our results show that tuna are spawning inside of PIPA, the lack of other larval tuna studies in the tropical Pacific limits our ability to contextualize the role of PIPA in overall stock productivity. The only broad-scale larval tuna studies in the tropical Pacific ended between 40 (Nishikawa et al., 1985) and 70 years ago (Matsumoto, 1958; Strasburg, 1960). Still, given the remoteness of PIPA, as well as its size, this work represents a significant contribution to the scientific understanding of tuna spawning in open waters of the Pacific and to the use of protected areas by highly migratory species.

Recently, several studies have focused on the role of protected areas, including large-scale MPAs, in the conservation and management of highly migratory species. Around the long-standing Galápagos marine reserve, there is evidence of "spillover effects" in the yellowfin tuna purse seine fishery, indicating that the protected area is 
increasing recruitment locally — whether by protecting a fairly resident population or by attracting very large temporary aggregations of yellowfin (Boerder et al., 2017). In a different management context, temporary closures of the striped marlin long-line fishery in Baja California coincided with rapid increases in fish abundance, again with some uncertainty about whether the increase is driven by high recruitment of a local population or import of individuals from outside the closed area (Jensen et al., 2010). In a counter example, it was deemed unlikely that a proposed MPA at Ascension Island (tropical Atlantic) would lead to population benefits for the yellowfin tuna population; although individuals spent several months at a time foraging around the island, they were not found to be reproductively active (Richardson et al., 2018). In an example from a highly migratory species with a very different life cycle, tagging studies on green turtles in the Chagos Archipelago MPA indicate that turtles spend a very small proportion of time inside the MPA, using it for nesting but not for foraging (Hays et al., 2014; Naro-Maciel et al., 2018). In all of these examples, the value of the protected area comes from the combination of adult presence and reproductive activity.

We have demonstrated that there are reproductively active individuals within PIPA, but a critical piece of missing information that would allow for a better assessment of the protection afforded by PIPA would be the residence times of tuna within PIPA. Otolith chemistry, which is related to natal origin using geographicallybased water properties, suggests that both yellowfin and bigeye tuna populations in the tropical Pacific are structured on large regional scales (Rooker et al., 2016). Likewise, tagging data suggest stock structure and regional retention on large spatial scales for bigeye tuna (Schaefer et al., 2015) and that yellowfin tuna will remain in an area similar in size to PIPA for periods of weeks to months (Richardson et al., 2018; Schaefer et al., 2011). A global synthesis of dart tag data indicated that all 
three tropical tuna species are capable of both rapid large-scale movements and regional fidelity or periodic returns to feeding and spawning locations (Fonteneau and Hallier, 2015). This evidence suggests that, if foraging conditions in PIPA are attractive, tuna could spend enough time there to benefit from the protection in order to spawn numerous times before becoming vulnerable to fishing again. A tagging study specifically focused on tuna movements in the vicinity of PIPA would further elucidate the scale of PIPA's impact on tuna population productivity.

In addition to short-term contributions to sustainable management, PIPA may be important for the conservation of tuna populations affected by climate change. Several papers have predicted that climate change will have neutral effects or benefits for tuna fisheries in island nations in the central Pacific Ocean (Bell et al., 2013; Dueri et al., 2014). Climate projections indicate that tuna abundances in PIPA, and in Kiribati in general, will increase because warming in the western Pacific warm pool will drive the population distribution of skipjack tuna towards the east (Ganachaud et al., 2013; Lehodey et al., 2013). Likewise for bigeye tuna, climate change projection models predict that adult abundances will increase in the eastern Pacific and will decrease in the western and central Pacific (Lehodey et al., 2010). Part of the reasoning is that climate projections indicate that spawning habitat for skipjack tunas in the western Pacific will decrease substantially (Lehodey et al., 2013; Venegas et al., 2018). Thus, under certain climate scenarios, PIPA may have a disproportionate opportunity to bolster reproductive stocks if surface water temperatures cause adults to spend more time within the MPA boundaries.

The Phoenix Islands Protected Area is unique as a large, continuous MPA that encloses almost an entire archipelago and encompasses both shallow reef environments and deep pelagic waters. Larval studies, including the analysis of distribution, abundance, growth, and backtracking simulations as in in this study, contribute to 
overall understanding of the species and/or the stock because events in early life can have an outsized impact on stock recruitment and productivity. However, linking a study of the distribution of tuna larvae in PIPA with the population dynamics of skipjack, yellowfin, and bigeye tunas in the central Tropical Pacific is difficult, and should be approached cautiously. The great power of the standard ichthyoplankton sampling scheme presented here is that it provides the baseline for a growing time series that, as annual sampling continues through at least 2022, will enable monitoring of tuna spawning inside PIPA. This time series may reveal interannual changes in the spawning output or shifts in its spatial distribution, providing insight into how tuna spawning in and around PIPA is likely to change under climate change conditions. Furthermore, the protection of large areas like PIPA, where the only anthropogenic effects are from global-scale climate change, potentially enables us to disentangle climate-related impacts from the other multiple stressors that most ecosystems face. In addition to being a reservoir for biodiversity and biomass, mega-MPAs like PIPA are large-scale living laboratories that can help scientists better understand ocean ecosystems.

\subsection{Methods}

\subsubsection{Field sampling}

Sampling took place aboard the SSV Robert C. Seamans following similar cruise tracks and dates in 2015 (July 18 to August 7), 2016 (July 15 to August 6), and 2017 (July 17 to August 4) (Figure 3-1). A few stations were sampled on transits from Honolulu, HI to PIPA (2015 and 2016) and between Pago Pago, American Samoa and PIPA (2017). Of the stations outside PIPA, only those reasonably close 
to the PIPA boundaries are included here, i.e. all stations between $7^{\circ} \mathrm{S}$ and $2^{\circ} \mathrm{N}$ (Table S1). Sampling beyond this latitudinal range is excluded from this study, including 7 stations in 2015 that yielded a total of 1 skipjack tuna larva; 8 stations in 2016 that yielded a total of 9 skipjack larvae (from 4 stations) and 2 Thunnus spp. larvae (from 1 station); and 9 stations in 2017 that together yielded 1 Thunnus sp. larva.

Station work occurred at approximately local noon and midnight each day. At each station, the hydrographic rosette, equipped with conductivity, temperature, and depth (CTD) sensors, was deployed to $600 \mathrm{~m}$ depth or $10 \mathrm{~m}$ off the bottom. To sample ichthyoplankton, up to 3 different types of plankton net tows were performed, with all 3 used at the majority of stations (Table 3.1). Net tows were performed for approximately 30 minutes at a speed of 2 knots. First, a $1-\mathrm{m}^{2}$ rectangular opening Tucker trawl with a single net of $333 \mu \mathrm{m}$ mesh was towed obliquely to the typical depth of the thermocline (approximately $100 \mathrm{~m}$ ). Second, the same Tucker trawl was re-deployed for a shallower, double-oblique tow to approximately $50 \mathrm{~m}$, intended to sample larval tuna habitat more intensively. Third, a $0.5 \times 1 \mathrm{~m}$ rectangular neuston net was deployed off the side, sampling the upper $0.25 \mathrm{~m}$.

The Tucker Trawl nets were equipped with an internally recording depth sensor and a General Oceanics flow meter, giving tow depth and volume filtered. Neuston tow flow was estimated using vessel speed, net area, and tow duration. Samples were fixed in $95 \%$ ethanol.

In addition to our in-situ environmental data, we mapped the average July surface temperature from the Multi-scale Ultra-high Resolution (MUR) SST data set (JPL MUR SST 2019) and sea surface chlorophyll data from the Visible and Infrared Imager/Radiometer Suite (VIIRS) satellite (NASA Goddard Space Flight Center et al., 2014b). To compare environmental conditions within PIPA beyond our sam- 
pling years, we used the MUR SST dataset (JPL MUR SST 2019) and the MODIS chlorophyll-a dataset (NASA Goddard Space Flight Center et al., 2014a). Using daily data for July in 2003-2018, we calculated the mean values in PIPA (latitude $6.6^{\circ} \mathrm{S}$ to $0.98^{\circ} \mathrm{S}$ and longitude $175.8^{\circ} \mathrm{W}$ to $169.7^{\circ} \mathrm{W}$ ). These two time series are compared with the Niño3.4 index (Niño 3.4 SST Index 2019) and the Multivariate ENSO index (Multivariate ENSO Index Version 2 (MEI.v2) 2019). All four time series are represented as anomalies by subtracting the $2003-2018$ average value.

\subsubsection{Lab processing}

Fish larvae and fish eggs were separated from the bulk plankton samples under a light microscope. Using morphological characters, tuna larvae were identified as skipjack tuna (Katsuwonus pelamis) or Thunnus sp. (Nishikawa and Rimmer, 1987; Richards, 2005). Fish larvae and eggs were stored in $95 \%$ ethanol.

Abundance of larval tuna for each net tow $\left(a_{n e t}, \mathrm{n}\right.$ larvae per $\left.\mathrm{m}^{2}\right)$ was calculated by multiplying the density ( $\mathrm{n}$ larvae per $\mathrm{m}^{3}$ ) in each net tow by the vertical distance it sampled. The standardization by vertical distance is required to combine multiple net observations, which each sampled different depths, into a single value of abundance per station. Then, the station abundance was calculated by taking the mean $a_{\text {net }}$ of the two Tucker trawl tows and adding the neuston $a_{\text {net }}$.

The two expected species of Thunnus larvae in our samples were bigeye tuna (Thunnus obesus) and yellowfin tuna (T. albacares) (Ueyanagi, 1969). These two species have limited morphological characters that can differentiate them, and larvae under $5 \mathrm{~mm}$ are not well described. As such, species identification was confirmed genetically on a subset of Thunnus larvae by the Canadian Center for DNA Barcoding. Additionally, a subset of eggs that were visually identified as possible scombrid eggs 
were barcoded to empirically confirm spawning within PIPA. Barcoding sequences were obtained for 36 Thunnus larvae and 7 Thunnus eggs. Most of these could be classified using the Barcode of Life Database's (www.bold.org) 'Species DB' search function, but manual inspection and classification of sequences was required for 11 of the 36 barcoded larvae (further details in SI).

Photographs were taken of each larva using a Leica M205C stereomicroscope with a Canon EOS 60D camera attached. Fish standard lengths were measured using ImageJ with the ObjectJ plug-in (https://imagej.nih.gov;

https://sils.fnwi.uva.nl/bcb/objectj). Some fish larvae were damaged and could not be measured; however 191, 256, and 80 larvae (93, 75, and 85 percent of collection) were successfully measured from 2015,2016 , and 2017 , respectively. Length of damaged larvae was estimated using the mean length for that taxon in that sample. If the sample contained fewer than 3 measurable larvae of that taxon, then the mean length from all nets at the collection station was used, weighted by the number of larvae in each net ( 5 occasions); if this still contained fewer than 3 larvae of that taxon, then the two nearest stations were combined with the collection station to calculate the weighted mean length (17 occasions).

Length-at-age relationships were constructed using otolith-derived ages from skipjack and Thunnus spp. larvae from 2015 and 2016 collections. Otoliths were extracted and read from 118 tuna larvae total: 36 and 30 skipjack and 25 and 27 Thunnus spp. from 2015 and 2016, respectively. After quality control, otolith reads were retained for 32 and 29 skipjack larvae and 22 and 26 Thunnus spp. larvae from 2015 and 2016, respectively. Aged larvae ranged from 2.24 to $9.04 \mathrm{~mm}$ in length and from 1 to 12 daily otolith increments. More details on otolith methods are in the SI.

A least squares linear regression was fitted to the daily increment and length data for each year-taxon pair, as well as by taxon pooled across years (Figure 3-6). An 
ANOVA did not find a significant effect of year on larval length for skipjack tuna larvae $(\mathrm{p}=0.22)$, and there was a marginally significant effect for Thunnus spp. larvae $(p=0.06)$. We found that average growth rates over the first two weeks of life are 0.45 and $0.37 \mathrm{~mm}$ per day for skipjack tuna larvae and Thunnus spp. larvae, respectively (Figure 3-6). The size-at-age relationships derived from otolith analyses were used to assign the number of daily growth increments for larvae that were not aged. To inform backtracking, we need to estimate ages in days post spawning. It takes 18-30 hours for tuna eggs to hatch at the observed temperatures (Margulies et al., 2007; Reglero et al., 2018b). Yellowfin and skipjack tuna larvae begin to lay down increments within 12-24 hours of hatching (Radtke, 1983; Wexler et al., 2001). Therefore, we add 2 days to convert the estimates of increment number into age of each larva in days post-spawning.

\subsubsection{Relative spawning output estimation}

For particle backtracking, we used the Connectivity Modeling System (CMS) (Paris et al., 2013) with velocities from the Hybrid Coordinate Ocean Model (HYCOM) Global hindcast experiments 91.1 and 91.2. The HYCOM data server provides daily currents at a horizontal grid resolution of $1 / 12^{\circ}$. For each station at which tuna larvae were caught, 1000 virtual particles were released at noon on the calendar day of sampling at the mean geographical position of all net tows for that station (Table 3.1). Virtual particles were released at $25 \mathrm{~m}$ depth, and passively drifted at fixed depths: $10 \mathrm{~m}$ depth for Thunnus spp. larvae and $25 \mathrm{~m}$ depth for skipjack larvae. These depths were selected because they represent the mid-point of observed vertical distributions for these taxa (Habtes et al., 2014; Llopiz et al., 2010; Reglero et al., 2018a). The particles were tracked backwards in time for 15 days from collection 
date, with a model time step of 20 minutes. The model includes stochastic kicks to simulate sub-grid scale diffusivity, and releasing 1000 particles ensures that the output will broadly sample that probability space.

Using the simulation output, we built a dataset corresponding to all collected tuna larvae. For each larva, age in days post spawning was estimated using the pooled size-at-age relationships. In order to account for variance in size-at-age, we drew the estimated ages from a normal distribution with mean equal to the regression line for age-at-size and variance equal to the standard deviation of all of the residuals of age-at-size. We use this age for each larva to extract the positions of the 1000 virtual particles (from the corresponding simulation release point) on the estimated day of spawning. We calculated the 2-D frequency distributions of the 1000 particle positions at the estimated time of spawning, on a $0.05^{\circ}$ latitude by $0.05^{\circ}$ longitude grid, and defined this as the spatial probability density of spawning location for that larva.

Instead of only backtracking larvae to estimate where they originated, we also sought to estimate the relative spawning output needed to yield the abundances and ages of larvae in our samples. To do this, it is necessary to scale the spatial probability density of spawning location by the number of eggs that would need to be spawned to lead to the observation of each larva, which depends on the age of the larva and the daily mortality rate. Instantaneous daily mortality rates $(Z)$ for fish larvae strongly depend on temperature, and a meta-analysis across a wide range of latitudes, species, and ecosystems found that $Z=0.0256+0.0123 T$, where $T$ is the temperature that larvae experience (Houde, 1989). We used the average temperature in the upper $50 \mathrm{~m}$ at each station to calculate the $Z$ for larvae collected at that station: for our data, $Z$ ranges from 0.357 to 0.399 day $^{-1}$. This yielded a realistic estimate of the number of eggs that must have been spawned in order to 
lead to the observed catch.

For each larva, we scale the spatial probability density plot by the estimated number of eggs spawned, to generate the distribution of relative spawning output for that particular larva. We then sum the relative spawning output distributions across all larvae in a given year and taxon to produce maps that show the relative spawning output for the full collections of tuna larvae. Larval catch numbers and the resulting estimates of relative spawning output for each station are presented in Table 3.1.

\subsection{Supplemental Information}

\subsubsection{Manual inspection of DNA barcoding sequences for species identification of Thunnus larvae}

Of the 36 DNA barcodes recovered for Thunnus spp. larvae, 11 were too short for confident identification in the Barcode of Life Database (bold.org). For 4 of these, manual inspection of the sequence data enabled positive species identification through the use of diagnostic genetic markers and comparison with reference sequences (Richardson et al., 2007). The other 7 reads were very short ( $\sim 230 \mathrm{bp})$ and did not include both of the two necessary markers to perform a definite species identification . Instead, these individuals were identified as members of the Neothunnus subgenus, which includes T. albacares, T. tonggol, and T. atlanticus (Chow et al., 2006). Although these reads lacked a diagnostic genetic marker to differentiate among species within the Neothunnus subgenus, based on the distribution of T. tonggol in the Indian Ocean and T. atlanticus in the Atlantic Ocean, we have concluded that those larvae are T. albacares. 


\subsubsection{Genetic barcoding insights for morphological identifica- tion}

After receiving DNA barcoding results for larvae from 2015 that were still intact (the eye had been sent for barcoding instead of tail tissue), the 16 larvae that were identified with barcoding were re-examined to see if morphological characters could be used to differentiate the two species. Bigeye tuna often have a distinct pair of pigment spots on the lower jaw and 1 or 2 pigment spots on the ventral edge about 7 or 8 myomeres anterior to the caudal fin base, while yellowfin tuna are expected to have a single pigment spot on the lower jaw and no ventral body pigment (Nishikawa and Rimmer, 1987). However, amongst the tuna larvae that were genetically identified as bigeye and yellowfin, these characters were not found to be reliable. Jaw pigments can be quite similar and are easily rendered indistinguishable by degradation, and many of the individuals identified as yellowfin tuna had small ventral or midline pigment spots. Larvae that were genetically identified as either species could have a single distinct pigment spot dorsal to the notochord tip.

\subsubsection{Length at age analyses}

Otoliths were extracted from individual larvae with dissecting pins; both sagittae and lapillae were extracted and placed flat side down on a glass microscope slide in Type B immersion oil. Otoliths were imaged with a Leica DM2500 compound microscope with an oil-immersion 100X objective lens; images were taken with a Leica MC120 HD Camera and the Leica Application Suite software. Images were calibrated using a stage micrometer. Otoliths were read in ImageJ using the ObjectJ plug-in. All extractions and reads were performed by the same reader. All otoliths for a given year were read once, the order of the images was shuffled, and they were read again. 
If the two reads yielded ages within $+/-1$ day, the second read was retained. If the two reads differed by more than 1 day, a third read was performed. If the third read agreed to within $+/-1$ day of either the first or second read, then the third read was retained. If the third read differed by more than 1 day from both the first and second reads, then that fish was not retained in age analyses. Otoliths were extracted and read from 118 tuna larvae total: 36 and 30 skipjack and 25 and 27 Thunnus spp. from 2015 and 2016, respectively. Otolith reads were retained for 32 and 30 skipjack larvae and 21 and 26 Thunnus spp. larvae from 2015 and 2016, respectively.

Linear least squares regression was used to construct a model of larval length at age for each taxon-year pair (e.g. skipjack tuna larvae collected in 2015) and for the pooled data for a taxon across years (e.g. all aged skipjack tuna larvae) (Figure 3-6). Because of the strong region-wide difference in temperature and productivity between 2015 and 2016, an ANOVA test was used to investigate the difference in the slopes of the year-wise linear regressions. This ANOVA test did not find a significant effect of year on larval length for skipjack tuna larvae ( $p>0.2)$, and there was a marginally significant effect for Thunnus spp. larvae $(p=0.06)$. We found that average growth rates over the first two weeks of life are 0.45 and $0.37 \mathrm{~mm}$ per day for skipjack tuna larvae and Thunnus spp. larvae, respectively (Figure 3-6).

\subsubsection{HyCOM validation}

Before using a model for particle tracking, it is important to analyze how well that model represents the hydrodynamics of the study region. The Hybrid Coordinate Ocean Model (HyCOM) is a standard global ocean hydrodynamic model, and its data-assimilation procedures ensure quite good representation of the dynamics in any region with adequate observational coverage. However, tropical oceans can be 


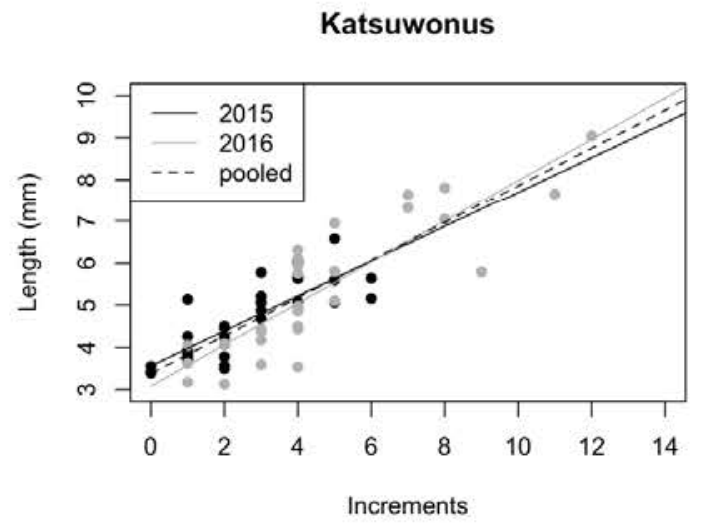

(a) Katsuwonus pelamis

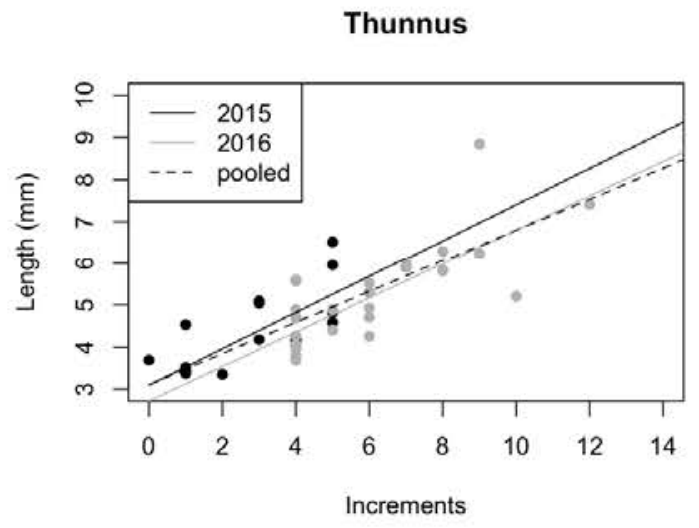

(b) Thunnus spp.

Figure 3-6: Larval growth curves for skipjack and Thunnus spp. larvae. Larval sizeat-age for skipjack (a) and Thunnus (b) larvae in the first 12 daily increments (i.e., days of life following the onset of exogenous feeding). Data from individuals collected in 2015 is plotted with dark black circles and data from individuals collected in 2016 is plotted with grey circles. Linear regression lines for each year of data are plotted in the color to match the circles, and a dashed line shows the regression relationship when data for both years are pooled. 
difficult to represent in global models because some of the physical assumptions that govern these models are weaker at low latitudes.

Temperature and salinity are often used for model validation instead of current velocities, because the temporal and spatial scales of a model like HyCOM is difficult to compare with data from a shipboard acoustic Doppler current profiler (ADCP). However, temperature and salinity will generally track large-scale differences in water masses and, therefore, are signals that are useful for validating HyCOM. The model runs that are used for larval backtracking simulations are HyCOM GLBu0.08 (global velocity at 0.08-degree resolution) experiments 91.1 (2015) and 91.2 (2016 and 2017).

For this study, temperature and salinity from CTD casts are compared with the nearest-neighbor HyCOM point in longitude-latitude space. CTD data were processed aboard the SSV Robert C. Seamans using SeaBird Electronics software. The 2015 and 2016 data were provided at a vertical resolution of less than $1 \mathrm{~m}$; the 2017 data were provided at a vertical resolution of $5 \mathrm{~m}$. For comparison with HyCOM, CTD data are binned to the same depth levels as HyCOM (when possible): $0,2,4,6,8,10,12,15,20,25,30,35,40,45,50,60$, and $70 \mathrm{~m}$ depth. HyCOM depths extend to $5000 \mathrm{~m}$, but the only dynamics pertinent to this study are in the upper ocean, where the larval tuna trajectories are simulated. Temperature and salinity measurements from the CTD are averaged, with the bin edges set at the midpoints between the HyCOM depth levels. For example, CTD data between 11 and 13.5 $\mathrm{m}$ is averaged to create an estimate of the temperature and salinity at $12 \mathrm{~m}$ depth. A number of stations (4 in 2015, 41 in 2016) had very low salinity values at the measurement nearest to the ocean surface ( $0.6 \mathrm{~m}$ water depth). This could be real data, caused by a lens of freshwater (i.e., rain) at the surface, or it could be due to startup effects, since these instruments are generally rinsed with freshwater between deployments. Either way, it is unlikely for HyCOM to match them, so these surface 
points were removed from the comparison. In 2017, the CTD data were processed differently on board, and the depth bins available for $\mathrm{HyCOM}$ validation are coarser. The HyCOM model output has missing data on 2 dates for which CTD casts were performed in PIPA (July-15-2016 and August-4-2017).

The HyCOM validation was quantified using 3 statistical measures: the rootmean-square temperature difference between modeled and observed temperatures, $r m s d=\sqrt{\sum_{i=1}^{N} \frac{\left(M_{i}-O_{i}\right)^{2}}{N}}$, the mean relative temperature difference (i.e., absolute difference divided by the observed value and averaged over all data points), $r e=$ $\frac{1}{N} \sum_{i=1}^{N} \frac{\left|M_{i}-O_{i}\right|}{\left|O_{i}\right|}$, and the cross correlation coefficient, $c c=\frac{\sum_{i=1}^{N}\left(M_{i}-\bar{M}\right)\left(O_{i}-\bar{O}\right)}{\sqrt{\sum_{i=1}^{N}\left(M_{i}-\bar{M}\right)^{2}} \sqrt{\sum_{i=1}^{N}\left(O_{i}-\bar{O}\right)^{2}}}$. In the above notation, $M$ represents a model-based value and $O$ represents an observation value; $\mathrm{N}$ is the number of data points; overbar denotes average of all data points; and vertical bars denote absolute value. If the model and observations were all perfectly matching, then rmsd and re would both be equal to 0 , and the cc would be equal to 1 . As points move off of the 1:1 line, rmsd and re increase and cc decreases.

Figure 3-7 shows that the relationship is strong for both temperature and salinity but both variables have a handful of outliers. For salinity, the rmsd is 0.3 , the re is 0.006 , and the cc is 0.715 . For temperature, the rmsd is 0.465 , the re is 0.01 , and the $\mathrm{cc}$ is 0.798 .

\subsubsection{CTD data}

Figure 3-8 shows temperature profiles in the upper $300 \mathrm{~m}$ for stations in the western half of PIPA, in the portion of the transect that extended roughly north-south. 


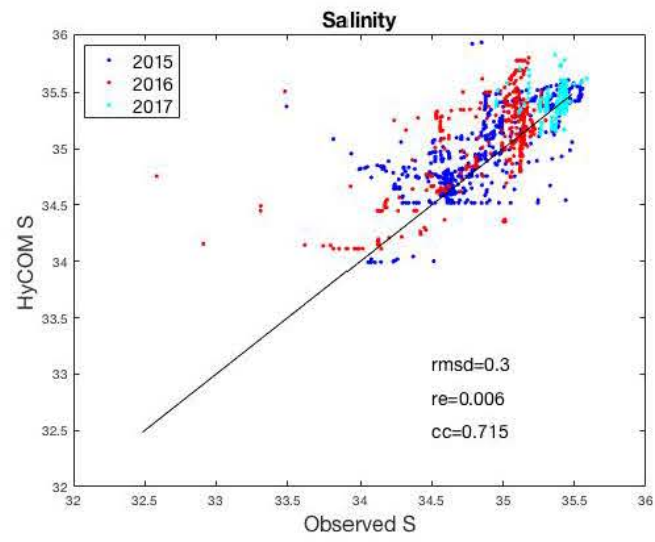

(a) Salinity validation

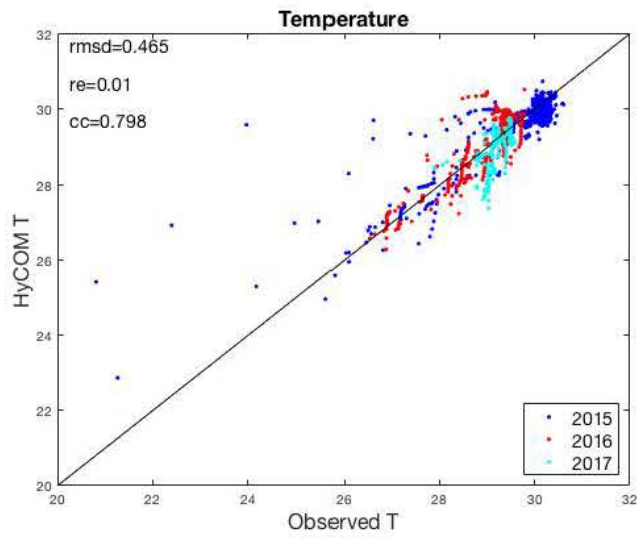

(b) Temperature validation

Figure 3-7: HYCOM validation plots. Observed values from CTD casts are plotted against HYCOM output values for salinity (a) and temperature (b). The different colors represent the years of sampling. RMSD, $\mathrm{RE}$, and $\mathrm{CC}$ values are also shown. 


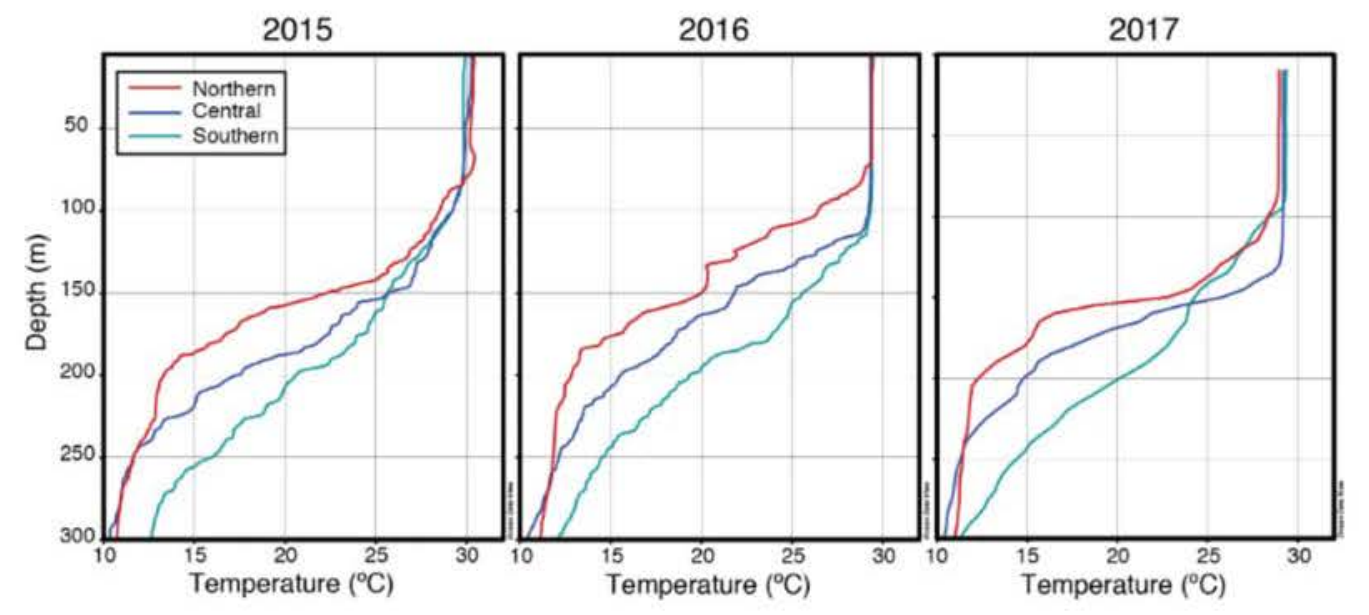

Figure 3-8: Temperature-at-depth profiles for (a) 2015, (b) 2016, and (c) 2017. Profiles are plotted for stations near the northern boundary, central latitude, and southern boundary of PIPA for each year. 
Table 3.1: Information on stations with non-zero catch of larval tunas. Possible net tows include a deep Tucker Trawl to $100 \mathrm{~m}$ (TTD), a shallow Tucker Trawl to $50 \mathrm{~m}$ (TTS), and a neuston tow (NT). Stations that are outside of PIPA are indicated with a *. For each station, the average temperature (upper $50 \mathrm{~m}$ ) from hydrocast data, latitude, and longitude are reported. For the two taxa (Katsuwonus pelamis and Thunnus spp.), we report the number of larvae collected, the abundance in number per $10 \mathrm{~m}^{2}$, and the spawning output needed to lead to the observed catch number. Additionally, the number of genetically identified larvae are reported for Thunnus spp. larvae in parentheses (T. albacares first, $T$. obesus second).

\begin{tabular}{|c|c|c|c|c|c|c|c|c|c|c|c|}
\hline \multirow[b]{2}{*}{ Year } & \multirow[b]{2}{*}{ Station } & \multirow[b]{2}{*}{ Nets Used } & \multirow[b]{2}{*}{$\begin{array}{c}\text { Mean } \\
T \text { to } \\
50 \mathrm{~m}\left({ }^{\circ} \mathrm{C}\right)\end{array}$} & \multirow[b]{2}{*}{$\begin{array}{c}\text { Station } \\
\text { Latitude } \\
\left({ }^{\circ} \mathrm{N}\right) \\
\end{array}$} & \multirow[b]{2}{*}{$\begin{array}{c}\text { Station } \\
\text { Longitude } \\
\left({ }^{\circ} \mathrm{E}\right)\end{array}$} & \multicolumn{3}{|c|}{ Katsuwonus pelamis } & \multicolumn{3}{|c|}{ Thunnus spp. } \\
\hline & & & & & & $\begin{array}{c}\mathbf{N} \\
\text { collected }\end{array}$ & $\begin{array}{l}N \text { per } \\
10 \mathrm{~m}^{2}\end{array}$ & $\begin{array}{l}\text { Spawning } \\
\text { output } \\
\text { needed }\end{array}$ & $\begin{array}{c}\mathbf{N} \\
\text { collected }\end{array}$ & $\begin{array}{l}N \text { per } \\
10 \mathrm{~m}^{2}\end{array}$ & $\begin{array}{l}\text { Spawning } \\
\text { output } \\
\text { needed }\end{array}$ \\
\hline \multirow[t]{18}{*}{2015} & $17^{*}$ & NT & 30.00 & 1.87 & -166.61 & 1 & 0.006 & 2 & - & - & - \\
\hline & $18^{*}$ & TTD, NT & 30.02 & 0.67 & -167.28 & 101 & 42.50 & 1333 & $1(1,-)$ & 0.42 & 2 \\
\hline & $20^{*}$ & TTD, NT & 30.15 & -0.49 & -168.91 & 2 & 0.64 & 27 & $4(3,-)$ & 1.29 & 101 \\
\hline & 21 & TTD, NT & 30.08 & -1.02 & -169.76 & - & - & - & $9(3,-)$ & 3.7 & 114 \\
\hline & 22 & TTD, NT & 30.21 & -1.51 & -170.08 & - & - & - & $5(4,-)$ & 2.81 & 55 \\
\hline & 23 & TTD, NT & 30.16 & -1.83 & -170.38 & 26 & 9.81 & 251 & $6(3,-)$ & 2.13 & 76 \\
\hline & 24 & TTD, NT & 30.09 & -2.16 & -170.57 & 2 & 1.16 & 54 & - & - & - \\
\hline & 25 & TTD, NT & 30.08 & -2.47 & -170.85 & 2 & 0.64 & 8 & $1(-, 1)$ & 0.64 & 11 \\
\hline & 26 & TTD, NT & 30.01 & -3.12 & -171.14 & 1 & 1.05 & 5 & $2(1,-)$ & 2.1 & 9 \\
\hline & 28 & TTD, NT & - & -3.01 & -171.39 & 1 & 0.38 & 35 & 1 & 0.38 & 3 \\
\hline & 29 & TTD, NT & 30.12 & -2.85 & -171.74 & 3 & 1.36 & 31 & $1(1,1)$ & 0.46 & 16 \\
\hline & 31 & TTD, NT & 30.11 & -3.37 & -171.66 & 1 & 0.004 & 2 & - & - & - \\
\hline & 35 & TTD, TTS, NT & 30.01 & -3.74 & -172.85 & 1 & 0.39 & 7 & $1(1,-)$ & 0.72 & 11 \\
\hline & 42 & TTD, TTS, NT & 30.33 & -1.44 & -174.49 & 1 & 0.83 & 3 & $4(1,2)$ & 1.4 & 56 \\
\hline & 44 & TTD, TTS, NT & 30.29 & -1.66 & -174.68 & - & - & - & $2(-, 2)$ & 0.009 & 4 \\
\hline & 56 & TTD, TTS, NT & 30.24 & -2.93 & -174.86 & - & - & - & 1 & 0.32 & 11 \\
\hline & 57 & TTD, TTS, NT & 30.22 & -3.41 & -174.66 & 1 & 0.74 & 3 & - & - & - \\
\hline & 61 & TTD, TTS, NT & 29.98 & -4.71 & -174.55 & 2 & 0.72 & 23 & - & - & - \\
\hline
\end{tabular}




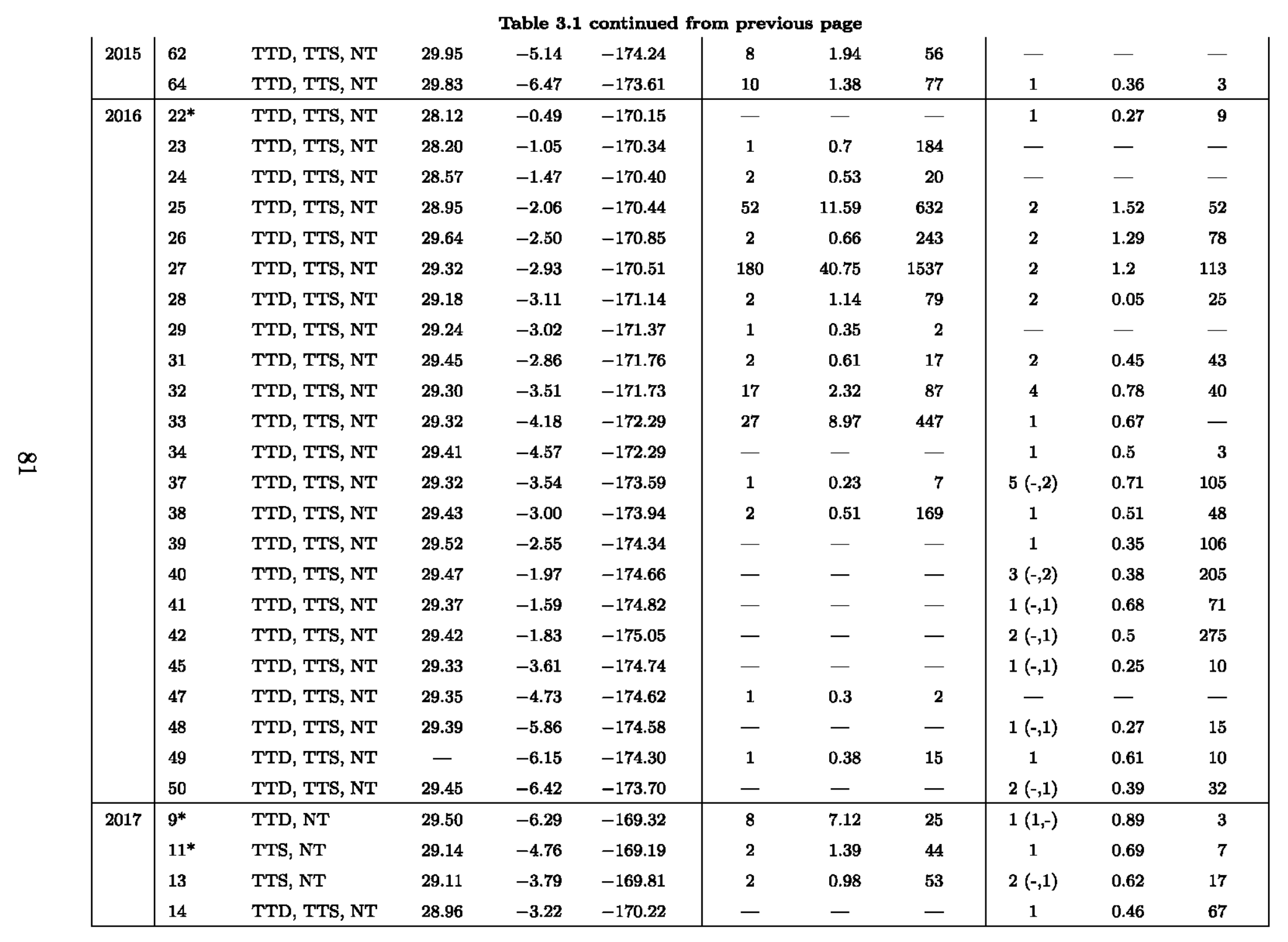




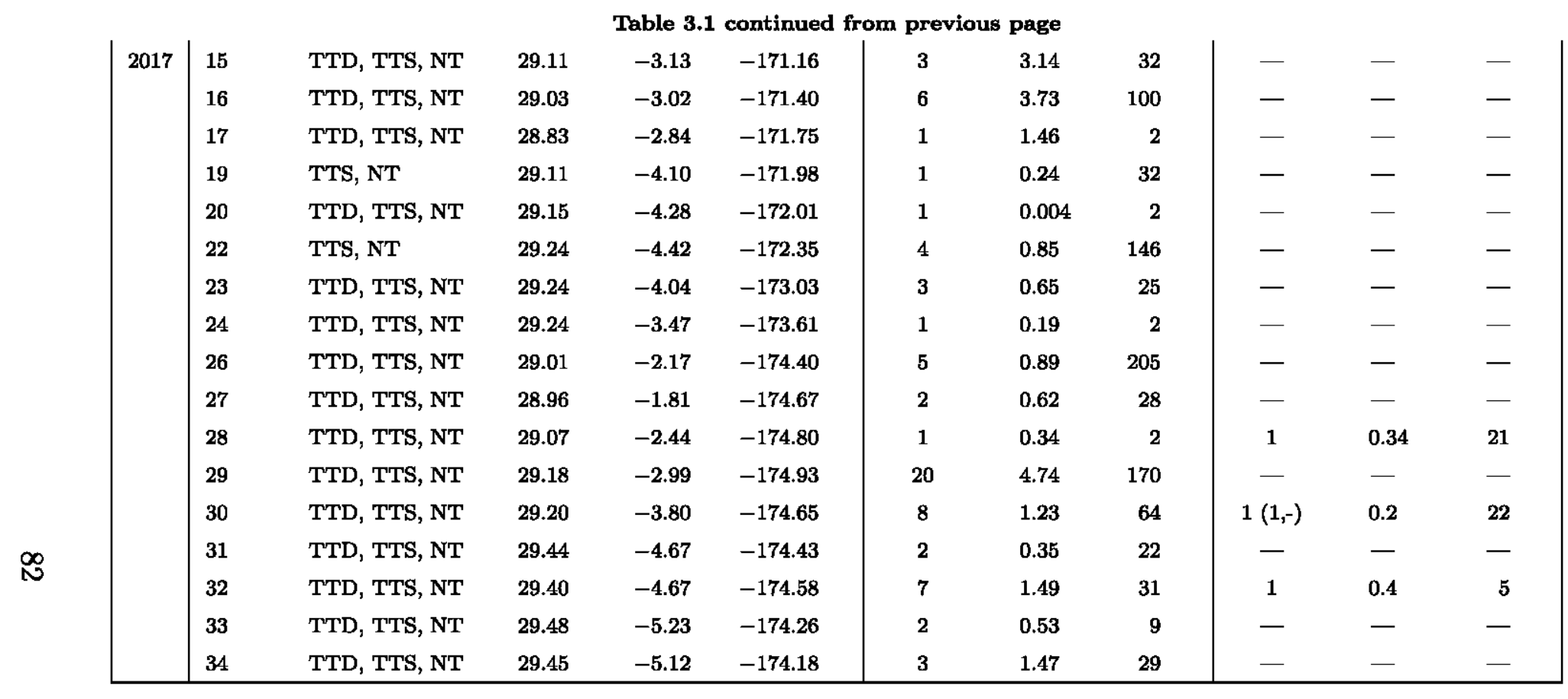




\section{Chapter 4}

\section{Support for the Slope Sea as a major spawning ground for Atlantic bluefin}

tuna: evidence from larval

abundance, growth rates, and backtracking simulations

\subsection{Abstract}

Atlantic bluefin tuna are both commercially and ecologically valuable, but their management can be complicated by their highly-migratory nature. Although there has long been speculation that spawning may occur outside the Gulf of Mexico and Mediterranean spawning grounds, recent collections of larvae have focused attention on the Slope Sea as a third major spawning ground. We analyzed bluefin tuna larvae 
collected in the Slope Sea and the Gulf of Mexico in 2016 to estimate abundance, growth rates, and maternal investment. We also used a high-resolution regional hydrodynamic model to estimate the locations of spawning activity and to predict larval position at the onset of swimming. Our results support the classification of the Slope Sea as a major spawning ground with conditions that support the growth and survival of bluefin tuna larvae. The abundance of bluefin tuna larvae observed in the Slope Sea aligns with typical observations in the Gulf of Mexico and the Mediterranean Sea. We did not detect a regional difference in larval growth rates, but we did find that Slope Sea larvae are larger than Gulf of Mexico larvae before the onset of exogenous feeding. Slope Sea larvae, with the exception of those collected along the Gulf Stream front, were backtracked to locations north of Cape Hatteras and would have been retained within the Slope Sea until the onset of swimming. Slope Sea spawning is likely to be important for the population dynamics of this species, and further study of larvae and spawning adults in the region should be prioritized to support management decisions.

\subsection{Introduction}

Atlantic bluefin tuna (Thunnus thynnus) are an iconic marine species - valuable to commercial and sport fishers alike, and ecologically important for their role as top predators. However, their highly migratory life cycle complicates the study and management of their populations because individuals cross international boundaries and occupy multiple oceanographic regimes on both short (annual) and long (lifespan) time scales. Tagging studies (Block et al., 2001; Block et al., 2005; Galuardi and Lutcavage, 2012), otolith microchemistry (Rooker et al., 2014; Rooker et al., 2008), and population movement models (Kerr et al., 2013) have advanced our understand- 
ing of adult movements and stock structure. Still, there are outstanding questions about the distribution of spawning and larval habitat that can affect our life cycle models and, as a result, resource management decisions.

Although the prevailing understanding is that Atlantic bluefin tuna (bluefin hereafter) comprise two populations with strong natal homing to spawning grounds in the Gulf of Mexico and the Mediterranean Sea, there has long been speculation that spawning may occur in other regions (Lutcavage et al., 1999; Mather et al., 1995). Evidence from tagging in the Western Atlantic has shown that large individuals (presumed mature) may not visit either the Gulf of Mexico or the Mediterranean during the spawning season (Block et al., 2005; Galuardi et al., 2010). Studies of gonad status have also suggested that Western bluefin spawn much closer to the Gulf of Maine feeding grounds than the Gulf of Mexico (Baglin, 1976; Goldstein et al., 2007). Furthermore, although very few bluefin under $210 \mathrm{~cm}$ fork length (FL) are observed in the Gulf of Mexico (Diaz and Turner, 2007; Richardson et al., 2016), reproductive hormones indicate that individuals as small as $134 \mathrm{~cm} \mathrm{FL}$ are reproductively capable (Heinisch et al., 2014). Larval surveys near Cuba, the Straits of Florida, and the Blake Plateau have all found some larval bluefin, but never in numbers or abundance high enough to compare with the Gulf of Mexico and Mediterranean spawning grounds.

In 2013, enough larval bluefin were collected during opportunistic sampling in the Slope Sea, a wedge of ocean bounded by the U.S. shelf break and the Gulf Stream as it peels away from the U.S. east coast, to prompt classification of this region as a third spawning ground (Richardson et al., 2016). Together with past lines of evidence from tagging, histology, and reproductive hormones, an alternate theory of bluefin life history was put forward: that both the Eastern and Western stocks exhibit maturity at 3-5 years of age, but that younger Western bluefin spawn in the 
Slope Sea until they reach a size where the longer migration to the Gulf of Mexico is favorable (Richardson et al., 2016).

The response to this discovery has been mixed, with some voices advocating against the alternate life cycle hypothesis (Safina, 2016; Walter et al., 2016) and others arguing that it calls for more innovative studies to resolve our understanding of bluefin life history (Di Natale, 2017). A major argument against the classification of the Slope Sea as a third major spawning ground focuses on the nature of the larval bluefin observations as arising from a single year of opportunistic sampling (Walter et al., 2016). Although the temperature and transport conditions in the Slope Sea are suitable for bluefin spawning, larval growth, and larval retention (Rypina et al., 2019), there are important open questions about whether conditions in the Slope Sea actually support larval bluefin growth and survival. Another argument against the assertions of Richardson et al. (2016) is that drifter transit times were used to assert that larvae could not have originated in the Gulf of Mexico, but it did not estimate spawning locations (i.e., via particle backtracking simulations). Finally, a major open question regards the implications of Slope Sea residency and spawning for population structure and mixing, which has prompted new studies of population genetics (Puncher et al., 2018; Rodríguez-Ezpeleta et al., 2019).

In this paper, we address several of these arguments against the importance of the Slope Sea as spawning habitat for Atlantic bluefin tuna, and assert that larval observations from 2016 continue to support the classification of the Slope Sea as a third major spawning ground. We calculated the abundance of bluefin tuna larvae from sampling on several cruises in the Slope Sea in the summer of 2016. Using a subset of those collected larvae, we analyzed otoliths to investigate larval growth in the Slope Sea. We also analyzed otoliths from larvae collected in the Gulf of Mexico in 2016, enabling a comparison of estimated larval bluefin growth between 
the two regions. Finally, we used a high-resolution oceanographic model to estimate the locations of spawning activity that would have led to our larval observations.

\subsection{Methods}

\subsubsection{Larval sampling methods}

Larval samples from the Slope Sea were collected in 2016 during two cruises off the U.S. northeast continental shelf, conducted by the Northeast Fisheries Science Center (NEFSC) of the National Oceanic and Atmospheric Association (NOAA).

The first set of samples used in this study was collected during the third leg of the spring ecosystem monitoring program that samples plankton throughout the northeast U.S. shelf. This third leg of cruise GU1608 on the NOAA Ship Gordon Gunter transited from Rhode Island to Norfolk, Virginia, from June 17 to 20, 2016. Plankton sampling was performed at 24 stations crossing the north wall of the Gulf Stream to target bluefin tuna larvae as a follow-up to the collections from 2013 (Richardson et al., 2016), with tow locations chosen based on satellite-derived sea surface temperature data. Net tows employed a bongo net with $61-\mathrm{cm}$ diameter openings and 333- $\mu \mathrm{m}$ mesh, with an additional $20-\mathrm{cm}$ bongo net with $165-\mu \mathrm{m}$ mesh mounted $0.5 \mathrm{~m}$ above the larger bongo, and a CTD mounted $1 \mathrm{~m}$ above the smaller one. Targeting the larval habitat of bluefin tuna and billfish, the net was lowered to

$25 \mathrm{~m}$ and brought back to the surface over a 5 minute period, and this was repeated for a tow duration of 10 minutes. Samples from all 4 nets were preserved in $95 \%$ ethanol which was refreshed after 24 hours.

The second set of samples were collected during the Atlantic Marine Assessment Program for Protected Species (AMAPPS) between June 27 and August 25 on the 
NOAA Ship Henry B. Bigelow (Cruise ID HB1603). AMAPPS cruises collect standard plankton samples three times per day to complement observations of marine mammals: before visual surveys begin for the day (approximately 0500), at mid-day (approximately 1200), and after visual surveys are completed for the day (approximately 1800). These standard samples were also collected with a $61-\mathrm{cm}$ bongo net with 333- $\mu \mathrm{m}$ mesh, with a CTD mounted on the wire $1 \mathrm{~m}$ above the bongo. The bongo was deployed to $200 \mathrm{~m}$ or within $5 \mathrm{~m}$ of the bottom, in an oblique tow at outgoing wire speed of $50 \mathrm{~m} / \mathrm{min}$ and incoming wire speed of $20 \mathrm{~m} / \mathrm{min}$. One of the net samples was preserved in $95 \%$ ethanol to preserve otoliths and DNA of ichthyoplankton, and the other net sample was preserved in $5 \%$ formaldehyde and seawater to optimize for morphological identification of zooplankton. The ethanol-preserved sample was refreshed after 24-48 hours.

In addition to these standard day-time bongo samples, additional plankton sampling was carried out at night, in areas where the bottom depth exceeded $1000 \mathrm{~m}$ and the sea surface temperature (SST) exceeded $22^{\circ} \mathrm{C}$. At these nighttime stations, the standard 61-cm bongo was deployed according to the standard protocol described above for the daytime samples. An additional tow with a weighted 2-by-1 $\mathrm{m}$ frame net with 333- $\mu \mathrm{m}$ mesh was used to increase catch of bluefin tuna and other ichthyoplankton; deployments of this net were double-oblique tows to $25 \mathrm{~m}$ over a 10 minute period. Samples from the frame net were preserved in $95 \%$ ethanol and the ethanol was refreshed after 24-48 hours. Each of the $61 \mathrm{~cm}$ bongo and 2-by-1 $\mathrm{m}$ frame nets were deployed with a General Oceanics flowmeter. 


\subsubsection{Laboratory processing of plankton samples}

From nearly every bongo station on GU1608 and HB1603, one of the net samples was processed at the Morski Instytut Rybacki in Szcezecin, Poland following established protocols for both ichthyoplankton (Walsh et al., 2015) and zooplankton analyses (Kane, 2007). For the ichthyoplankton analysis, all fish larvae, fish eggs and cephalopod paralarvae were removed and counted. Fish larvae were then identified to the lowest possible taxonomic category and were measured. Identification of scombrid larvae, including bluefin tuna, were then verified at the Narragansett Laboratory of the Northeast Fisheries Science Center.

Stations that were most likely to contain bluefin tuna larvae were identified as those with bottom depth exceeding $1000 \mathrm{~m}$, SST exceeding $22^{\circ} \mathrm{C}$, and sea surface salinity of 34.5-36 PSU. Samples matching these specifications from the bongo that were not sent to Poland were sorted under a light microscope to extract all ichthyoplankton. From these ichthyoplankton, bluefin tuna (Thunnus thynnus) were identified using morphological characters (Richards and Potthoff, 1974) and species identification for some of these fish was confirmed using genetic markers.

Some of the samples from the smaller bongo net (20-cm diameter with $165-\mu \mathrm{m}$ mesh) were sorted to evaluate whether there was extrusion of small bluefin tuna larvae from the 333- $\mu \mathrm{m}$ mesh in the $61-\mathrm{cm}$ bongo. Some of the bluefin larvae identified from the 20-cm bongo samples were used for ageing, but they were not included in calculations of abundance.

Bluefin tuna larvae from the Slope Sea that were not sent to Poland were photographed using either a Leica M205 microscope with a phototube, or Nikon SMZ1500 microscope with a Nikon Ri-2 camera and imaging software. The scale for photographs was determined using a microscope calibration slide. Fish standard 
lengths were measured in ImageJ from the tip of the bottom jaw to the tip of the notocord for pre-flexion larvae or to the point of flexion in post-flexion larvae.

\subsubsection{Larval distribution maps}

For the Slope Sea collection, we generated a map of the abundance of bluefin tuna larvae from $61-\mathrm{cm}$ bongo net tows. When both nets of the bongo station were

processed, we summed the number of larvae and the volume filtered from the two nets of the bongo. Abundance for each tow, expressed as $n$ per $10 \mathrm{~m}^{2}$ is calculated as $a_{i}=10 * n_{i} / v_{i} * h_{i}$, where $n_{i}$ is the number of individuals collected, $v_{i}$ is the volume filtered, and $h_{i}$ is the range of depth sampled (Irisson et al., 2010). We plot negative observations (abundance of 0 larvae per $\mathrm{m}^{2}$ ) only at bongo sampling locations deeper than $1000 \mathrm{~m}$ and between June 15 and August 15. There were two bongo sampling stations that meet these criteria that were not processed in Poland or the U.S., so those two stations are excluded from maps and calculations of larval abundance.

\subsubsection{Age and growth analyses}

Larval otoliths display daily growth increments, with each increment corresponding to one day of growth since the onset of exogenous feeding (Brothers et al., 1976). From the identified larvae in the Slope Sea samples, 66 bluefin tuna larvae were selected for otolith analyses across the range of stations and lengths sampled. Of those 66, 9 larvae had issues with preservation (dessication of tissues or otolith dissolution) that prevented successful extraction of otoliths.

Otoliths were extracted from individual larvae with dissecting pins; both sagittae and lapillae were extracted and placed flat side down on a glass microscope slide in Type B immersion oil. Otoliths were imaged with a Leica DM2500 compound 
microscope with an oil-immersion 100X objective lens; images were taken with a Leica MC120 HD camera and the Leica Application Suite software. Images were calibrated using a stage micrometer. Otoliths were read in ImageJ using the Object $J$ plug-in. All extractions and reads were performed by the same reader. For each larva, sagittae and lapillae were identified based on otolith radius, because the sagittae are larger. If two sagittae had been extracted, the clearest was selected for reading. There were 8 larvae for which we were able to extract and photograph only 1 or 2 otoliths. Among these 8 , there were 3 fish from which we had extracted 2 otoliths with a visible size difference. This leaves 5 for which we could not use visual cues to determine if we had extracted a sagittal otolith (for 3 larvae, we extracted 1 otolith, and for another 2 larvae, we extracted 2 otoliths that did not have a visually obvious size difference). After reading otoliths from all larvae (see below), we analyzed how these 5 larvae were distributed on a plot of otolith radius vs. otolith increments (Figure 4-5). We found that 3 of the otoliths in question fell in the middle of the distributions of otolith radius, given the number of increments. The other 2 otoliths were the two smallest amongst otoliths with 2 daily increments. These 2 fish were excluded from the subsequent analyses.

The selected images of sagittal otoliths, one per larva, were read once, the order of the images was shuffled, and they were read again. If the two reads yielded ages within $+/-1$ day, the second read was retained. If the two reads differed by more than 1 day, a third read was performed. If the third read agreed to within $+/-1$ day of either the first or second read, then the third read was retained. If the third read differed by more than 1 day from both the first and second reads, then that fish was not retained in age analyses.

In addition to the Slope Sea samples, otoliths were analyzed from 143 larval bluefin tuna collected in the Gulf of Mexico in 2016 by the Southeast Fisheries 
Science Center (SEFSC) as part of the Southeast Area Monitoring and Assessment Program (SEAMAP). These larvae were collected by oblique tows of a $61-\mathrm{cm}$ bongo, either following the standard protocol with 333- $\mu \mathrm{m}$ mesh to a sampling depth of $200 \mathrm{~m}$, or with $505-\mu \mathrm{m}$ mesh to a sampling depth of $10 \mathrm{~m}$. The 143 larvae that were examined were selected to cover a range of locations, oceanographic conditions, and sizes. For all of these larvae, standard length was also measured. The same protocols were used for extracting otoliths as for the Slope Sea larvae. Otoliths for Gulf of Mexico bluefin larvae were imaged with a Zeiss Axio Scope.A1 compound microscope with an oil-immersion 100X objective lens; images were taken with a Qimaging MicroPublisher 3.3 RTV camera and ImagePro Plus 7 software.

Both the Slope Sea and Gulf of Mexico otoliths from 2016 were read by the same reader following consistent protocols for marking images and quality control of reads. After quality control, 52 larval otoliths from the Slope Sea and 142 from the Gulf of Mexico were retained for age and growth analyses.

We used linear least-squares to fit age-length relationships for the Slope Sea and Gulf of Mexico data sets. Because the Slope Sea data set had no larvae with more than 8 increments, and few larvae with more than 4 increments, we also estimated best-fit lines for three subsets of the data: larvae from the Gulf of Mexico with 0-8 increments, larvae from the Gulf of Mexico with 0-4 increments, and larvae from the Slope Sea with 0-4 increments. The slopes of these lines are estimates of the daily growth rates for each of the subsets of larvae.

We used an analysis of covariance (ANCOVA) approach to determine if there is a significant effect of region on either the slope or intercept of the linear models of the age-length relationships. We pooled the data from the Gulf of Mexico and the Slope Sea, and added a factor for region. We then used the aov function in $\mathrm{R}$ to fit a linear model to these data, including an interaction term between the number of 
increments and the region. This function returns a p-value for each covariate and the interaction term. If the interaction term was not significant, we interpreted this as no significant difference in the slopes of the two regression lines. We then used the aov function without the interaction term to test for a significant effect of region on the intercept of the best-fit lines. We performed this step-wise analysis for all larvae with 0-8 increments, and then a second time for the subset of larvae with 0-4 increments.

Otolith radius tends to be strongly correlated with larval length, so the width of each daily increment is a proxy for daily growth rate, and the distance (or radius) to each daily increment is a proxy for length at age (Sponaugle et al., 2009). We measured the increment width for increments within a given otolith starting from the first daily growth ring (e.g., a larva with 5 increments marked will yield 4 increment widths, corresponding to 4 days of larval growth). To control for effects such as selective mortality, we restricted our analysis of Gulf of Mexico increment widths and otolith radii to only those larvae with 8 or fewer increments, since the oldest larva in our Slope Sea data set has 8 increments. For each regional data set, we calculated the mean increment width and mean radius to increment for each day of larval life if there are at least 3 larvae with that increment (i.e., we did not calculate a mean increment width for the Slope Sea for increments 6 or 7 because there are only 2 larvae with 7 rings and 1 larva with 8 rings). We also calculated the standard error of the mean as $\frac{\sigma}{\sqrt{n}}$, where $\sigma$ is the sample standard deviation and $n$ is the sample size at that increment index.

We also tested for a significant difference in the mean otolith radius at the first increment between the Slope Sea and the Gulf of Mexico, using a two-sided Welch t-test. We performed this test for larvae with 0-8 increments and then again for those larvae with 0-4 increments. 


\subsubsection{Larval drift simulations}

We estimated the spawning locations of larvae collected in the Slope Sea in 2016 using particle backtracking in the MABGOM2 model (Rypina et al., 2019). This regional ROMS-based model has a high resolution of $1 \mathrm{~km}$ in the cross-shore direction and 2 $\mathrm{km}$ in the alongshore direction, and was previously validated for the Slope Sea region (Rypina et al., 2019). Because of this high resolution, we treat the larval trajectories as deterministic and do not add any stochasticity to the simulated larval drift.

Larvae included in otolith analyses had direct age estimates. For larvae that were not aged, we used the overall size-at-age relationship derived from Slope Sea otolith analyses to estimate the number of daily growth increments. We also accounted for spread around the best-fit line by defining the distribution of expected ages using the best-fit line as the mean and the standard deviation of the residuals as the variance. For each larva that was measured but not aged, we drew a value from this normal distribution and then rounded it to the nearest 1 day, resulting in an estimated number of increments for that larva.

This gives age in days since the onset of exogenous feeding, but to inform backtracking, we needed estimated ages in days post spawning. At the typical temperatures of field collections of larval bluefin tuna, it takes 40-50 hours for bluefin tuna eggs to hatch (Reglero et al., 2018b) and approximately 2 days until the onset of exogenous feeding after hatching (Yúfera et al., 2014). Therefore, we added 4 days to convert the estimates of increment number into age of each larva in days postspawning, which is also consistent with work on Pacific bluefin tuna reared in the laboratory (Itoh et al., 2000).

We performed individual-based particle simulations for each unique combination

of station and larval days-post-spawning. These simulations were run backwards in 
time to the estimated spawning date. Additionally, we ran simulations forward in time until the larva would have been 25 days old to examine whether the larva would have been retained in the Slope Sea during the larval period. Larvae were advected at $10 \mathrm{~m}$ depth for both the backwards-in-time and forwards-in-time simulations.

\subsection{Results}

In 2016, larval sampling in the Slope Sea yielded 207 bluefin tuna larvae, ranging in size from 2 to $8.2 \mathrm{~mm}$. Atlantic bluefin tuna larvae were observed across a wide geographic area, from 36.65 to $39.73^{\circ} \mathrm{N}$ and from 67.9 to $74.3^{\circ} \mathrm{W}$. There was one bluefin larva collected at a station inshore of the shelf break, with a bottom depth of $55 \mathrm{~m}$. All other observations of bluefin larvae were at locations with a bottom depth of $2000 \mathrm{~m}$ or greater. All but one of the bluefin tuna larvae observed in the Slope Sea in 2016 were collected between June 18 and July 13. One additional bluefin larva was collected on August 1, and it is also the northernmost observation.

At stations where bluefin tuna larvae were observed, the abundance ranged from 0.80 to 27.47 bluefin larvae per $10 \mathrm{~m}^{2}$ (mean=9.57 larvae per $10 \mathrm{~m}^{2}$ ). The highest abundance, along with two more high-abundance stations, was observed in the southwestern portion of the Slope Sea on June 19-20, and another region of high abundance was sampled in the eastern portion of the sampling area at 3 stations on July 8.

Larvae from the Slope Sea that were used in otolith analyses ranged from 2.53 to $6.56 \mathrm{~mm}$ and had 0 to 8 increments (Figure 4-2A). The 52 larvae with high-quality otolith data represent a wide geographic range of observations, although no larvae were aged from several of the low-abundance stations in the central region of the sampling area (Figure 4-6a). The larvae we aged were collected between June 19 and 


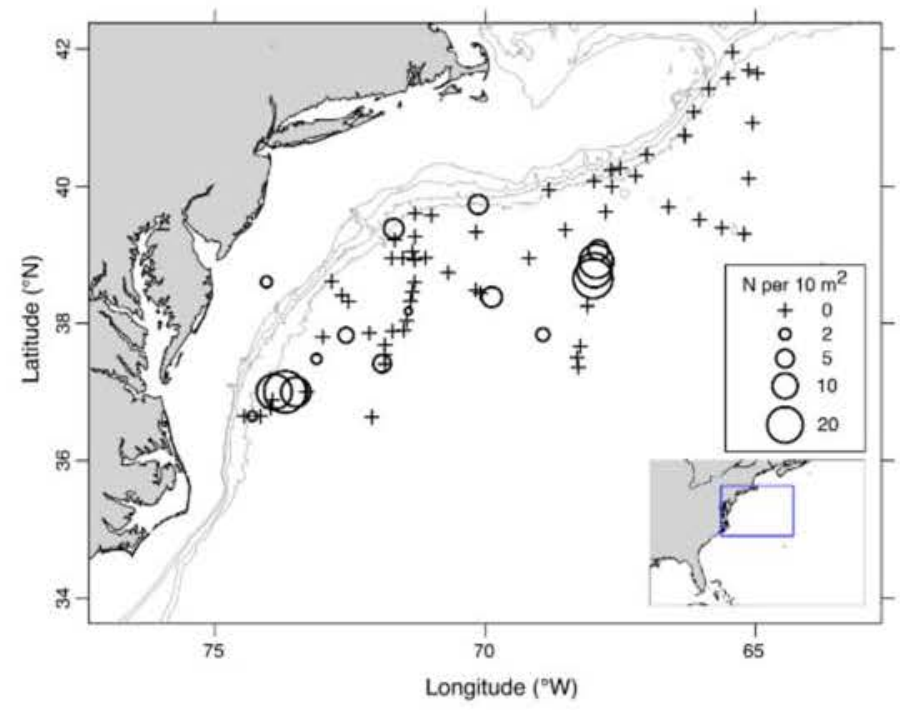

Figure 4-1: Abundance of Atlantic bluefin tuna larvae in the Slope Sea in 2016. Abundance of Atlantic bluefin tuna (Thunnus thynnus) larvae, expressed as $\mathbf{n}$ per 10 $\mathrm{m}^{2}$. Data is shown for all bongo stations at locations with $1000 \mathrm{~m}$ depth or greater that were sampled between June 15 and August 15, plus one station on the shelf where bluefin larvae were observed. Bathymetric contours at 100,200,1000, and $2000 \mathrm{~m}$ depth are shown in light grey (accessed through GEBCO).

July 12 (Table 4.1).

The estimated growth rate for bluefin tuna larvae collected in the Slope Sea was $0.37 \mathrm{~mm} \mathrm{day}^{-1}$, and the estimated length at 0 increments was $3.08 \mathrm{~mm}$ (Figure 42A). However, there are few larvae with more than 5 increments. If we restricted our analysis to only those larvae with 4 or fewer increments, we found that the estimated growth rate was slightly lower, $0.32 \mathrm{~mm}$ day $^{-1}$, and the estimated length at 0 increments was slightly higher, $3.15 \mathrm{~mm}$.

Larvae from the Gulf of Mexico that were used in otolith analyses ranged from 2.52 to $7.93 \mathrm{~mm}$, and from 0 to 13 increments. The 142 larvae with high-quality otolith data represent a wide geographic range of sampling locations across the northern Gulf of Mexico (Figure 4-6b). These larvae were collected between April 30 and 
May 30, 2016.

The estimated growth rate for bluefin tuna larvae collected in the Gulf of Mexico in 2016 was $0.37 \mathrm{~mm}$ day $^{-1}$, and the estimated length at 0 increments was $2.85 \mathrm{~mm}$ (Figure 4-2B). If we restricted our analysis to only those larvae with 8 or fewer increments (to facilitate comparison with the Slope Sea data), we found that the estimated growth rate was $0.42 \mathrm{~mm}$ day $^{-1}$, and the estimated length at 0 increments was $2.65 \mathrm{~mm}$. If we restricted our analysis to only those larvae with 4 increments or fewer (again, for comparison with the Slope Sea data), we found that the estimated growth rate was $0.38 \mathrm{~mm}$ day $^{-1}$, and the estimated length at 0 increments was 2.72 mm.

The stepwise ANCOVA analysis found no significant effect of region (Slope Sea
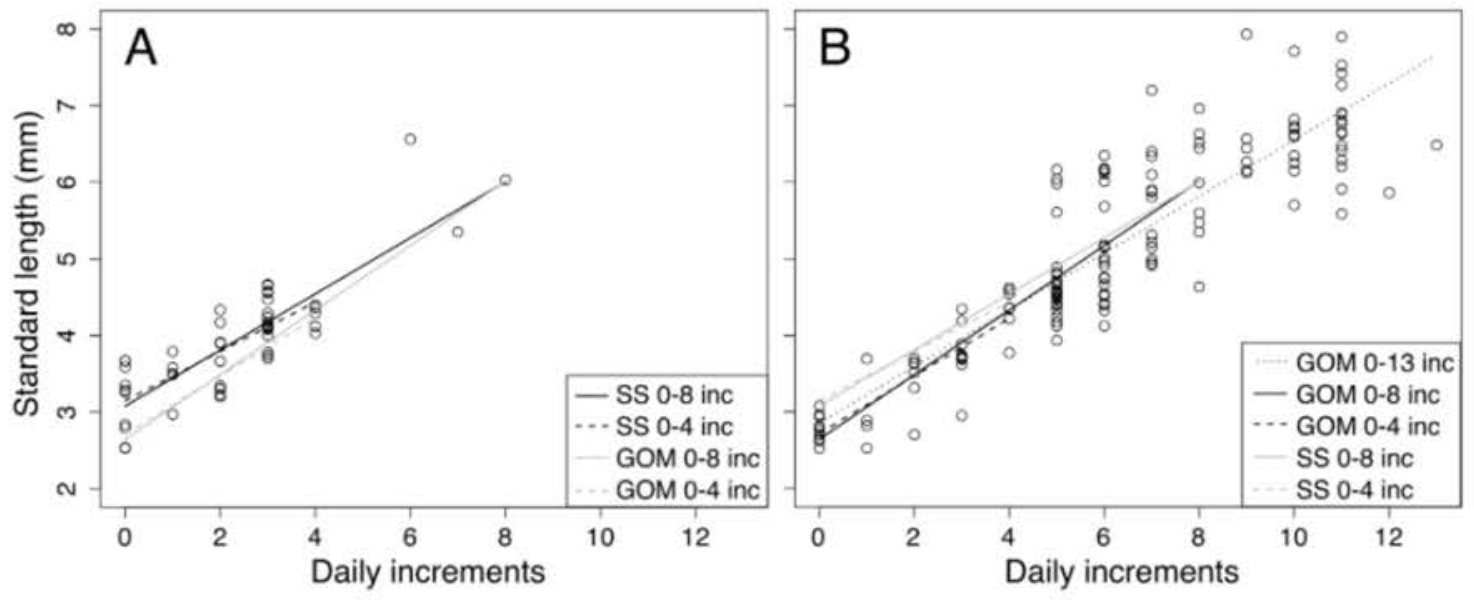

Figure 4-2: Larval growth curves for bluefin tuna larvae in 2016. Larval size-at-age for Atlantic bluefin tuna larvae (Thunnus thynnus) collected in (a) the Slope Sea and (b) the Gulf of Mexico in 2016. On each plot, the circles show the standard length (min) for larvae with 0-13 daily growth increments. The black lines are best-fit lines to the circles, and the grey lines show the best-fit lines from the opposite panel. Solid lines show the relationship for larvae with 0-8 increments, dashed lines correspond to larvae with 0-4 increments, and the dotted line in (b) shows the best-fit line for the overall dataset from the Gulf of Mexico (0-13 increments). 
vs. Gulf of Mexico) on the slope of the larval age-length relationship in our dataset ( $p=0.24$ for $0-8$ increments, $p=0.31$ for $0-4$ increments). There was, however, $a$ significant effect of region on the intercept ( $p<0.01$ for $0-8$ increments, $p<0.0001$ for 0-4 increments). Therefore, we determined that there is no significant difference in the average daily growth rate of bluefin larvae based on whether they were collected in the Slope Sea or the Gulf of Mexico, but that the larvae collected in the Slope Sea were significantly larger prior to exogenous feeding and potentially at hatching.
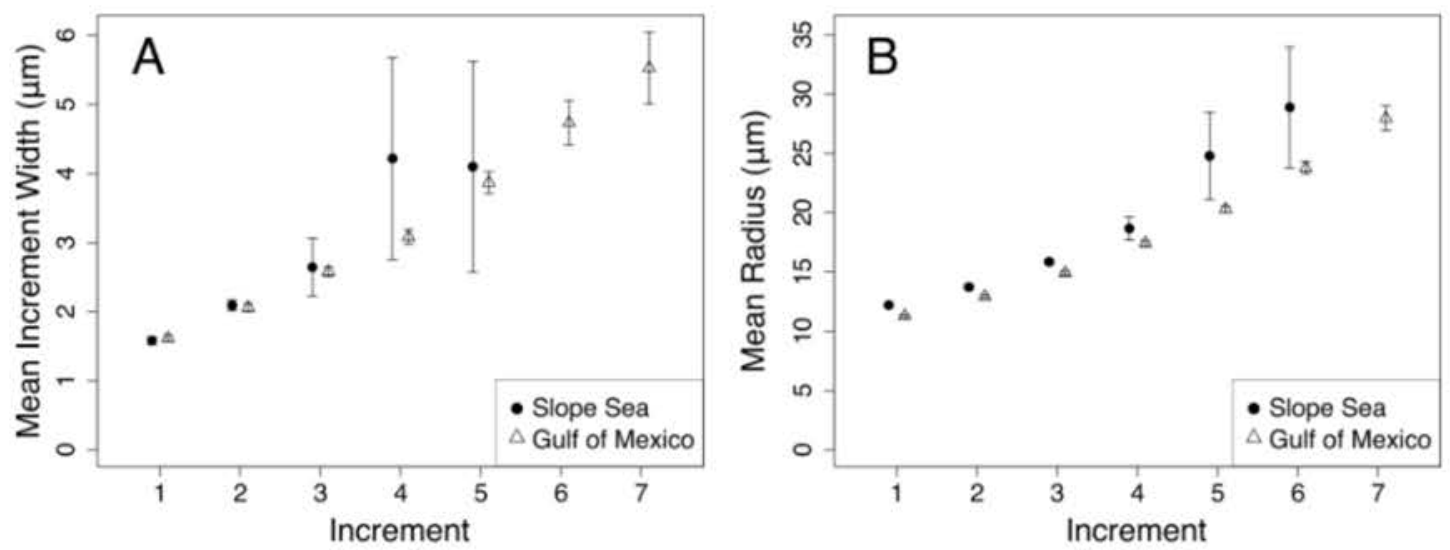

Figure 4-3: Otolith measurements from bluefin tuna larvae collected in 2016. Otolith increment width is a proxy for daily growth rate on a given day of larval growth (e.g., width of increment 1 is measured as the distance between the first to the second increments), and otolith radius to a given increment is a proxy for larval size. In order to compare between the Slope Sea and Gulf of Mexico datasets, we include only those larvae with 0-8 increments. For each region, the mean increment width (A) and the mean radius to increment (B) are shown for each day of larval life if there are at least 3 larvae with that increment. Error bars show the standard error of the mean, calculated as $\frac{\sigma}{\sqrt{n}}$, where $\sigma$ is the sample standard deviation and $n$ is the sample size at that increment index.

In our measure of daily growth rate, using increment width as a proxy for daily growth, we observed that the first 3 increment widths (from increments 1 through 3 to increments 2 through 4) are extremely similar in the Slope Sea and the Gulf of 
Mexico (Figure 4-3A). The error bars for Slope Sea values at increments 4 and 5 also overlapped with Gulf of Mexico values, but the small sample size of Slope Sea larvae over 4 increments restricted our ability to interpret those values. Otolith radius, as a proxy for larval size, is higher in Slope Sea larvae at the first increment, and then that difference appears to carry over across the rest of the increments (Figure 4-3B).

The otolith distance to the first ring is higher in the Slope Sea $(12.21 \mu \mathrm{m}$ for larvae with 0-8 increments and $12.16 \mu \mathrm{m}$ for larvae with $0-4$ increments) than in the Gulf of Mexico (11.29 $\mu \mathrm{m}$ for larvae with 0-8 increments and $11.58 \mu \mathrm{m}$ for larvae with 0-4 increments). The Welch t-test determined that this difference was statistically significant for the larvae with $0-8$ increments $(\mathbf{p}<0.0001)$ and for larvae with $0-4$ increments $(p=0.029)$.

Particle tracking simulations for Slope Sea larvae placed the vast majority of larvae within the Slope Sea domain on the estimated day of spawning and at the onset of directed swimming (approximately 25 days post hatch, Fukuda et al., 2010). We observed 68 unique combinations of collection location and estimated age in days post hatch (dph) in the Slope Sea in 2016. There were 60 trajectories that backtracked to locations within the Slope Sea, which formed 3 clusters near: (1) the southeastern flank of Georges Bank, (2) the shelf slope off New Jersey and Maryland, and (3) the southwestern corner of the Slope Sea (Figure 4-4). There were 5 trajectories that backtracked to locations near or just outside of the southern boundary of the Slope Sea near Cape Hatteras. There was one bluefin larva collected on the shelf that was estimated to have been spawned on the shelf, as well as 2 estimated spawning locations near the Gulf Stream around what appears to be a persistent meander in 2016 (Figure 4-4). There were 61 simulated larvae that were retained within the Slope Sea until $25 \mathrm{dph}$, and 7 trajectories that exited the MABGOM2 model domain through the eastern boundary—and 5 of these are trajectories that also backtracked 

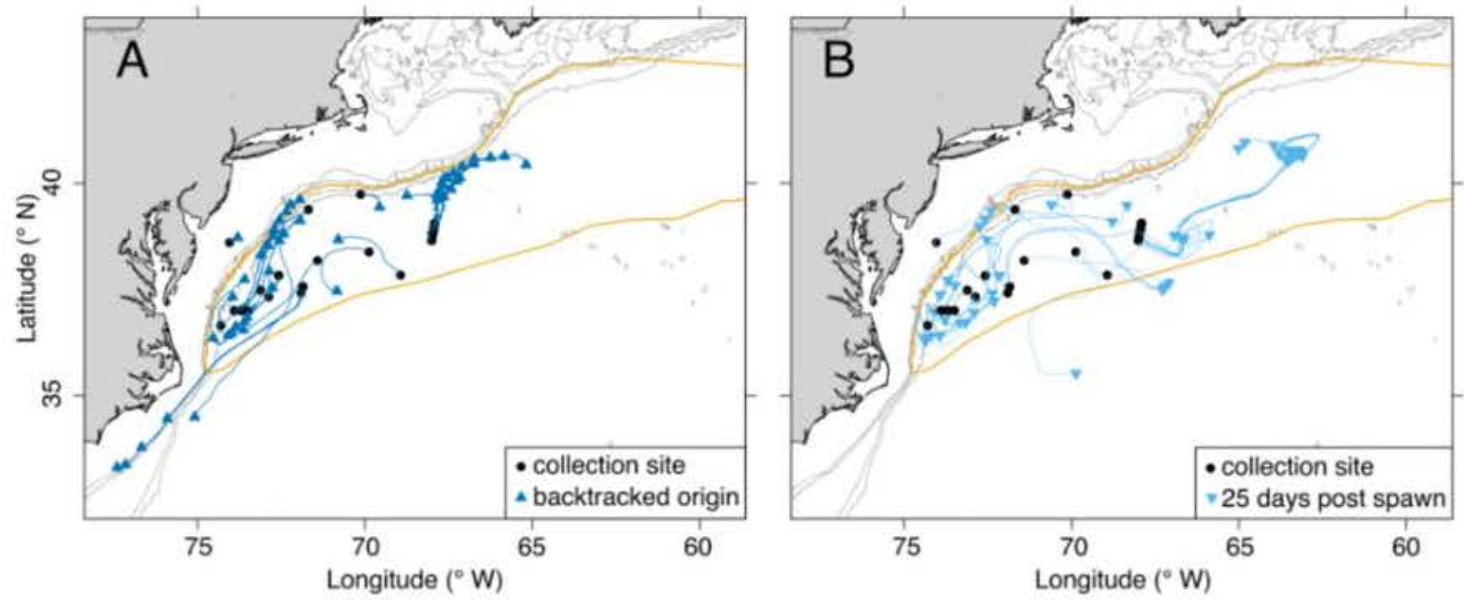

Figure 4-4: Simulated trajectories for larvae collected in the Slope Sea in 2016. For each unique combination of station and age (days post hatch, either estimated directly from otoliths or indirectly from the age-length relationship), larval trajectories were simulated backwards in time to estimate spawning location (A), and forwards in time until the onset of directed swimming behavior (an estimated larval age of 25 days post hatch, B). Bathymetric contours at 100, 200, 1000, and $2000 \mathrm{~m}$ depth are shown in light grey (accessed through GEBCO). The Slope Sea bounding box (orange outline) is defined in Richardson et al., 2016; the shapefile was downloaded from $<$ https: $/$ marineregions.org/gazetteer.php?p=details\&id=59314 $>$.

to locations near Cape Hatteras (Figures 4-4 and 4-7). The 5 sampling locations that correspond to larvae that were not retained in the Slope Sea (or the MABGOM2 model domain) until $25 \mathrm{dph}$ all occur along the Gulf Stream boundary of the Slope Sea (Figure 4-7).

\subsection{Discussion}

The collections of Atlantic bluefin tuna larvae in the Slope Sea in 2016, together with the otolith analyses and particle tracking simulations that they enabled, have demonstrated that the conditions in the Slope Sea are suitable for the growth and 
survival of bluefin larvae, and that they originated from spawning within the Slope Sea. Larvae were observed across a wide geographic area in the Slope Sea from midJune to early August, at high abundance. Otolith analyses found that, in 2016, Slope Sea larvae appear to have hatched at larger sizes and grew at similar rates to larvae collected in the Gulf of Mexico. Particle backtracking simulations confirmed that larvae collected in the Slope Sea were spawned in the Slope Sea. These results support the previous assertions that widespread spawning by bluefin occurs in the Slope Sea and that the conditions are suitable for spawning and larval growth (Richardson et al., 2016; Rypina et al., 2019).

We have now collected larvae in the Slope Sea in both 2013 and 2016, and can compare the larval abundance, duration of larval presence, and spatial extent of observations in those two years with observations from the other spawning grounds. In our study as well as previous larval studies in the Slope Sea, Gulf of Mexico, and Mediterranean, larval observations generally span a 2-month period, with the phenology modulated by local environmental conditions (Reglero et al., 2018b; Richardson et al., 2016). The locations of larval presence in the Slope Sea in 2016 spanned $8^{\circ}$ of longitude and $4^{\circ}$ of latitude (Figure 4-1); larvae were observed across $12^{\circ}$ of longitude and $5^{\circ}$ of latitude during 25 years of comprehensive sampling in the Gulf of Mexico (Muhling et al., 2010). In the Mediterranean, spawning occurs across an even larger spatial extent, but much of the recent sampling focus has been on the smaller spawning hotspot around the Balearic Islands, an area of $5^{\circ}$ longitude and $2^{\circ}$ latitude (Alemany et al., 2010).

Observations of larval bluefin abundance in the Slope Sea are comparable to those from the Gulf of Mexico and the Mediterranean given the limited sampling in the Slope Sea and the highly patchy nature of bluefin larvae. At the bongo stations where we observed larval bluefin in 2016, the average abundance is 9.57 larvae per 
$10 \mathrm{~m}^{2}$. We also calculated station abundances for the bongo stations where bluefin tuna larvae were observed in the Slope Sea in 2013 (Richardson et al., 2016) and found that they ranged from 2.5 to 116.9 bluefin per $10 \mathrm{~m}^{2}$, with an average of 21.4 bluefin per $10 \mathrm{~m}^{2}$ amongst the 8 positive bongo stations. Larval bluefin abundance in the Gulf of Mexico in 2010-2011 was approximately 20 larvae per $10 \mathrm{~m}^{2}$ (Habtes et al., 2014). In 2016, the abundance at positive stations in the SEAMAP dataset ranged from 3.6 to 349.8 bluefin per $10 \mathrm{~m}^{2}$, with a mean of 38 larvae per $10 \mathrm{~m}^{2}$ (Figure 4-8), but it's important to point out that bluefin abundance in the Gulf of Mexico in 2016 seems to be an outlier compared to the past two decades (see below for discussion of the time series of the larval abundance index; Ingram, 2018). The mean abundance of bluefin larvae at positive stations around the Balearic Islands in the Mediterranean from 2001 to 2005 was 31.1 larvae per $10 \mathrm{~m}^{2}$, and the highest observed station abundance was 867.4 bluefin per $10 \mathrm{~m}^{2}$ (Alemany et al., 2010). While the mean abundance observed in the Slope Sea was somewhat lower than the mean abundance observed in standard larval monitoring programs in the Gulf of Mexico and the Mediterranean, these means are affected by a few extremely high observations. It is possible that the opportunistic and short time series of sampling in the Slope Sea has not yet revealed as many high station abundances to match the other spawning grounds.

To account for the difference in sampling intensity, we can estimate the larval abundance index in 2016 following Scott et al. (1993, Ingram et al., 2010). We included bongo sampling stations that occurred between June 15 and August 15 at locations with a bottom depth of at least $1000 \mathrm{~m}$. If we assumed that the larval loss rate (daily mortality) is the same in the Gulf of Mexico and the Slope Sea, and we used our linear growth model to estimate ages of the catch, we found that the larval abundance index for the Slope Sea in 2016 is 0.72 larvae per $100 \mathrm{~m}^{2}$. This is 
comparable to the larval abundance index estimates for the Gulf of Mexico between 1981 and 2015, which ranged from 0.11 to 1.2 with a mean of 0.51 (Ingram, 2018). However, the larval index in the Gulf of Mexico in 2016 was estimated at 2.47 larvae per $100 \mathrm{~m}^{2}$, the highest value estimated for the Gulf of Mexico since 1981 (Ingram, 2018). Estimates available for 1977 and 1978 are also quite high, 2.42 and 4.63 larvae per $100 \mathrm{~m}^{2}$, respectively (Ingram, 2018).

The scope of larval bluefin collections in the Slope Sea in 2016 - 207 larvae collected at 17 out of 79 bongo stations - align much better with collections from the major spawning grounds than with other scattered observations. For example, the Slope Sea larvae are often compared with a southeast U.S. cruise, which found 14 larvae at 10 stations out of 147 sampled stations (McGowan and Richards, 1989) or the surveys in Mexican waters near Campeche Bank which found 5 larvae at 4 stations out of sampling at 40 stations (Muhling et al., 2011). That is a 7\% positive station rate in the southeast U.S. region and a $10 \%$ positive rate in Mexican waters. We estimate a $21 \%$ positive station rate in the Slope Sea in 2016, which agrees well with the SEAMAP positive station rate of 0-30\% (mean of 15\%) between 1993 and 2009 (Domingues et al., 2016), and a 14\% positive station rate in the Balearic Sea surveys from 2001 to 2005 (Alemany et al., 2010). By several metrics, the distribution of bluefin larvae in the Slope Sea is comparable to the observations on the two other recognized major spawning grounds.

Our growth analyses, performed with the same reader analyzing otoliths from both the Slope Sea and the Gulf of Mexico from 2016, reveal that Slope Sea larvae grow at comparable rates to Gulf of Mexico larvae. Otolith analyses from bluefin larvae collected in the Balearic Sea in 2003-2005 estimated the growth rate at 0.35 to $0.41 \mathrm{~mm} \mathrm{day}^{-1}$, similar to the rates that we estimated for both the Slope Sea and Gulf of Mexico in 2016 (García et al., 2013). Another study of larval bluefin tuna 
growth analyzed larvae collected in the Gulf of Mexico in 2000-2012, and found a lower intercept ( 2.24 vs. $2.85 \mathrm{~mm})$ and higher slope ( 0.46 vs. $\left.0.37 \mathrm{~mm} \mathrm{day}^{-1}\right)$ as compared to our results from the Gulf of Mexico in 2016, for a similar size and age range of larvae (Malca et al., 2017). Data from an older study of bluefin tuna larvae collected in the Straits of Florida (Brothers et al., 1983) provides a larval growth estimate of approximately $0.27 \mathrm{~mm}^{-1 a y^{-1}}$ (McGowan and Richards, 1989). There may be inter-annual variability in larval growth conditions on the various spawning grounds, as has been shown in the Balearic Sea (García et al., 2013), but detailed studies of inter-annual variability in larval growth have not been published for the Gulf of Mexico. If growth conditions in the Gulf of Mexico were anomalously poor in 2016 (for example, due to the high larval abundance index), then our comparison of Slope Sea and Gulf of Mexico growth rates is incomplete. Therefore, we should increase our larval sampling in the Slope Sea to gain a more complete understanding of the typical larval growth conditions there.

Our otolith analyses also suggest that Slope Sea larvae are larger at the onset of exogenous feeding, using two different proxies. The intercept of the size-at-age relationship (Figure 4-2) and the otolith radius to the first increment (Figure 4-3B) were both found to be significantly higher in the Slope Sea than the Gulf of Mexico, regardless of whether we used a dataset including larvae with 0-8 increments or 04 increments. There are two possible mechanisms for a difference in larval size at hatching: temperature and maternal provisioning. Larval length at hatching for a given species decreases with increasing temperature (Peck et al., 2012). The average sea surface temperature at the time of collection for aged larvae from 2016 from the Slope Sea was $25.5^{\circ} \mathrm{C}$, and it was $27.0^{\circ} \mathrm{C}$ for aged larvae from the Gulf of Mexico. This temperature difference may be sufficient to account for the difference in size at hatching. On the other hand, larval size at hatching and growth before the onset of 
exogenous feeding also depend on the resources provided in the egg, which has been shown to be related to body condition of the mother (Chambers et al., 1989). The maternal condition and allocation of resources (both per-egg provisioning and total provisioning) to reproduction depend on size, recent food availability, and metabolic activity (Green, 2008). Increased maternal provisioning in Slope Sea larvae could indicate that spawning adults in the Slope Sea are in better condition than those in the Gulf of Mexico, and that the shorter spawning migration confers an advantage to the adults (Chapman et al., 2011). However, reproductive investment and offspring quality can also vary with maternal size or age (Green, 2008), so it is important that we identify the distribution of ages amongst bluefin tuna that spawn in the Slope Sea.

Although it was previously estimated that none of the larvae collected in the Slope Sea in 2013 could have been spawned in the Gulf of Mexico or the Straits of Florida (Richardson et al., 2016), it has been often repeated that larvae collected in the Slope Sea could easily be transported there from more southerly locations where small collections of larvae have been observed previously, such as the Straits of Florida (Brothers et al., 1983) and the Blake Plateau (McGowan and Richards, 1989). In this study, we simulate larval trajectories using a high-resolution circulation model for the Mid-Atlantic Bight and Gulf of Maine (MABGOM2), which was previously validated using hydrocast data from NOAA cruises (Rypina et al., 2019). We find that nearly all of the larvae collected in the Slope Sea in 2016 backtrack to locations north of Cape Hatteras on the estimated dates of spawning (Figure 4-4). When we simulated trajectories forward in time, we likewise found that nearly all larvae collected in the Slope Sea would have been retained within the Slope Sea domain (Figure 4-4). For both backward and forward tracking, the handful of trajectories that originate or end up outside of the Slope Sea correspond to larvae that were 
collected along the Gulf Stream front (Figure 4-7). Furthermore, larval collections in both 2013 and 2016 coincide well with spatial and temporal patterns of spawning habitat suitability predicted from particle tracking simulations with larval growth and retention criteria (Figure 4-1, Richardson et al., 2016; Rypina et al., 2019). This is strong evidence in support of repeated and predictable spawning activity by bluefin tuna in the Slope Sea.

It is imperative that we increase our studies of the Slope Sea to understand how bluefin tuna spawning in this region influences the ecology and population dynamics of this valuable stock. Ichthyoplankton sampling occurs routinely on the northeast U.S. shelf (Walsh et al., 2015) but plankton monitoring, and ship traffic in general, is limited beyond the shelf break. However, the spatial and temporal patterns of larval tuna distributions in the Slope Sea are reliable and can be used to inform future cruises (Figure 4-1, Richardson et al., 2016; Rypina et al., 2019). Additional years of larval bluefin collections will strengthen our understanding of age and growth and enable us to build a time series of the larval abundance index in the Slope Sea (Ingram et al., 2010; Scott et al., 1993). With multiple years of data, we can investigate inter-annual differences and test for relationships between metrics of growth and environmental conditions. There is a need for ecological work on the diets and zooplankton food availability for bluefin larvae in the Slope Sea, and comparisons with the other major spawning grounds (Llopiz and Hobday, 2015).

An important open question is the identity of the spawning adults in the Slope Sea. Are they western individuals that mature earlier than previously understood, or is there significant stock mixing occurring between eastern and western individuals? Bluefin in the Slope Sea should be sampled across a wide range of sizes for histological analyses to determine what sizes of bluefin are reproductively active in the region. Reproductively active individuals can also be tested for stock identity using otolith 
microchemistry (Rooker et al., 2008) or population genetics (Puncher et al., 2018; Rodríguez-Ezpeleta et al., 2019).

Atlantic bluefin tuna are an iconic commercial and sport fish that captivate human imaginations and taste buds. Climate change is threatening their ability to reproduce in the Gulf of Mexico, even if they were to shift their phenology (Muhling et al., 2015). Spawning in the Slope Sea may offer the species additional resilience in the face of both harvesting and climate change. If we hope to conserve this species and sustain the industries that depend on it, we must acknowledge Slope Sea spawning and integrate it into our understanding of the bluefin tuna life cycle and our management of stock dynamics. 


\subsection{Supplemental Information}

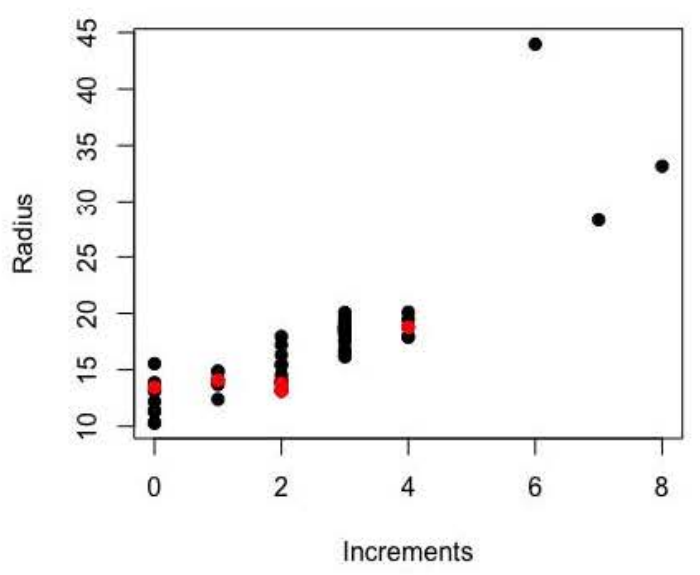

Figure 4-5: Using otolith size to determine if sampled otoliths include only sagittae. We plotted otolith radius against the number of daily increments. Measurements from larvae where we could not visually determine if we had sampled a sagittal otolith are highlighted in red. We determined that the two otoliths that are the smallest amongst otoliths with two daily increments should be excluded from further analyses. 


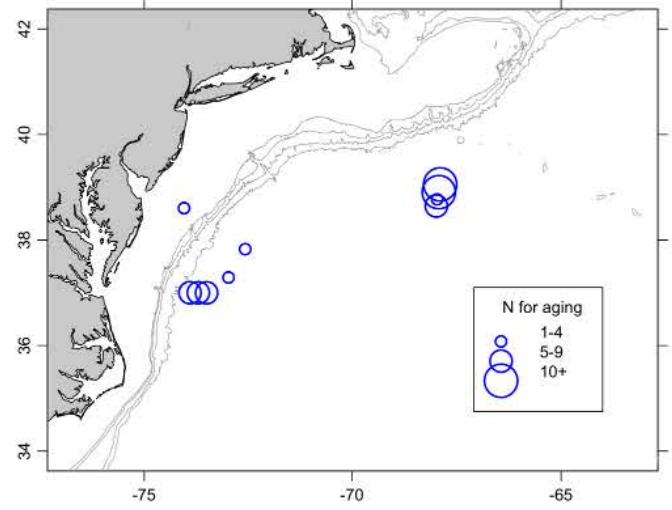

(a) Slope Sea

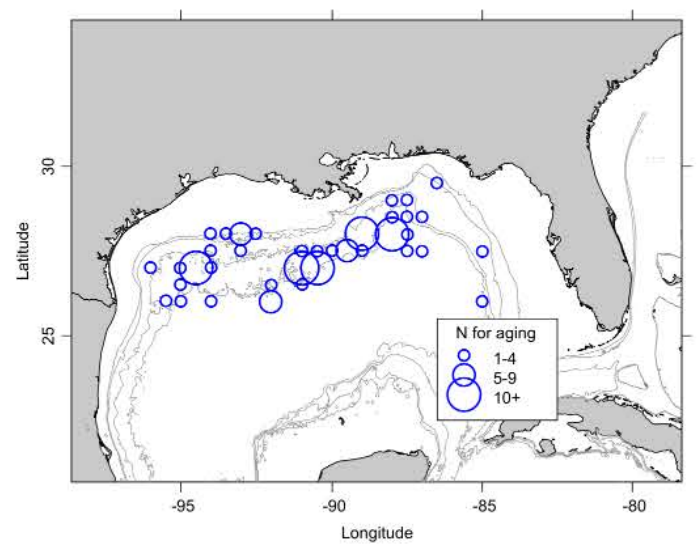

(b) Gulf of Mexico

Figure 4-6: Maps of larvae used in otolith analyses for (a) the Slope Sea and (b) the Gulf of Mexico. Circles, with size scaled to the number of aged larvae from each net, are plotted at the geographic collection location. Bathymetric contours at 100, 200, 1000 , and $2000 \mathrm{~m}$ depth are shown in light grey (accessed through GEBCO). 


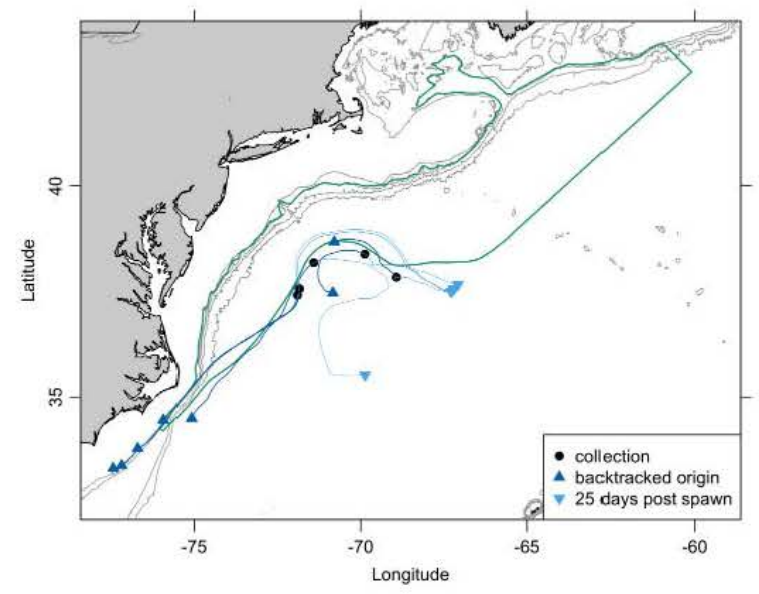

Figure 4-7: Subset of simulated trajectories for larvae that exit the model domain through the eastern boundary during forward tracking. Larval trajectories were simulated backwards in time to estimate spawning location, and forwards in time until the onset of directed swimming behavior. These 7 larval trajectories, corresponding to 5 collection locations, all exit the model domain before the forward tracking simulation completes. They were all collected in the vicinity of the north wall of the Gulf Stream near a persistent northward meander, and 5 of them (corresponding to 3 collection locations) have estimated spawning locations near Cape Hatteras. Circles show the collection sites, upward facing triangles plot the estimated spawning locations, and downward facing triangles plot the estimated location at the onset of directed swimming behavior. Bathymetric contours at 100, 200, 1000, and 2000 $m$ depth are shown in light grey (accessed through GEBCO). The green polygon is defined by the $200-\mathrm{m}$ isobath on the inshore side and the average position of the north wall of the Gulf Stream during the simulation period on the offshore side. We use this definition here to highlight the persistent meander that influences the trajectories included here. 


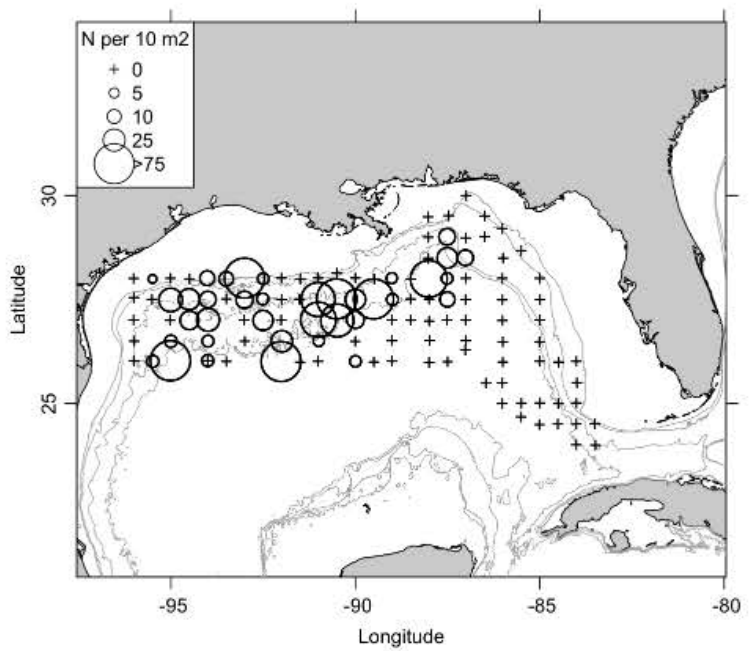

Figure 4-8: Abundance of Atlantic bluefin tuna larvae in the Gulf of Mexico in 2016. Abundance of Atlantic bluefin tuna (Thunnus thynnus) larvae, expressed as $\mathbf{n}$ per $10 \mathrm{~m}^{2}$. Data is shown for bongo samples collected with 333- $\mu \mathrm{m}$ mesh as part of the SEAMAP sampling program. Bathymetric contours at 100, 200, 1000, and $2000 \mathrm{~m}$ depth are shown in light grey (accessed through GEBCO). 
Table 4.1: Station information for collections of Atlantic bluefin tuna larvae in the Slope Sea in 2016. Three types of nets were used, indicated in the "Gear" column: "6B3" refers to the 61-cm bongo with $333-\mu \mathrm{m}$ mesh, "2B1" is the $20-\mathrm{cm}$ bongo with $165-\mu \mathrm{m}$ mesh, and "2N3" is the 2-by-1 m frame net with $333-\mu \mathrm{m}$ mesh. $\mathrm{N}$ is the number of bluefin tuna larvae identified from those net samples, with the number of aged larvae given in parentheses. Station abundance (in $\mathrm{n}$ per $10 \mathrm{~m}^{2}$ ) is listed for the 61-cm bongo samples.

\begin{tabular}{|c|c|c|c|c|c|c|c|c|c|}
\hline Cruise & Station & Date & Gear & $\begin{array}{c}\text { Latitude } \\
\left({ }^{\circ} \mathbf{N}\right)\end{array}$ & $\begin{array}{c}\text { Longitude } \\
\left({ }^{\circ} \mathbf{W}\right)\end{array}$ & $\begin{array}{l}\text { Bottom } \\
\text { Depth } \\
\text { (m) }\end{array}$ & $\begin{array}{l}\text { SST } \\
\left({ }^{\circ} \mathbf{C}\right)\end{array}$ & N (Aged) & $\begin{array}{c}\text { Abundance } \\
\text { (n per } \\
\left.10 \mathrm{~m}^{2}\right)\end{array}$ \\
\hline GU1608 & 224 & June-18-2016 & $6 \mathrm{~B} 3$ & 38.18 & 71.42 & 3061 & 23.54 & 1 & 0.80 \\
\hline GU1608 & 229 & June-19-2016 & $6 \mathrm{~B} 3$ & 37.83 & 72.57 & 2911 & 23.65 & $6(1)$ & 3.60 \\
\hline GU1608 & 231 & June-19-2016 & $6 \mathrm{~B} 3$ & 37.48 & 73.12 & 2916 & 24.26 & 2 & 1.58 \\
\hline GU1608 & 234 & June-19-2016 & 2B1 & 37.00 & 73.50 & 2862 & 25.98 & $2(2)$ & \\
\hline GU1608 & 234 & June-19-2016 & $6 \mathrm{B3}$ & 37.00 & 73.50 & 2862 & 25.98 & $23(3)$ & 13.53 \\
\hline GU1608 & 235 & June-19-2016 & $2 \mathrm{~B} 1$ & 37.00 & 73.70 & 2721 & 25.16 & 1 & \\
\hline GU1608 & 235 & June-19-2016 & $6 \mathrm{~B} 3$ & 37.00 & 73.70 & 2721 & 25.16 & $43(5)$ & 27.47 \\
\hline GU1608 & 236 & June-20-2016 & 2B1 & 37.00 & 73.90 & 2490 & 24.62 & $3(3)$ & \\
\hline GU1608 & 236 & June-20-2016 & $6 \mathrm{B3}$ & 37.00 & 73.90 & 2490 & 24.62 & $25(2)$ & 19.40 \\
\hline GU1608 & 240 & June-20-2016 & $6 \mathrm{~B} 3$ & 36.65 & 74.30 & 2037 & 26.7 & 1 & 0.71 \\
\hline HB1603 & 16 & July-1-2016 & $6 \mathrm{~B} 3$ & 37.41 & 71.91 & 3351 & 28.33 & 1 & 4.91 \\
\hline HB1603 & 17 & July-1-2016 & $2 \mathrm{~N} 3$ & 37.56 & 71.85 & 3284 & 24.56 & 3 & \\
\hline HB1603 & 21 & July-1-2016 & $2 \mathrm{~N} 3$ & 37.33 & 72.87 & 3049 & 27.92 & $2(2)$ & \\
\hline HB1603 & 36 & July-4-2016 & $6 \mathrm{~B} 3$ & 38.38 & 69.88 & 3529 & 28.05 & 1 & 3.32 \\
\hline HB1603 & 42 & July-6-2016 & $6 \mathrm{~B} 3$ & 37.84 & 68.93 & 4124 & 27.69 & 1 & 2.67 \\
\hline HB1603 & 50 & July-8-2016 & $2 \mathrm{~N} 3$ & 39.04 & 67.92 & 3724 & 25.56 & $49(13)$ & \\
\hline HB1603 & 50 & July-7-2016 & $6 \mathrm{~B} 3$ & 39.07 & 67.90 & 3629 & 25.62 & $3(3)$ & 6.27 \\
\hline HB1603 & 51 & July-8-2016 & 2N3 & 38.91 & 67.94 & 3793 & 25.56 & $20(9)$ & \\
\hline HB1603 & 51 & July-8-2016 & $6 \mathrm{~B} 3$ & 38.91 & 67.94 & 3805 & 25.56 & $4(1)$ & 17.90 \\
\hline $\mathrm{HB} 1603$ & 52 & July-8-2016 & $6 \mathrm{~B} 3$ & 38.78 & 67.98 & 4053 & 25.67 & $5(1)$ & 18.58 \\
\hline HB1603 & 53 & July-8-2016 & $6 \mathrm{~B} 3$ & 38.65 & 68.00 & 4170 & 25.85 & $7(6)$ & 24.11 \\
\hline HB1603 & 68 & July-12-2016 & $6 \mathrm{~B} 3$ & 38.61 & 74.04 & 55 & 24.57 & $1(1)$ & 1.92 \\
\hline HB1603 & 70 & July-13-2016 & $6 \mathrm{B3}$ & 39.38 & 71.69 & 2200 & 23.94 & 2 & 6.15 \\
\hline HB1603 & 125 & Aug-1-2016 & $6 \mathrm{B3}$ & 39.73 & 70.13 & 2058 & 26.13 & 1 & 2.76 \\
\hline
\end{tabular}




\section{Chapter 5}

\section{Conclusion}

When I set out to study oceanography, my goal was to focus on the early life stages of fish and how new studies of larvae could help us to improve fisheries management. What I have done is to build a diversity of skills, including field, laboratory, and modeling techniques, which combine to be greater than the sum of their parts. Likewise, this thesis may appear to combine three disparate studies, but their common thread is the investigation of larval fish in service of sustainable management.

In Chapter 2, I explored a novel trait-based approach to the study of population connectivity of coral reef fishes. Using a large dataset on the vertical distributions of coral reef fish, which encompassed a broad spatial and temporal scale, I investigated patterns of larval vertical distribution across taxa and across the larval period (using larval length as a proxy for age). As anyone who has studied life in the ocean might expect, there is a great diversity of larval behaviors across taxa. The ontogenetic vertical distribution patterns of the 14 families, 3 subfamilies, and 6 genera of coral reef fishes could be categorized into five behaviors: (1) a persistent association with surface waters throughout the larval phase; (2) downward ontogenetic vertical mi- 
gration, such as is classically associated with damselfishes (Pomacentridae) such as the bi-color damselfish Stegastes partitus (Paris and Cowen, 2004); (3) a relatively consistent depth preference throughout ontogeny; (4) a depth preference that widens with ontogeny; (5) no discernible depth preference. Importantly, there were also differences within a taxon, such as the unclear overall pattern for the family Labridae that is partially caused by the divergence between observed behaviors in the genus Xyrichtys from those in the genera Thalassoma and Halichoeres.

This comprehensive analysis of the vertical behaviors of larvae then yielded a small set of generalized trait-based inputs: (1) surface-dwelling throughout ontogeny, (2) no depth preference (evenly-distributed throughout ontogeny), and (3) a downward ontogenetic vertical migration (a composite of observations). The results reveal that dwelling below the water's surface does decrease dispersal distance, but that the evenly-distributed behavior had as strong of an effect on retention as did ontogenetic vertical migration behavior. In contrast to these overall results, there is much more nuance at local and regional scales, where surface-dwelling behavior sometimes leads to the greatest settlement at the natal habitat patch. In general, the impacts of behavior on dispersal distance, retention, and connectivity held for two pelagic larval durations that are typical of coral reef fishes.

The results that I presented in Chapter 2 confirm that hydrodynamics, the distribution of habitat patches, and larval traits (both PLD and larval behavior) form a complex interaction that determines larval dispersal and population connectivity. The work is novel in its scope and the generalized trait-based approach. It can be used directly by other scientists or managers that seek to estimate potential connectivity based on the traits of their species of interest. Future studies might use genetic or otolith microchemistry approaches to investigate the realized connectivity of species with similar traits. It can also serve as a template for future studies-by 
combining high-quality field data with an in-depth but generalized modeling analysis, we have gained insights that apply beyond a single species and location.

In Chapter 3, I demonstrated that ichthyoplankton sampling in a large, remote, no-take Marine Protected Area, the Phoenix Islands Protected Area, could allow us to infer adult use of the protected area. We used low-cost sampling efforts aboard an educational platform, the tall ship SSV Robert C. Seamans, to engage undergraduate students in both scientific and policy topics. Through this project, I learned how difficult it is to do fieldwork in the tropics (sample preservation is truly non-trivial at those temperatures), the extreme value of tuna species to island nations, and the urgent need for more ichthyoplankton sampling in the central tropical Pacific. Again, I combined field observations with individual-based modeling simulations to maximize the information that we can glean from limited sampling. In this case, the simulations were run backwards in time to identify the most likely locations where spawning would have occurred to generate our observed pattern of larval abundance. Through this, I was able to show that spawning occurs both inside and around the northeast corner of PIPA, for both taxa of interest and in all years that we examined.

The results presented in Chapter 3 are important to the government of the Republic of Kiribati as they decide how to manage PIPA in future years. Demonstrating that tuna spawn within the protected area is important for justifying ongoing closures. Our time series of tuna larvae is continuing to grow, since Sea Education Association has committed to running the Phoenix Islands course that enables this sampling at least through 2022. Time series analysis will help us investigate relationships among larval abundance, climate variables, and adult populations or fisheries yield. I am also hopeful that this work will inspire more ichthyoplankton sampling throughout the tropical Pacific. Larval tuna data across a larger area and across the annual cycle would enable studies of larval growth, population/stock structure, and 
the contribution to population dynamics of local/regional spawning activity or larval conditions. Together, these pieces of information can help fisheries managers, across the various small island nations that rely on tuna for food and income, to develop management strategies and improve their resilience to climate change impacts.

In Chapter 4, I dove deep into my interest in Atlantic bluefin tuna, a most iconic marine species. In some ways, our understanding of the population dynamics of this species has always depended on larvae. Spawning grounds have largely been identified through observations of larvae, because the high metabolism of bluefin restricts our ability to use histological gonad analyses to identify spawning time and location. And yet, the discovery of Atlantic bluefin tuna larvae in the Slope Sea in 2013 (Richardson et al., 2016) did not lead to widespread acceptance of this location as a "third major spawning ground." Similar to Chapter 3, sampling in the Slope Sea has been quite limited, with extensive sampling occurring in conjunction with marine mammal surveys in 2013 and 2016. In 2017, I participated in two additional cruises that took place at inopportune times or geographic locations - the only cruise specifically targeting bluefin tuna larvae occurred approximately one month too early. As such, my work focused on thoroughly analyzing the samples collected in 2016, which yielded 207 bluefin tuna larvae, 56 of which I used for otolith aging analyses. I also collaborated with Kathryn Shulzitski, formerly at NOAA's Southeast Fisheries Science Center, to analyze otoliths from 143 larvae collected in the Gulf of Mexico in 2016. While there have been previous studies that sought to use inter-reader calibrations to compare age and growth data between regions (Malca et al., 2017), this is the first study of Atlantic bluefin tuna that uses data from a single otolith reader to compare age, growth, and length data from two putative spawning grounds.

By several measures, the Slope Sea appears to conform to larval observations seen on the two widely recognized spawning grounds, the Gulf of Mexico and the 
Mediterranean Sea. The geographical and temporal extent of larval observations is comparable. Tuna larvae are often present in a highly patchy distribution, so although we have not yet observed very high abundance stations to match the other two spawning grounds, the larval abundance index for the Slope Sea in 2016 was at the higher end of the range of what has been observed in the Gulf of Mexico. My otolith analyses detected no difference in the daily growth rate between the Gulf of Mexico and the Slope Sea in 2016, and in fact indicated that Slope Sea larvae are larger at the onset of exogenous feeding. Slope Sea larvae start out slightly larger than Gulf of Mexico larvae, and then grow at essentially the same rate; in other words, conditions in the Slope Sea are sufficiently favorable for the growth and survival of bluefin tuna larvae spawned there. In this Chapter, I used both backward and forward tracking simulations to demonstrate that larvae collected in the Slope Sea were nearly all spawned in that region (north of Cape Hatteras) and that nearly all of them would have been retained to the west of the Gulf Stream by the onset of directed swimming. Taken together, these results suggest that Slope Sea larvae can contribute to the stock productivity of Atlantic bluefin tuna.

Future work on Atlantic bluefin tuna in the Slope Sea should focus on both adults and larvae. We need to invest in larval monitoring of that region in order to establish the relative abundance in the Gulf of Mexico and the Slope Sea. While I argue that the abundance in those two regions is comparable, sampling in the Gulf of Mexico occurs via a directed and systematic sampling program, a much more robust study method than the opportunistic sampling that occurs in the Slope Sea. Bluefin tuna management will benefit from an understanding of interannual variability in larval abundance and larval growth rates in both the Gulf of Mexico and the Slope Sea. Furthermore, there are important remaining questions about the age of individuals that spawn in the Slope Sea, and whether that region represents significant mixing 
between the Eastern and Western stocks - studies of adults (tagging, genetics, or histology) collected in the Slope Sea are the best way to answer these questions.

In addition to the specific suggestions for future extensions of the studies I have presented in this dissertation, I continue to be generally fascinated by the events surrounding reproduction of marine fish species. I wonder what role migration distance plays in the fecundity, maternal provisioning, and subsequent larval growth and survival for Atlantic bluefin tuna that spawn in the Gulf of Mexico or the Slope Sea. How do the energetics play out for other migratory species, such as the anadromous alewife (Alosa pseudoharengus) which are much smaller than bluefin tuna but must swim upstream while changing their physiology to cope with the transition to freshwater? Larval ecologists have historically focused on the role of extrinsic mechanisms such as temperature, food availability, predator abundance, and transport. What of intrinsic mechanisms, like genetic variation, epigenetic effects, or maternal provisioning? Unobserved (or unobservable, given the dispersion and rapid mortality of larval fish) variation may play a critically important role in demography and population dynamics of fishes, further complicating our attempts to relate recruitment with adult biomass.

In total, this dissertation reflects my training in fisheries oceanography and larval fish ecology, wherein I have combined multiple methods to arrive at robust results. In each study, I have combined field observations of larval fish with particle-tracking models. In each case, our results are relevant for population and ecosystem management, as well as deepening our ecological knowledge. At the close of this dissertation, I remain convinced that information on early life stages is critically important to the management of ocean resources, particularly in the face of the myriad anthropogenic impacts on marine ecosystems. 


\section{Chapter 6}

\section{References}

Aiken, C. M., \& Navarrete, S. A. (2011). Environmental fluctuations and asymmetrical dispersal: Generalized stability theory for studying metapopulation persistence and marine protected areas. Marine Ecology Progress Series, 428, 77-88. https://doi.org/10.3354/meps09079

Alemany, F., Quintanilla, L., Velez-Belchí, P., García, A., Cortés, D., Rodríguez, J. M., Fernández de Puelles, M. L., González-Pola, C., \& López-Jurado, J. L. (2010). Characterization of the spawning habitat of Atlantic bluefin tuna and related species in the Balearic Sea (western Mediterranean). Progress in Oceanography, 86(1-2), 21-38. https://doi.org/10.1016/j.pocean.2010.04.014

Andrade, C. A., Barton, E. D., \& Mooers, C. N. (2003). Evidence for an eastward flow along the Central and South American Caribbean coast. Journal of Geophysical Research C: Oceans, 108(6). https://doi.org/10.1029/2002jc001549

Andréfouët, S. (2008). Coral reef habitat mapping using remote sensing: A user vs producer perspective. implications for research, management and capacity building. Journal of Spatial Science, 53(1), 113-129. https://doi.org/10. $1080 / 14498596.2008 .9635140$

doi: $10.1080 / 14498596.2008 .9635140$

Arrizabalaga, H., Dufour, F., Kell, L., Merino, G., Ibaibarriaga, L., Chust, G., Irigoien, X., Santiago, J., Murua, H., Fraile, I., Chifflet, M., Goikoetxea, N., Sagarminaga, Y., Aumont, O., Bopp, L., Herrera, M., Marc Fromentin, J., \& Bonhomeau, S. (2015). Global habitat preferences of commercially valuable 
tuna. Deep-Sea Research Part II: Topical Studies in Oceanography, 113, 102112. https://doi.org/10.1016/j.dsr2.2014.07.001

Baglin, R. E. (1976). A preliminary study of the gonadal development and fecundity of the western Atlantic bluefin tuna. Collect. Vol. Sci. Pap. ICCAT, 5(2), 279-289. https://iccat.int/Documents/CVSP/CV005\%7B\%5C_\%7D1976/ no\%7B\%5C_\%7D2/CV005020279.pdf

Bell, J. D., Reid, C., Batty, M. J., Lehodey, P., Rodwell, L., Hobday, A. J., Johnson, J. E., \& Demmke, A. (2013). Effects of climate change on oceanic fisheries in the tropical Pacific: Implications for economic development and food security. Climatic Change, 119(1), 199-212. https://doi.org/10.1007/s10584-012-06062

Block, B. A., Dewar, H., Blackwell, S. B., Williams, T. D., Prince, E. D., Farwell, C. J., Boustany, A., Teo, S. L. H., Seitz, A., Walli, A., \& Fudge, D. (2001). Migratory movements, depth preferences, and thermal biology of Atlantic bluefin tuna. Science, 293(5533), 1310-1314. https://doi.org/10.1126/science. 1061197

Block, B. A., Teo, S. L. H., Walli, A., Boustany, A., Stokesbury, M. J. W., Farwell, C. J., Weng, K. C., Dewar, H., \& Williams, T. D. (2005). Electronic tagging and population structure of Atlantic bluefin tuna. Nature, 434(7037), 11211127. https://doi.org/10.1038/nature03463

Boehlert, G. W., \& Mundy, B. C. (1994). Vertical and onshore-offshore distributional patterns of tuna larvae in relation to physical habitat features. Marine Ecology Progress Series, 107(1-2), 1-14. https://doi.org/10.3354/meps107001

Boehlert, G. W., Watson, W., \& Sun, L. C. (1992). Horizontal and vertical distributions of larval fishes around an isolated oceanic island in the tropical Pacific. Deep-Sea Research, 39(3/4), 439-466.

Boerder, K., Bryndum-Buchholz, A., \& Worm, B. (2017). Interactions of tuna fisheries with the Galápagos marine reserve. Marine Ecology Progress Series, 585, 1-15. https://doi.org/10.3354/meps12399

Botsford, L. W., Hastings, A., \& Gaines, S. D. (2001). Dependence of sustainability on the configuration of marine reserves and larval dispersal distance. Ecology Letters, 4 (2), 144-150.

Brainard, R. E., Oliver, T., McPhaden, M. J., Cohen, A., Venegas, R., Heenan, A., Vargas-Ángel, B., Rotjan, R., Mangubhai, S., Flint, E., \& Hunter, S. A. (2018). Ecological impacts of the 2015/16 El Niño in the Central Equatorial Pacific [in "Explaining extreme events of 2016 from a climate perspective"]. Bulletin of the American Meteorological Society, 99(1), S21-S26. https://doi. org/10.1175/BAMS-D-17-0128.1 
Brochier, T., Lett, C., Tam, J., Fréon, P., Colas, F., \& Ayón, P. (2008). An individualbased model study of anchovy early life history in the northern Humboldt Current system. Progress in Oceanography, 79(2-4), 313-325. https://doi. org $/ 10.1016 / \mathrm{j}$.pocean.2008.10.004

Brothers, E. B., Williams, D., \& Sale, P. F. (1983). Length of larval life in twelve families of fishes at "One Tree Lagoon", Great Barrier Reef, Australia. Marine Biology, 76, 319-324.

Brothers, E. B., Mathews, C. P., \& Lasker, R. (1976). Daily growth increments in otoliths from larval and adult fishes. Fishery Bulletin, 74(1), 1-8. https: //doi.org/10.1006/jfbi.1993.1006

Burgess, S. C., Nickols, K. J., Griesemer, C. D., Barnett, L. A., Dedrick, A. G., Satterthwaite, E. V., Yamane, L., Morgan, S. G., White, J. W., \& Botsford, L. W. (2014). Beyond connectivity: How empirical methods can quantify population persistence to improve marine protected-area design. Ecological Applications, 24 (2), 257-270. https://doi.org/10.1890/13-0710.1

Butler, M. J., Paris, C. B., Goldstein, J. S., Matsuda, H., \& Cowen, R. K. (2011). Behavior constrains the dispersal of long-lived spiny lobster larvae. Marine Ecology Progress Series, 422, 223-237. https://doi.org/10.3354/meps08878

Cha, S. S., Mcgowan, M. F., \& Richards, W. J. (1994). Vertical distribution of fish larvae off the Florida Keys, 26 May - 5 June 1989. Bulletin of Marine Science, $54(3), 828-842$.

Chambers, R. C., Leggett, W. C., \& Brown, J. A. (1989). Egg size, female effects, and the correlations between early life history traits of capelin, Mallotus villosus: an appraisal at the individual level. Fishery Bulletin, 87(3), 515-523.

Chapman, E., Jørgensen, C., \& Lutcavage, M. (2011). Atlantic bluefin tuna (Thunnus thynnus): A state-dependent energy allocation model for growth, maturation, and reproductive investment. Can. J. Fish. Aquat. Sci., 68, 1934-1951. https: //doi.org/10.1139/F2011-109

Chow, S., Nakagawa, T., Suzuki, N., Takeyama, H., \& Matsunaga, T. (2006). Phylogenetic relationships among Thunnus species inferred from rDNA ITS1 sequence. Journal of Fish Biology, 68(SUPPL. 1), 24-35. https://doi.org/10. $1111 / \mathrm{j} .0022-1112.2006 .00945 . \mathrm{x}$

Cowen, R. K., \& Sponaugle, S. (2009). Larval dispersal and marine population connectivity. Ann Rev Mar Sci, 1, 443-466. https://doi.org/10.1146/annurev. marine.010908.163757

Cowen, R. K., Lwiza, K. M., Sponaugle, S., Paris, C. B., \& Olson, D. B. (2000). Connectivity of marine populations: Open or closed? Science, 287(5454), 857859. 
Cowen, R. K., Paris, C. B., \& Srinivasan, A. (2006). Scaling of connectivity in marine populations. Science, 311(5760), 522-527. https://doi.org/10.1126/science. 1122039

Cushing, D. H. (1990). Plankton production and year-class strength in fish populations: An update of the match/mismatch hypothesis. Advances in Marine Biology, 26(100), 249-293.

Di Lorenzo, M., Claudet, J., \& Guidetti, P. (2016). Spillover from marine protected areas to adjacent fisheries has an ecological and a fishery component. Journal for Nature Conservation, 32, 62-66. https://doi.org/10.1016/j.jnc.2016.04.004

Di Natale, A. (2017). Scientific needs for a better understanding of the Atlantic bluefin tuna (Thunnus thynnus) spawning areas using larval surveys. ICCAT, $73(7), 2255-2279$.

Diaz, G. A., \& Turner, S. C. (2007). Size frequency distribution analysis, age composition, and maturity of western bluefin tuna in the Gulf of Mexico from the US (1981-2005) and Japanese (1975-1981) longline fleets. ICCAT Collected Volume of Scientific Papers, 6(4), 1160-1170.

Domingues, R., Goni, G., Bringas, F., Muhling, B., Lindo-Atichati, D., \& Walter, J. (2016). Variability of preferred environmental conditions for Atlantic bluefin tuna (Thunnus thynnus) larvae in the Gulf of Mexico during 1993-2011. Fisheries Oceanography, 25(3), 320-336. https://doi.org/10.1111/fog.12152

Dueri, S., Bopp, L., \& Maury, O. (2014). Projecting the impacts of climate change on skipjack tuna abundance and spatial distribution. Global Change Biology, 20(3), 742-753. https://doi.org/10.1111/gcb.12460

Duffy, L. M., Kuhnert, P. M., Pethybridge, H. R., Young, J. W., Olson, R. J., Logan, J. M., Goñi, N., Romanov, E., Allain, V., Staudinger, M. D., Abecassis, M., Choy, C. A., Hobday, A. J., Simier, M., Galván-Magaña, F., Potier, M., \& Ménard, F. (2017). Global trophic ecology of yellowfin, bigeye, and albacore tunas: Understanding predation on micronekton communities at oceanbasin scales. Deep-Sea Research Part II: Topical Studies in Oceanography, 140(March), 55-73. https://doi.org/10.1016/j.dsr2.2017.03.003

Edwards, K. P., Hare, J. A., \& Werner, F. E. (2008). Dispersal of black sea bass (Centropristis striata) larvae on the southeast U.S. continental shelf: Results of a coupled vertical larval behavior - 3D circulation model. Fisheries Oceanography, 17(4), 299-315. https://doi.org/10.1111/j.1365-2419.2008.00480.x

Espinosa-Fuentes, M. d. l. L., Flores-Coto, C., Sanvicente-Añorve, L., \& ZavalaGarcía, F. (2009). Vertical distribution of zooplankton biomass and ichthyoplankton density during an annual cycle on the continental shelf of the south- 
ern Gulf of Mexico. Revista de biología marina y oceanografía, 44(2). https: //doi.org/10.4067/s0718-19572009000200020

Faillettaz, R., Paris, C. B., \& Irisson, J.-O. (2018). Larval fish swimming behavior alters dispersal patterns from marine protected areas in the north-western Mediterranean Sea. Frontiers in Marine Science, 5(March), 1-12. https:// doi.org/10.3389/fmars.2018.00097

Fonteneau, A., \& Hallier, J. P. (2015). Fifty years of dart tag recoveries for tropical tuna: A global comparison of results for the western Pacific, eastern Pacific, Atlantic, and Indian Oceans. Fisheries Research, 163, 7-22. https://doi.org/ 10.1016/j.fishres.2014.03.022

Fukuda, H., Torisawa, S., Sawada, Y., \& Takagi, T. (2010). Ontogenetic changes in schooling behaviour during larval and early juvenile stages of Pacific bluefin tuna Thunnus orientalis. Journal of Fish Biology, 76(7), 1841-1847. https: //doi.org/10.1111/j.1095-8649.2010.02598.x

Galuardi, B., \& Lutcavage, M. (2012). Dispersal routes and habitat utilization of juvenile Atlantic bluefin tuna, Thunnus thynnus, tracked with mini PSAT and archival tags. PLOS ONE, 7(5). https://doi.org/10.1371/journal.pone. 0037829

Galuardi, B., Royer, F., Golet, W., Logan, J., Neilson, J., \& Lutcavage, M. (2010). Complex migration routes of Atlantic bluefin tuna (Thunnus thynnus) question current population structure paradigm. Canadian Journal of Fisheries and Aquatic Sciences, 67(6), 966-976. https://doi.org/10.1139/F10-033

Ganachaud, A., Sen Gupta, A., Brown, J. N., Evans, K., Maes, C., Muir, L. C., \& Graham, F. S. (2013). Projected changes in the tropical Pacific ocean of importance to tuna fisheries. Climatic Change, 119(1), 163-179. https://doi. org/10.1007/s10584-012-0631-1

García, A., Cortés, D., Quintanilla, J., Rámirez, T., Quintanilla, L., Rodríguez, J. M., \& Alemany, F. (2013). Climate-induced environmental conditions influencing interannual variability of Mediterranean bluefin (Thunnus thynnus) larval growth. Fisheries Oceanography, 22(4), 273-287. https://doi.org/10.1111/ fog. 12021

GDP (Current US\$). (2018). https: / / data . worldbank .org/indicator/NY. GDP. MKTP.C

Goldstein, J., Heppell, S., Cooper, A., Brault, S., \& Lutcavage, M. (2007). Reproductive status and body condition of Atlantic bluefin tuna in the Gulf of Maine, 2000-2002. Marine Biology, 151(6), 2063-2075. https://doi.org/10.1007/ s00227-007-0638-8 
Green, B. S. (2008). Chapter 1: Maternal effects in fish populations, In Advances in marine biology. https://doi.org/10.1016/S0065-2881(08)00001-1

Guigand, C. M., Cowen, R. K., Llopiz, J. K., \& Richardson, D. E. (2005). A coupled asymmetrical multiple opening closing net with environmental sampling system. Marine Technology Society Journal, 39(2), 22-24.

Habtes, S., Muller-Karger, F. E., Roffer, M. A., Lamkin, J. T., \& Muhling, B. A. (2014). A comparison of sampling methods for larvae of medium and large epipelagic fish species during spring SEAMAP ichthyoplankton surveys in the Gulf of Mexico. Limnology and Oceanography: Methods, 12(Feb), 86-101. https://doi.org/10.4319/lom.2014.12.86

Halpern, B. S., Lester, S. E., \& Kellner, J. B. (2009). Spillover from marine reserves and the replenishment of fished stocks. Environmental Conservation, 36(4), 268-276. https://doi.org/10.1017/S0376892910000032

Hanich, Q., Rotjan, R., Aqorau, T., Bailey, M., Campbell, B., Gray, N., Gruby, R., Hampton, J., Ota, Y., Parris, H., Reid, C., Sumaila, U. R., \& Swartz, W. (2018). Unraveling the blue paradox: Incomplete analysis yields incorrect conclusions about Phoenix Islands Protected Area closure. Proceedings of the National Academy of Sciences, 115(52), E12122-E12123. https://doi.org/10. 1073/pnas. 1815600115

Hanski, I. (1998). Metapopulation dynamics. Nature, 396(6706), 41-49. https://doi. org $/ 10.1038 / 23876$

Hastings, A., \& Botsford, L. W. (2006). Persistence of spatial populations depends on returning home. Proceedings of the National Academy of Sciences of the United States of America, 103(15), 6067-6072. https://doi.org/10.1073/pnas. 0506651103

Hays, G. C., Mortimer, J. A., Ierodiaconou, D., \& Esteban, N. (2014). Use of longdistance migration patterns of an endangered species to inform conservation planning for the world's largest marine protected area. Conservation Biology, 28(6), 1636-1644. https://doi.org/10.1111/cobi.12325

Heinisch, G., Rosenfeld, H., Knapp, J. M., Gordin, H., \& Lutcavage, M. E. (2014). Sexual maturity in western Atlantic bluefin tuna. Scientific reports, 4, 7205. https://doi.org/10.1038/srep07205

Hernandez-Guerra, A., \& Joyce, T. M. (2000). Water masses and circulation in the surface layers of the Caribbean at $66^{\circ} \mathrm{W}$. Geophysical Research Letters, 27(21), 3497-3500. https://doi.org/10.1029/1999GL011230

Hjort, J. (1914). Fluctuations in the great fisheries of northern europe. Rapports et ProcésVerbaux des Réunions du Conseil Permanent International pour l'Exploration de la Mer, 20(1), 228. 
Hopkins, T. L. (1982). The vertical distribution of zooplankton in the eastern Gulf of Mexico. Deep Sea Research Part A, Oceanographic Research Papers, 29(9), 1069-1083. https://doi.org/10.1016/0198-0149(82)90028-0

Houde, E. D. (1989). Comparative growth, mortality, and energetics of marine fish larvae: Temperature and implied latitudinal effects. Fishery Bulletin, 87(3), 471-495. https://doi.org/10.1.1.475.1985\&rep=rep1

Houde, E. D. (1997). Patterns and trends in larval-stage growth and mortality of teleost fish. Journal of Fish Biology, 51 (sa), 52-83. https://doi.org/10.1111/ j.1095-8649.1997.tb06093.x

Hovestadt, T., Messner, S., \& Poethke, H. J. (2001). Evolution of reduced dispersal mortality and 'fat-tailed' dispersal kernels in autocorrelated landscapes. Proceedings of the Royal Society B: Biological Sciences, 268(1465), 385-391. https://doi.org/10.1098/rspb.2000.1379

Huebert, K. B., Cowen, R. K., \& Sponaugle, S. (2011). Vertical migrations of reef fish larvae in the Straits of Florida and effects on larval transport. Limnology and Oceanography, 56(5), 1653-1666. https://doi.org/10.4319/lo.2011.56.5.1653

Huebert, K. B., Sponaugle, S., \& Cowen, R. K. (2010). Predicting the vertical distributions of reef fish larvae in the Straits of Florida from environmental factors. Canadian Journal of Fisheries and Aquatic Sciences, 67(11), 17551767. https://doi.org/10.1139/F10-116

Iles, T. D., \& Sinclair, M. (1982). Atlantic herring: Stock discreteness and abundance. Science, 215(4533), 627-633. https://doi.org/10.1126/science.215.4533.627

Ingram, G. W. J. (2018). Annual indices of bluefin tuna (Thunnus thynnus) spawning biomass in the Gulf of Mexico (1977-2016). Collect. Vol. Sci. Pap. ICCAT, $74(6), 2751-2771$.

Ingram, G. W., Richards, W. J., Lamkin, J. T., \& Muhling, B. (2010). Annual indices of Atlantic bluefin tuna (Thunnus thynnus) larvae in the Gulf of Mexico developed using delta-lognormal and multivariate models. Aquatic Living Resources, 23(1), 35-47. https://doi.org/10.1051/alr/2009053

Irisson, J., Paris, C. B., Guigand, C., \& Planes, S. (2010). Vertical distribution and ontogenetic "migration" in coral reef fish larvae. Limnology and Oceanography, 55(2), 909-919.

Itano, D. G. (2000). The reproductive biology of yellowfin tuna (Thunnus albacares) in Hawaiian waters and the western tropical Pacific ocean: Project summary. SOEST 00-01 JIMAR Contribution 00-328 (Joint Institute of Marine and Atmospheric Research, University of Hawaii, Honolulu), 69pp.

Itoh, T., Shiina, Y., Tsuji, S., Endo, F., \& Tezuka, N. (2000). Otolith daily increment formation in laboratory reared larval and juvenile bluefin tuna Thunnus 
thynnus. Fisheries Science, 66(5), 834-839. https://doi.org/10.1046/j.14442906.2000.00135.x

Jensen, O. P., Ortega-Garcia, S., Martell, S. J. D., Ahrens, R. N. M., Domeier, M. L., Walters, C. J., \& Kitchell, J. F. (2010). Local management of a "highly migratory species": The effects of long-line closures and recreational catch-andrelease for Baja California striped marlin fisheries. Progress in Oceanography, 86(1-2), 176-186. https://doi.org/10.1016/j.pocean.2010.04.020

Johnson, G. C., Sloyan, B. M., Kessler, W. S., \& McTaggart, K. E. (2002). Direct measurements of upper ocean currents and water properties across the tropical Pacific during the 1990s. Progress in Oceanography, 52(1), 31-61. https:// doi.org/10.1016/S0079-6611(02)00021-6

JPL MUR SST. (2019). https://mur.jpl.nasa.gov/InformationText.php

Kane, J. (2007). Zooplankton abundance trends on Georges Bank, 1977-2004. ICES Journal of Marine Science, 64(5), 909-919. https://doi.org/10.1093/icesjms/ fsm066

Kerr, L. a., Cadrin, S. X., Secor, D. H., \& Taylor, N. (2013). A simulation tool to evaluate effects of mixing between Atlantic bluefin tuna stocks. Collective Volume of Scientific Papers ICCAT, 69(2), 742-759.

Koido, T., \& Suzuki, Z. (1989). Main spawning season of yellowfin tuna, Thunnus albacares, in the western tropical Pacific ocean based on the gonad index.

Kool, J. T., Paris, C. B., Andréfouët, S., \& Cowen, R. K. (2010). Complex migration and the development of genetic structure in subdivided populations: An example from Caribbean coral reef ecosystems. Ecography, 33(3), 597-606. https://doi.org/10.1111/j.1600-0587.2009.06012.x

Kough, A. S., Paris, C. B., \& Butler, M. J. (2013). Larval connectivity and the international management of fisheries. PLOS One, 8(6), e64970. https://doi. org/10.1371/journal.pone.0064970

Kough, A. S., \& Paris, C. B. (2015). The influence of spawning periodicity on population connectivity. Coral Reefs. https://doi.org/10.1007/s00338-015-1311-1

Lehodey, P., Bertignac, M., Hampton, J., Lewis, A., \& Picaut, J. (1997). El Niño Southern Oscillation and tuna in the western Pacific. Nature, 389(6652), 715718. https://doi.org/10.1038/39575

Lehodey, P., Senina, I., Sibert, J., Bopp, L., Calmettes, B., Hampton, J., \& Murtugudde, R. (2010). Preliminary forecasts of Pacific bigeye tuna population trends under the A2 IPCC scenario. Progress in Oceanography, 86(1-2), 302315. https://doi.org/10.1016/j.pocean.2010.04.021 
Lehodey, P., Senina, I., Calmettes, B., Hampton, J., \& Nicol, S. (2013). Modelling the impact of climate change on Pacific skipjack tuna population and fisheries. Climatic Change, 119(1), 95-109. https://doi.org/10.1007/s10584-012-0595-1

Leis, J. M. (1991). Vertical distribution of fish larvae in the Great Barrier Reef Lagoon, Australia. Marine Biology, 109(1), 157-166. https://doi.org/10. $1007 / \mathrm{BF} 01320243$

Leis, J. M. (2006). Are larvae of demersal fishes plankton or nekton? Advances in Marine Biology, 51, 57-141. https://doi.org/10.1016/S0065-2881(06)51002-8

Leis, J. M., Trnski, T., Vivien, M. H., Renon, J., Dufour, V., Moudni, K. E., \& Galzin, R. (1991). High concentrations of tuna larvae (Pisces: Scombridae) in near-reef waters of French Polynesia (Society and Tuamotu Islands), 48(1), $150-158$.

Llopiz, J. K. (2008). The trophic ecologies of larval billfishes, tunas, and coral reef fishes in the Straits of Florida: Piscivory, selectivity, and niche separation (Doctoral dissertation).

Llopiz, J. K., \& Cowen, R. K. (2008). Precocious, selective and successful feeding of larval billfishes in the oceanic Straits of Florida. Marine Ecology Progress Series, 358(Robertson 1991), 231-244. https://doi.org/10.3354/meps07320

Llopiz, J. K., \& Hobday, A. J. (2015). A global comparative analysis of the feeding dynamics and environmental conditions of larval tunas, mackerels, and billfishes. Deep-Sea Research Part II: Topical Studies in Oceanography, 113, 113-124. https://doi.org/10.1016/j.dsr2.2014.05.014

Llopiz, J. K., Richardson, D., Shiroza, A., Smith, S., \& Cowen, R. (2010). Distinctions in the diets and distributions of larval tunas and the important role of appendicularians. Limnology and Oceanography, 55(3), 983-996. https: //doi.org/10.4319/lo.2010.55.3.0983

Lutcavage, M. E., Brill, R. W., Skomal, G. B., Chase, B. C., \& Howey, P. W. (1999). Results of pop-up satellite tagging of spawning size class fish in the Gulf of Maine: Do North Atlantic bluefin tuna spawn in the mid-Atlantic? Canadian Journal of Fisheries and Aquatic Sciences, 56(2), 173-177. https://doi.org/ DOI10.1139/cjfas-56-2-173

Malca, E., Muhling, B., Franks, J., García, A., Tilley, J., Gerard, T., Ingram, W., \& Lamkin, J. T. (2017). The first larval age and growth curve for bluefin tuna (Thunnus thynnus) from the Gulf of Mexico: Comparisons to the Straits of Florida, and the Balearic Sea (Mediterranean). Fisheries Research, 190, 2433. https://doi.org/10.1016/j.fishres.2017.01.019 
Margulies, D., Suter, J. M., Hunt, S. L., Olson, R. J., Scholey, V. P., Wexler, J. B., \& Nakazawa, A. (2007). Spawning and early development of captive yellowfin tuna (Thunnus albacares). Fishery Bulletin, 105, 249-265.

Martínez, S., Carrillo, L., \& Marinone, S. G. (2019). Potential connectivity between marine protected areas in the Mesoamerican Reef for two species of virtual fish larvae: Lutjanus analis and Epinephelus striatus. Ecological Indicators, 102(November 2018), 10-20. https://doi.org/10.1016/j.ecolind.2019.02.027

Mather, F. J., Mason, J. M. J., \& Jones, A. C. (1995). Historical document: Life history and fisheries of Atlantic bluefin tuna. NOAA Technical Memorandum, NMFS-SEFSC, 405.

Matsumoto, W. (1958). Description and distribution of larvae of four species of tuna in central Pacific waters. Fish.Bull.U.S.Fish Wild.Serv, 58(128), 31-72.

Mccauley, D. J., Woods, P., Sullivan, B., Bergman, B., Jablonicky, C., Roan, A., Hirshfi, M., \& Boerder, K. (2016). Ending hide and seek at sea. Science, 351 (6278), 1148-1150. https://doi.org/10.1126/science.aad5686

McGowan, M. F., \& Richards, W. J. (1989). Bluefin tuna, Thunnus thynnus, larvae in the Gulf Stream off the southeastern United States: Satellite and shipboard observations of their environment. Fishery Bulletin, 87(3), 615-631.

Miller, T. J., Crowder, L. B., Rice, J. A., \& Marschall, E. A. (1988). Larval size and recruitment mechanisms in fishes: toward a conceptual framework. Canadian Journal of Fisheries and Aquatic Sciences, 45(9), 1657-1670. https://doi. org $/ 10.1139 / \mathrm{f} 88-197$

Ministry of Finance and Economic Development, \& Ministry of Fisheries and Marine Resource Development. (2016). Fishing license revenues in Kiribati: 2016 report, (August), 1-14.

Mora, C., Treml, E. A., Roberts, J., Crosby, K., Roy, D., \& Tittensor, D. P. (2012). High connectivity among habitats precludes the relationship between dispersal and range size in tropical reef fishes. Ecography, 35(1), 89-96. https://doi. org $/ 10.1111 / \mathrm{j} .1600-0587.2011 .06874 . \mathrm{x}$

Muhling, B. A., Lee, S.-K., Lamkin, J. T., \& Liu, Y. (2011). Predicting the effects of climate change on bluefin tuna (Thunnus thynnus) spawning habitat in the Gulf of Mexico. ICES Journal of Marine Science, 68(6), 1051-1062. https: //doi.org/10.1093/icesjms/fsr008

Muhling, B. A., Lamkin, J. T., \& Roffer, M. A. (2010). Predicting the occurrence of atlantic bluefin tuna (thunnus thynnus) larvae in the northern gulf of mexico: Building a classification model from archival data. Fisheries Oceanography, 19(6), 526-539. https://doi.org/10.1111/j.1365-2419.2010.00562.x 
Muhling, B. A., Liu, Y., Lee, S.-K., Lamkin, J. T., Roffer, M. A., Muller-Karger, F., \& Walter, J. F. (2015). Potential impact of climate change on the IntraAmericas Sea: Part 2. Implications for Atlantic bluefin tuna and skipjack tuna adult and larval habitats. Journal of Marine Systems, 148, 1-13. https: //doi.org/10.1016/j.jmarsys.2015.01.010

Multivariate ENSO Index Version 2 (MEI.v2). (2019). https://www.esrl.noaa.gov/ psd/enso/mei/

Naro-Maciel, E., Arengo, F., Galante, P., Vintinner, E., Holmes, K. E., Balazs, G., \& Sterling, E. J. (2018). Marine protected areas and migratory species: Residency of green turtles at Palmyra Atoll, Central Pacific. Endangered Species Research, 37, 165-182. https://doi.org/10.3354/esr00922

NASA Goddard Space Flight Center, Ocean Ecology Laboratory, \& O. B. P. G. (2014a). Moderate-resolution Imaging Spectroradiometer (MODIS) Aqua Inherent Optical Properties Data; 2014 Reprocessing. https://doi.org/10.5067/ AQUA/MODIS/L2/IOP/2014

NASA Goddard Space Flight Center, Ocean Ecology Laboratory, \& O. B. P. G. (2014b). Visible and infrared imager/radiometer suite (viirs) chlorophyll data; 2014 reprocessing. https://doi.org/10.5067/NPP/VIIRS/L3B/CHL/2014

Niño 3.4 SST Index. (2019). https://www.esrl.noaa.gov/psd/gcos_wgsp/Timeseries/ Nino34/

Nishikawa, Y., Honma, M., Ueyanagi, S., \& Kikawa, S. (1985). Average distribution of larvae of oceanic species of scombroid fishes, 1956-1981. Bulletin of Far Seas Fisheries Research Laboratory $S$ series, 12, 99 pp.

Nishikawa, Y., \& Rimmer, D. W. (1987). Identification of larval tunas, billfishes and other scombroid fishes (Suborder Scombroidei): An illustrated guide.

Paris, C. B., Cherubin, L. M., \& Cowen, R. K. (2007). Surfing, spinning, or diving from reef to reef: Effects on population connectivity. Marine Ecology Progress Series, 347, 285-300. https://doi.org/10.3354/meps06985

Paris, C. B., \& Cowen, R. K. (2004). Direct evidence of a biophysical retention mechanism for coral reef fish larvae. Limnology and Oceanography, 49(6), 1964-1979. https://doi.org/10.4319/1o.2004.49.6.1964

Paris, C. B., Cowen, R. K., Claro, R., \& Lindeman, K. C. (2005). Larval transport pathways from Cuban snapper (Lutjanidae) spawning aggregations based on biophysical modeling. Marine Ecology Progress Series, 296(93-106), 93-106. https://doi.org/10.3354/meps296093

Paris, C. B., Helgers, J., van Sebille, E., \& Srinivasan, A. (2013). Connectivity modeling system: A probabilistic modeling tool for the multi-scale tracking of biotic 
and abiotic variability in the ocean. Environmental Modelling \& Software, 42, 47-54. https://doi.org/10.1016/j.envsoft.2012.12.006

Peck, M. A., Huebert, K. B., \& Llopiz, J. K. (2012). Intrinsic and extrinsic factors driving match-mismatch dynamics during the early life history of marine fishes (1st ed.). Advances in Ecological Research, 47, 177-302. https://doi.org/10. 1016/B978-0-12-398315-2.00003-X

Petrik, C. M., Duffy-Anderson, J. T., Castruccio, F., Curchitser, E. N., Danielson, S. L., Hedstrom, K., \& Mueter, F. (2016). Modelled connectivity between Walleye Pollock (Gadus chalcogrammus) spawning and age-0 nursery areas in warm and cold years with implications for juvenile survival. ICES Journal of Marine Science: Journal du Conseil, 73(7), 1890-1900. https://doi.org/10. 1093/icesjms/fsw004

Pineda, J., Hare, J., \& Sponaugle, S. (2007). Larval transport and dispersal in the coastal ocean and consequences for population connectivity. Oceanography, 20(3), 22-39. https://doi.org/10.5670/oceanog.2007.27

Puncher, G. N., Cariani, A., Maes, G. E., Van Houdt, J., Herten, K., Cannas, R., Rodriguez-Ezpeleta, N., Albaina, A., Estonba, A., Lutcavage, M., Hanke, A., Rooker, J., Franks, J. S., Quattro, J. M., Basilone, G., Fraile, I., Laconcha, U., Goñi, N., Kimoto, A., ... Tinti, F. (2018). Spatial dynamics and mixing of bluefin tuna in the Atlantic Ocean and Mediterranean Sea revealed using nextgeneration sequencing. Molecular Ecology Resources, 18(3), 620-638. https: //doi.org/10.1111/1755-0998.12764

Radtke, R. L. (1983). Otolith formation and increment deposition in laboratory reared skipjack tuna, Euthynnus pelamis, larvae. Proceedings of the International Workshop on Age Determination of Oceanic Pelagic Fishes: Tunas, Billfishes, and Sharks, 8(December), 99-103.

Reglero, P., Blanco, E., Alemany, F., Ferrá, C., Alvarez-Berastegui, D., Ortega, A., de la Gándara, F., Aparicio-González, A., \& Folkvord, A. (2018a). Vertical distribution of Atlantic bluefin tuna Thunnus thynnus and bonito Sarda sarda larvae is related to temperature preference. Marine Ecology Progress Series, 594, 231-243. https://doi.org/10.3354/meps12516

Reglero, P., Ortega, A., Balbín, R., Abascal, F. J., Medina, A., Blanco, E., de la Gándara, F., Alvarez-Berastegui, D., Hidalgo, M., Rasmuson, L., Alemany, F., \& Fiksen, $\varnothing$. (2018b). Atlantic bluefin tuna spawn at suboptimal temperatures for their offspring. Proceedings of the Royal Society B: Biological Sciences, 285(1870), 20171405. https://doi.org/10.1098/rspb.2017.1405

Reglero, P., Tittensor, D. P., Álvarez-Berastegui, D., Aparicio-González, A., \& Worm, B. (2014). Worldwide distributions of tuna larvae: Revisiting hypotheses on 
environmental requirements for spawning habitats. Marine Ecology Progress Series, 501, 207-224. https://doi.org/10.3354/meps10666

Richards, W. J., \& Potthoff, T. (1974). Analysis of the taxonomic characters of young scombrid fishes, genus Thunnus (J. H. S. Blaxter, Ed.). In J. H. S. Blaxter (Ed.), The early life history of fish, Berlin, Heidelberg, Springer Berlin Heidelberg.

Richards, W. J. (2005). Early stages of Atlantic fishes: An identification guide for the western central north Atlantic (1st). CRC Press.

Richardson, A. J., Downes, K. J., Nolan, E. T., Brickle, P., Brown, J., Weber, N., \& Weber, S. B. (2018). Residency and reproductive status of yellowfin tuna in a proposed large-scale pelagic marine protected area. Aquatic Conservation: Marine and Freshwater Ecosystems, (July). https://doi.org/10.1002/aqc.2936

Richardson, D. E., Marancik, K. E., Guyon, J. R., Lutcavage, M. E., Galuardi, B., Lam, C. H., Walsh, H. J., Wildes, S., Yates, D. A., \& Hare, J. A. (2016). Discovery of a spawning ground reveals diverse migration strategies in Atlantic bluefin tuna (Thunnus thynnus). Proceedings of the National Academy of Sciences, 201525636. https://doi.org/10.1073/pnas.1525636113

Richardson, D. E., Vanwye, J. D., Exum, A. M., Cowen, R. K., \& Crawford, D. L. (2007). High-throughput species identification: From DNA isolation to bioinformatics. Molecular Ecology Notes, 7(2), 199-207. https://doi.org/10.1111/ j.1471-8286.2006.01620.x

Rodríguez-Ezpeleta, N., Díaz-Arce, N., Walter, J. F., Richardson, D. E., Rooker, J. R., Nøttestad, L., Hanke, A. R., Franks, J. S., Deguara, S., Lauretta, M. V., Addis, P., Varela, J. L., Fraile, I., Goñi, N., Abid, N., Alemany, F., Oray, I. K., Quattro, J. M., Sow, F. N., ... Arrizabalaga, H. (2019). Determining natal origin for improved management of Atlantic bluefin tuna. Frontiers in Ecology and the Environment, 17(8), 439-444. https://doi.org/10.1002/fee.2090

Rooker, J. R., Arrizabalaga, H., Fraile, I., Secor, D. H., Dettman, D. L., Abid, N., Addis, P., Deguara, S., Karakulak, F. S., Kimoto, A., Sakai, O., Macías, D., \& Santos, M. N. (2014). Crossing the line: Migratory and homing behaviors of Atlantic bluefin tuna. Marine Ecology Progress Series, 504, 265-276. https: //doi.org/10.3354/meps10781

Rooker, J. R., David Wells, R. J., Itano, D. G., Thorrold, S. R., \& Lee, J. M. (2016). Natal origin and population connectivity of bigeye and yellowfin tuna in the Pacific ocean. Fisheries Oceanography, 25(3), 277-291. https://doi.org/10. 1111/fog. 12154 
Rooker, J. R., Secor, D. H., de Metrio, G., Schloesser, R., Block, B. A., \& Neilson, J. D. (2008). Natal homing and connectivity in Atlantic bluefin tuna populations. Science, 322(5902), 742-744. https://doi.org/10.1126/science.1161473

Ross, R. E., Nimmo-Smith, W. A. M., \& Howell, K. L. (2017). Towards 'ecological coherence': Assessing larval dispersal within a network of existing marine protected areas. Deep-Sea Research Part I: Oceanographic Research Papers, 126(May), 128-138. https://doi.org/10.1016/j.dsr.2017.06.004

Rotjan, R., Jamieson, R., Carr, B., Kaufman, L., Mangubhai, S., Obura, D., Pierce, R., Rimon, B., Ris, B., Sandin, S., Shelley, P., Sumaila, U. R., Taei, S., Tausig, H., Teroroko, T., Thorrold, S., Wikgren, B., Toatu, T., \& Stone, G. (2014). Establishment, management, and maintenance of the Phoenix Islands Protected Area. Advances in Marine Biology, 69, 289-324. https://doi.org/10. 1016/B978-0-12-800214-8.00008-6

Rypina, I. I., Chen, K., Hernández, C. M., Pratt, L. J., \& Llopiz, J. K. (2019). Investigating the suitability of the Slope Sea for Atlantic bluefin tuna spawning using a high-resolution ocean circulation model. ICES Journal of Marine Science. https://doi.org/10.1093/icesjms/fsz079

Rypina, I. I., Llopiz, J. K., Pratt, L. J., \& Susan Lozier, M. (2014). Dispersal pathways of American eel larvae from the Sargasso Sea. Limnology and Oceanography, 59(5), 1704-1714. https://doi.org/10.4319/lo.2014.59.5.1704

Safina, C. (2016). Data do not support new claims about bluefin tuna spawning or abundance. Proceedings of the National Academy of Sciences of the United States of America, 113(30), E4261. https://doi.org/10.1073/pnas.1606077113

Schaefer, K. M., Fuller, D. W., \& Miyabe, N. (2005). Reproductive biology of bigeye tuna (Thunnus obesus) in the Eastern and Central Pacific Ocean. IATTC Bulletin, 23(1).

Schaefer, K. M. (1998). Reproductive biology of yellowfin tuna (Thunnus albacares) in the eastern Pacific ocean. Inter-American Tropical Tuna Commission Bulletin, 21(5).

Schaefer, K. M., \& Fuller, D. W. (2010). Vertical movements, behavior, and habitat of bigeye tuna (Thunnus obesus) in the equatorial eastern Pacific ocean, ascertained from archival tag data. Marine Biology, 157(12), 2625-2642. https: //doi.org/10.1007/s00227-010-1524-3

Schaefer, K. M., Fuller, D. W., \& Block, B. A. (2011). Movements, behavior, and habitat utilization of yellowfin tuna (Thunnus albacares) in the Pacific ocean off Baja California, Mexico, determined from archival tag data analyses, including unscented Kalman filtering. Fisheries Research, 112(1-2), 22-37. https: //doi.org/10.1016/j.fishres.2011.08.006 
Schaefer, K., Fuller, D., Hampton, J., Caillot, S., Leroy, B., \& Itano, D. (2015). Movements, dispersion, and mixing of bigeye tuna (Thunnus obesus) tagged and released in the equatorial central Pacific ocean, with conventional and archival tags. Fisheries Research, 161, 336-355. https://doi.org/10.1016/j. fishres.2014.08.018

Scott, G. P., Turner, S. C., Grimes, C. B., Richards, W. J., \& Brothers, E. B. (1993). Indices of larval bluefin tuna, Thunnus thynnus, abundance in the Gulf of Mexico; modelling variability in growth, mortality, and gear selectivity. Bulletin of Marine Science, 53(2), 912-929.

Selkoe, K. A., Gaggiotti, O. E., Bowen, B. W., \& Toonen, R. J. (2014). Emergent patterns of population genetic structure for a coral reef community. Molecular Ecology, 23(12), 3064-3079. https://doi.org/10.1111/mec.12804

Sponaugle, S., \& Cowen, R. K. (1997). Early life history traits and recruitment patterns of Caribbean wrasses (Labridae). Ecological Monographs, 67(2), 177202.

Sponaugle, S., \& Cowen, R. K. (1996). Larval supply and patterns of recruitment for two Caribbean reef fishes, Stegastes partitus and Acanthurus bahianus. Marine and Freshwater Research, 47(2), 433-447. https://doi.org/10.1071/ MF9960433

Sponaugle, S., Cowen, R. K., Shanks, A., Morgan, S. G., Leis, J. M., Pineda, J., Boehlert, G. W., Kingsford, M. J., Lindeman, K. C., Grimes, C., \& Munro, J. L. (2002). Predicting self-recruitment in marine populations: Biophysical correlates and mechanisms. Bulletin of Marine Science, 70(Suppl.1), 341-375.

Sponaugle, S., Llopiz, J. K., Havel, L. N., \& Rankin, T. L. (2009). Spatial variation in larval growth and gut fullness in a coral reef fish. Marine Ecology Progress Series, 383, 239-249. https://doi.org/10.3354/meps07988

Staaterman, E., Paris, C. B., \& Helgers, J. (2012). Orientation behavior in fish larvae: A missing piece to Hjort's critical period hypothesis. Journal of Theoretical Biology, 304, 188-196. https://doi.org/10.1016/j.jtbi.2012.03.016

Strasburg, D. (1960). Estimates of larval tuna abundance in the central Pacific. Fish.Bull.U.S.Fish Wildl.Serv, 60(167), 231-255.

Strathmann, R. R., Hughes, T. P., Kuris, A. M., Lindeman, K. C., Morgan, S. G., Pandolfi, J. M., \& Warner, R. R. (2002). Evolution of local recruitment and its consequences for marine populations. Bulletin of Marine Science, 70(Suppl.1), 377-396.

Sundelöf, A., \& Jonsson, P. R. (2012). Larval dispersal and vertical migration behaviour - a simulation study for short dispersal times. Marine Ecology, 33(2), 183-193. https://doi.org/10.1111/j.1439-0485.2011.00485.x 
Swearer, S. E., Treml, E. A., \& Shima, J. S. (2019). A review of biophysical models of marine larval dispersal. Oceanography and Marine Biology: An Annual Review, 57, 325-356. https://doi.org/10.1201/9780429026379-7

Tang, L., Sheng, J., Hatcher, B. G., \& Sale, P. F. (2006). Numerical study of circulation, dispersion, and hydrodynamic connectivity of surface waters on the Belize shelf. Journal of Geophysical Research: Oceans, 111(1), 1-18. https: //doi.org/10.1029/2005JC002930

Thompson, A. R., Chen, D. C., Guo, L. W., Hyde, J. R., \& Watson, W. (2017). Larval abundances of rockfishes that were historically targeted by fishing increased over 16 years in association with a large marine protected area. Royal Society Open Science, 4(9). https://doi.org/10.1098/rsos.170639

Thrush, S. F., Hewitt, J. E., Lohrer, A. M., \& Chiaroni, L. D. (2013). When small changes matter: The role of cross-scale interactions between habitat and ecological connectivity in recovery. Ecological Applications, 23(1), 226-238. https: //doi.org/10.1890/12-0793.1

Truelove, N. K., Kough, A. S., Behringer, D. C., Paris, C. B., Box, S. J., Preziosi, R. F., \& Butler, M. J. (2017). Biophysical connectivity explains population genetic structure in a highly dispersive marine species. Coral Reefs, 36(1), 233-244. https://doi.org/10.1007/s00338-016-1516-y

Ueyanagi, S. (1969). Observations on the distribution of tuna larvae in the IndoPacific ocean with emphasis on the delineation of the spawning areas of albacore, Thunnus alalunga. Bull Far Seas Fish Res Lab, 2, 177-256.

Vaz, A. C., Paris, C. B., Olascoaga, M. J., Kourafalou, V. H., Kang, H., \& Reed, J. K. (2016). The perfect storm: Match-mismatch of bio-physical events drives larval reef fish connectivity between Pulley Ridge mesophotic reef and the Florida Keys. Continental Shelf Research, 125(August), 136-146. https://doi.org/10. 1016/j.csr.2016.06.012

Venegas, R., Oliver, T., Brainard, R. E., Santos, M., Geronimo, R., \& Widlansky, M. (2018). Climate-induced vulnerability of fisheries in the Coral Triangle: Skipjack tuna thermal spawning habitats. Fisheries Oceanography, 28(2), 117130. https://doi.org/10.1111/fog. 12390

Victor, B. C. (1986). Duration of the planktonic larval stage of one hundred species of Pacific and Atlantic wrasses. Marine Biology, 90, 317-326.

Walsh, H. J., Richardson, D. E., Marancik, K. E., \& Hare, J. A. (2015). Long-term changes in the distributions of larval and adult fish in the northeast U.S. shelf ecosystem. PLoS ONE, 10(9), 1-31. https://doi.org/10.1371/journal.pone. 0137382 
Walter, J. F., Porch, C. E., Lauretta, M. V., Cass-calay, S. L., \& Brown, C. A. (2016). Implications of alternative spawning for bluefin tuna remain unclear, 113(30), 4259-4260. https://doi.org/10.1073/pnas.1605962113

Waser, P. M. (1985). Does competition drive dispersal? Ecology, 66(4), 1170-1175. https://doi.org/10.2307/1939169

Watson, J. R., Siegel, D. A., Kendall, B. E., Mitarai, S., Rassweiller, A., \& Gaines, S. D. (2011). Identifying critical regions in small-world marine metapopulations. Proceedings of the National Academy of Sciences, 108(43), E907-E913. https://doi.org/10.1073/pnas.1111461108

Werner, F. E., Cowen, R. K., \& Paris, C. B. (2007). Coupled biological and physical models: Present capabilities and future developments for future studies of population connectivity. Oceanography, 20(3).

Western and Central Pacific Fisheries Commission. (2018). Tuna fishery yearbook 2017.

Wexler, J. B., Margulies, D., Masuma, S., Tezuka, N., Teruya, K., Oka, M., Kanematsu, M., \& Nikaido, H. (2001). Age validation and growth of yellowfin tuna, Thunnus albacares, larvae reared in the laboratory. Bulletin of the InterAmerican Tropical Tuna Commission, IATTC, (January 2001).

Wiebe, P. H., Burt, K. H., Boyd, S. H., \& Morton, A. W. (1976). A multiple opening/closing net and environmental sensing system for sampling zooplankton. Journal of Marine Research, 34(3), 313-326.

Witkin, T., Reyer, A., \& Savitz, J. (2016). Global fishing watch reveals a fisheries management success in the Phoenix Islands. Oceana, 1-20. http:// globalfishingwatch.org/

Yannicelli, B., Castro, L., Parada, C., Schneider, W., Colas, F., \& Donoso, D. (2012). Distribution of Pleuroncodes monodon larvae over the continental shelf of south-central Chile: Field and modeling evidence for partial local retention and transport. Progress in Oceanography, 92-95, 206-227. https://doi.org/10. 1016/j.pocean.2011.07.005

Yúfera, M., Ortiz-Delgado, J. B., Hoffman, T., Siguero, I., Urup, B., \& Sarasquete, C. (2014). Organogenesis of digestive system, visual system and other structures in Atlantic bluefin tuna (Thunnus thynnus) larvae reared with copepods in mesocosm system. Aquaculture, 426-427, 126-137. https://doi.org/10.1016/j. aquaculture.2014.01.031

Zhu, G., Dai, X., Xu, L., \& Zhou, Y. (2010). Reproductive biology of bigeye tuna, Thunnus obesus, (Scombridae) in the eastern and central tropical Pacific ocean. Environmental Biology of Fishes, 88(3), 253-260. https://doi.org/ $10.1007 / \mathrm{s} 10641-010-9636-7$ 